\title{
Teachers' will and way to learn : studies on how teachers learn and their willingness to do so
}

Citation for published version (APA):

van Eekelen, I. M. (2005). Teachers' will and way to learn : studies on how teachers learn and their willingness to do so. [Doctoral Thesis, Maastricht University]. Universiteit Maastricht. https://doi.org/10.26481/dis.20050610ie

Document status and date:

Published: 01/01/2005

DOI:

10.26481/dis.20050610ie

Document Version:

Publisher's PDF, also known as Version of record

\section{Please check the document version of this publication:}

- A submitted manuscript is the version of the article upon submission and before peer-review. There can be important differences between the submitted version and the official published version of record. People interested in the research are advised to contact the author for the final version of the publication, or visit the DOI to the publisher's website.

- The final author version and the galley proof are versions of the publication after peer review.

- The final published version features the final layout of the paper including the volume, issue and page numbers.

Link to publication

\footnotetext{
General rights rights.

- You may freely distribute the URL identifying the publication in the public portal. please follow below link for the End User Agreement:

www.umlib.nl/taverne-license

Take down policy

If you believe that this document breaches copyright please contact us at:

repository@maastrichtuniversity.nl

providing details and we will investigate your claim.
}

Copyright and moral rights for the publications made accessible in the public portal are retained by the authors and/or other copyright owners and it is a condition of accessing publications that users recognise and abide by the legal requirements associated with these

- Users may download and print one copy of any publication from the public portal for the purpose of private study or research.

- You may not further distribute the material or use it for any profit-making activity or commercial gain

If the publication is distributed under the terms of Article $25 \mathrm{fa}$ of the Dutch Copyright Act, indicated by the "Taverne" license above, 


\title{
Teachers' will and way to learn
}

\author{
Studies on how teachers learn \\ and their willingness to do so
}

Ilse M. van Eekelen 
Van Eekelen, Ilse M.

Teachers" will and wy to learn. Studies on how teachers learn and their willingness to do so.

Profefshift Universiteit Maastricht.

Onslag ontwerp: Suze en Mimi

Opmaak: Joke Koehler

Druk: Ponsen \& Looijen b.w.

ISBN: $90-6464-946-4$

Copyright 0 Ilst van Eekelen

Alle rechten voorbehouden

All rights resored 


\title{
Teachers' will and way to learn
}

\author{
Studies on how teachers learn \\ and their willingness to do so
}

\section{Proefschrift}

ter verkrijging van de graad van doctor aan de Universiteit Maastricht, op gezag van de Rector Magnificus, Prof.mr. G.P.M.F. Mols, volgens het besluit van het College van Decanen in het openbaar te verdedigen op vrijdag 10 juni 2005 om 14.00 uur

Ilse Maria van Eekelen

Geboren op 10 april 1973 te Berkel-Enschot 


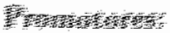

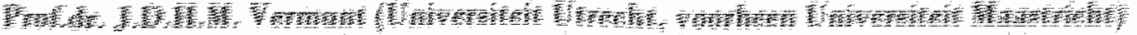

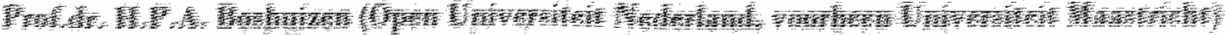

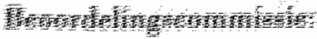

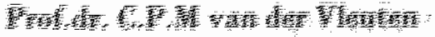

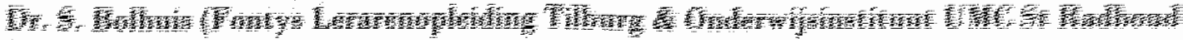

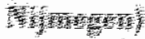

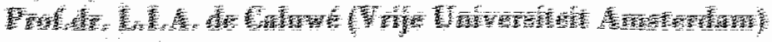

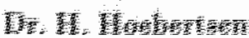

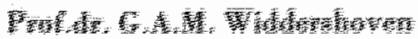




\section{Content}

1. Purpose And Relevance Of This Thesis

Research On Teacher Learning

Research Questions

An Overview of The Studies

Method

Research Design

Data Collection Instruments

Validity And Reliability

The Context For The Present. Studies

An Overview of This Thesis

References

2. Self-Regulation In Higher Education Teacher Learning

Introduction

Research Questions

Method

Results

Conclusions And Discussion

References

3. It Takes Two To Tango: Why Not Invite Both Partners To Dance?

Introduction

Research Questions

Method

Resultis

Discussion

References

Appendix $A$ 
4. Exploring "Teachers' Will To Leam

Introduction

Method

Resultas

Conclusiongs

Discussion

Referenoes

Appendix

5. Fostering Teachers" Will To Learn

Introduction

Melhod

Results 98

Conctusion 105

Discussion 108

References 109

6. General Conclusions And Diseassions

A Summary And Discussion Of The Findings Within The Context of The Six General Questions

Discussion: The Individual Constructivist Perspective Reconsidered

Practical Implications

A Critical Reflection And Suggestions For Future Research

References

Summary (In Dutch)

Beknopt Curriculum Vitae

Dankwoord 
ONE 


\section{Purpose and relevance of this thesis}

The general aim of the sudies presented in this thesis is to explore the practices adopted by qualified teachers to learn from their experiences at work. This aim can be split into two parts and expressed more specifically as: (a) to describe how teachers actually learn at the workplace and how this learning differs from that acquired by professionals in other occupations and (b) to describe and subseguently intervene in teachers" willingness to learn from experiences at work. The relevance of the general research aim is reflected in this thesis in both practical and theoretical terms.

The main practical purpose of this thesis is to contribute to the pool of knowledge available to school principals and educational consultants so that they can, firstly, recognize differences among teachers with respect to the way they learn and, secondly, approach teachers in an individually oriented manner to foster their learning and will to learn. Two recent developments in the field of edncation underpin the importance of these two practical concepts.

The first development is a re-thinking of the educational system which is resulting in reforms that are being implemented at almost all levels. These reforms imply the fostering of an active and self-regulative gathering of lonowledge in order to prepare students for lifelong learning. In order to be able to promote this kind of student learning, teachers are being required to adopt a new pedagogical approach. They can no longer adhere only to their traditional role of knowledge transmitters but, in addition, are expected to act as facilitator" or "coach" to students" leaning processes. This present-day trend that students are expected to self-regulate their leaming naturally leads to society"s expectation that teachers should learn accordingly, for how can they otherwise assist their students in acquiring the required lifelong learning skills? In order to test this expectation this thesis examines the manner in which teachers themselves learn and regulate their learning process.

A second development is an increased attention to Human Resource Development in schools. As in other occupations, the development of competencies, portfolios and Personal Development Plans have made their entré in educational institutes. School managers are using these tools within the framework of organizational development goals and individual teacher goals to stimulate teacher learning and development. However, problems may arise in the case of teacher. who appear to lack the will to learn in order to reach these organizational goals, or to reach any goal at all. The optimistic wiew on which these aforementioned tools are based does not take these problems into consideration. Moreover, most tools that are used to foster teacher learning processes (e.g. teacher training activitits, collegial consultation, etc.) assume that teachers will learn automatically. The prateticall goal of this thesis is to test this assumption by first exploring and describing the 
willingness of a teacher to learn and then proposing methods of positively modifying this willingness.

The main theoretical purpose of the present thesis is to make a scientific contribution to the topic of just how experienced teachers actually learn. Stubsequent sections and chapters will illuminate that there are at least four gaps in the literature when it comes to the description of how experienced teachers actually learn from their experiences at the workplace.

Theories and models of teacher learning already exist, bat many of these preseribe how teachers should learn instead of describe how the process actually takes place. As such, they forecast an ideal role model of teacher learning, whout taking into account whether this ideal either can be reached or is actually reached by contemporary teachers. Furthermore, most of educational literature available on this topic deals with student leaming and student teacher learning. In comparison, the field encompassing the learning of experienced teachers is a relatively underresearched area which, given the absence of an accurate model or theory that describes how teachers learn from experiences at work, even involves the theories and model of student learming to describe and explain the learning of experienced teachers. In addition, the studies that investigate teacher learning mostly focus on (the effectiveness of) professional development initiatives (such as training, peerconching, collegial visitation) for teacher learning. The learning from experiences at work (thus integrated in the teachers" work itself) has not often been studied. Finally, up to the present time most of the existing literature considers teacher learning from the viewpoint of how (phases, activities) teachers learn (best). Whether the teachers are indeed actually learning and/or whether they are actually willing to learn has not been taken into account in these studies. In fact, on the basis of studies reported in the literature, the concept of a teacher"s will to learn has not been studied to date. Most of the previous studies on teacher learning focus on how teachers (should) learn, and they do not incorporate the fact that some teachers might not (be willing to) learn. Thus, from a scientific point of view, this thesis exposes several gaps in our theoretical knowledge and makes a first attempt to fill them. It conceptualizes how teacher learning att work actually takes place and, correspondingly, offers suggestions of how to foster teacher learning at the worlsplace.

\section{Research on teacher learning}

Teacher learning is a relatively new research topic (Bransford, Brown. \& Cocking, 1999). It "body of knowledge" (if what exists can be defined as such) has been derved on the basis of two different theoretical perspectives (i.e., cognitive psyohological and workplace learning) and several related fields of study. As a result teacher learning is often described from various viewpoints, each with their own individual conception and definition, among which are teacher knowledge growth, teacher professional development, teacher workplace learning, teacher change, etc. This section consists of a short review of these two theoretical perspectives and related fields of studies. More extensive reviews are provided in the subsequent studies. 


\section{The cognitive psychological perspective}

The frst theoretical perspeotive having impontant implications for the field of teacher learning, and as such for the studies reported here as well, is the cogmtive psychologieal perspective. "Weacher cognitions became a "hot" topio of research around 1980. Until that time, the goal of research projects studying teacher education was to deteet those teaching behaviors that resulted in higher student achievement and, subsecquently, to train teachers in how to develop these desirable behaviors (Verloop, Van Driel. M Meijer, 2001). As a consequence of cognitive science, the influence of this behaviorism type of researoh diminished. Cognitive psychologists introduced cognitive structumes (such as schemes and scripts) as the representation of knowledge in memory (Anderson, 1980). Researoh on teaching changed from studying teacher behavior into studying teacher oggnitions and beliefs: Whille many of the present-day professional development initiatives for teachers (still) focus on expanding the knowledge base of teachers it has became clear that a teacher's initial knowledge and beliefs are not as easily replaceable with new knowledge as originally believed. Consequently, the transfer of what was being learned in the teacher training sessions to the actual teaching process often did not succed. These rather disappointing findings of the "teachers cognition" approach stimulated scholars and practitioners to new discussions on the nature of teacher knowledge, thinking, and learning. These discussions were influenced by a new vision of learning that emerged within the context of virtually all of the cognitive science theories: constructivism. From the time this vision was adopted, cognitive structures were typically wiewed within the framework of the process of interpreting experiences (meaning making) in a particular context (Palinesar, 1998). Whether this process is an individual (individual constructivism) or social endeavor (social constructivism) and whether it leads to the correct representations of knowledge (trivial constructivism), or whether the notion of correct representation is rejected completely (radical constructivism), are still ongoing debates among scientists. There are several ways to define constructivist learning, and in this thesis we distinguish between the individual and situated lines of constructivist research (see also Roth, 1.994).

\section{Individual construetivist learning}

The initial line of research within the framework of constructivism directed towards the individual was a cognitive approach hat localizes eognition and undorstanding within the individual. At least three related fields of studies into teacher learning have developed within this research direction. The "teacher practical knowledge" field of study examines the questions of how teahers develop their knowledge, the structure of this knowledge, and how this knowledge could be mapped oat. The goal is to provide an overview of "shared knowledge" among expert teachers in order to be able to communicate this with peer and/or student teachers. However, results obtained from studies carried otit in this field show that the degree of "shared" knowledge is still uncertain; teachers appear to very rarely think alike on any one topic (Meijer, 1999).

Schöns" influential work $(1983 ; 1987)$ on the reflective practitioner subsequently resulted in more attention being given to the reflection process in teacher learning. The question of how to provide teachers with knowledge 
developed elsewhere" was replaced with the principle of "reflection-in-action". The notion of reflection as a way in which teachers learn even beeame something of a buzz word in edweation (I Fancis 1995: Tillema 2000). Research in this area has resulted in: (a) an increased attention to split-second decisions during teaching, (b) several models that describe the reflection process both in and on action (Ferry Ross-Goidon, 1998; Korthagen, 1993; Korthagen \& Kessels, 1999; MeAlphime, Weston, Beanchamp. Wiseman, 8 Beauchamp, 1999), and (c) increased attention being given to teacher professional development for reflection. However, nowadays critics argue that the notion of reflection is fuzzy and that "any kind of thinking of" one"s practice tends to get described as reflection" (Knight, 2002 ) p. 293.

Most reently, the various learning activities adopted by teachers during their own learning processes have became a topic for research (for example, see Bakkones, Hoekstrin Meirink, \& Zwart, 2004, O0sterheert, 2001). Learning activities determine to a large extent the quality of the leaming outcomes that are achieved. By employing learning activities, learners are supposed to be able to link new knowledge whth existing knowledge (Limón, 2001). The majority of the studies on teacher learning activities are based primarily on findings found within the studemt self-regulated learning literature, while other studies are based on findings obtained within the field of workplace learning (self-directed learning). In the last two decennia these fiedds have elicited the characteristics of the learners self-regulation process, in which learriers ideally are perceived as being active, independent, and self directive with respect to their knowledge construction (Vermunt, 1996; Vermunt 4. Verloop, 1999, Zimmerman, 2000, 2002), From a teacher learning and development perpective, the goall of this research is to consider what will help teachers to become involved in setting their own goals, assessing their work, avaluating their growth and, thus, gaining control of their own learning (empowerment).

\section{Siluated constructivist learning}

The second line of reseath stemming form a constructivist perspective is the situated viow on learning. Situated theorists (such as Bureiter \& Scardamalia, 1993; Lave \& Wenger, 1991) challenge the assumption of the early cognitive theories of knowledge construction independent of context and intention. They propose that both how a person learns a particular set of knowledge and skills and the situation in which that person learns become a fundamental part of what is learned. Whereas traditional cogmitive perspectives focus on the individual as the basic unit of analysis, situated perspectives focus on interacting systems that inchde individuals as participants, interacting with each other as well as with materials and representational systems" (Putnam \& Borko, 2000, p. 4). The situated perspective implies that knowing and learning are situated in physical and social contexts and are social in nature and that knowledge is distributed across persons and tools.

Several related fields of research and professional development initiatives developed from the situated perspective. The most recent include research into discourse communities (communities of practice, learning communities) and several collaborative learning initiatives (for example, see Barab $\&$ Duffy, 2000; Butler, Lausoher, Jarvis-Selinger, \& Beckingham, 2004, Thomas, Wineburg, Grossman, Myhe, \& Woolworth, 1998). A basic premise behind these limes of study is that 
indriduals benefit from opportamities to share expertise while engaged in a common pursuit and that the knowledge constructed in a social setting is richer than the knowledge a teacher can construct on his or her own. Teachers and others (for example, scientists or consultants) work together to investigate their own assumptions and beliefs. The goal of such investigations in these fields is to understand, articulate, and alter practice and social relationships in order to bring about fundamental changes in the classirooms (Cochran-Smith \& Lytle, 1999), and they often involve the systematic and intentional collection, analysis, and interpretation of data sources.

\section{Workplace learning}

In addition to the aforementioned cognitive psychological perspective, the perspective of adult and/or workplace learning is an important source in the context of teacher learning and as such it is important to the studies reported in this thesis. Learning at work is rapidly becoming a primary focus for scholars and practitioners in adult education due to economic pressures and the sociological issues underpiming questions of learning and education during work (Fenwick, 2001). Relative to the cognitive theoretical orientation it is a less theoretion and more interdisciplinary perspective that even builds on several of the earlier proposed views on learning.

Research on experiential learning (Kolb, 1984) is a recurring topic in most of the literature on workplace learning. A description of experiential leaming emphasizes the active role of the learner and several phases in the leaming process. The learner experiences, reflects, conceptualizes, and experiments - and then starts experiencing again. Thus, through experience, a learner is believed to construct a personal understanding of relevant structures of meaning that are derived from his or her actions in the world. Sehön (1983) has been a significant proponent of this view of adult/workplace learning as well.

Another model, the andragogical model, has been a comer block of adult learning for many years. It is applicable to any cidult learning transaction, from community education to human resource development in organizations (Holton. Swanson, \& Naquin, 2001). This model comprises assumptions or principles of andragogy and steps for creating adult learning experiences. The six assumptions are (Knowles, Holton, \& Swanson, 1998):

1. adults need to know why they need to learn something before learning it;

2. the self-concept of adults is heavily dependent upon a move toward selfdirection;

3. prior experiences of the learner provide a rich resource for learning;

4. adults typically become ready to learn when they experience need to cope with a life situation or perform a task;

5. adults" orientation to learning is life-centered, and they see education as a process of developing increased competency levels to achieve their full potential;

6. the motivation for adult learners is internal rather than external.

At the present time the field of workplace learning is re-examining the link of experience, reflection, and learning. The assumptions of experiential learning and the andragogical model have been criticized for their focus on the individual"s 
reflective construction of knowledge. Many workplace learning scholars nowadays favor a more situated approach of workplace learning that resembles that of the aforementioned situated constructivists. The close relationship between working and learning makes it difficult to recognize learning separately from working since in most cases working and learning are intertwined (Eraut, 2000). Thus, workplace learning is situated within the framework of the work actiwity in which it takes place (Lave \& Wenger, 1991). As a result, it is estimated that $60-80 \%$ of the advit learning that occurs in todky's workplace is unintentional and informal (Callahan, Watkins Marsick, 2001).

Nevertheless, the situated learwing view has intrinsically at least three problems, as noted by Billet (2001): (a) workplace communities tend to conserve, protect, and recyelle their own knowledge, but not to critically challenge and extend it: (b) newcomers may actually learn incorrect or problematic techniques and ideas form experienced community participants; (c) natural community structures and power imbalances may exclude some learners from participation. Furthermore, despite the strong contributions provided by: workplaces, the participation of individuals in workplace experiences and the subsequent learning experiences are not wholly dependent on the situation. How individuals engage in worlk activities and interpret the worth of that participation will also influence the guality and nature of their laarning (Billett, 2002). Moreover, in a teacher learning context. Kwakman (2003) concluded that personal factors appear to be more significant in predicting professional teacher learning activities than task and work environment factors. She concludes that, "although the workplace is considered a powerful learning environment in theory, the teacher workplace is not powerful in itself in practice" (p.167). Thus, the debate between indiwidual and situated factors that influence learning is still going on.

In summary, both the cognitive psychological perspective and the adult/ workplace perspective show al trend towards a more situated view of learning. Questions have arisen with respect to the aceuracy of the individualistic perspective in learning. This perepentive emphasizes self-regulation in learning and, as such, the conscious application of several learning activities and reflection skills. However, as most of these theories and modes have a preseriptive character, they ignore the parameter of whether a learner is actually willing and able to apply these skills in the particular atuation in which the learning takes place. In situated learning theories and models this "situatedness" of learning is taken into account. However, by the same token, the situated view on learaing is not without ins own critics. "Therefore, questions still remain of how to conceptualize teacher learning and, correspondingly, of how to construct professional development so as to foster meaningful change" (Butler et al., 2004, p. 436).

This theoretical "rumor" or "discourse" is reflected in this thesis. Building on Kwakman"s conclusion that the teacher"s workplace is not powerful in itself, this thesis has focused on how teachers learn in this workplace. Influenced by the individual constructivist perspective and comparable views in the field of adult/workplace learning, we have attempted to describe (not prescribe) the actual learning activities, reflection, and regulation processes by which contemporary teachers learn while at the same time acknowledging that learning is inherently 
situated and thus influenced by the working context of the teacher. In this respect, this thesis also includes questions that bear on the teacher's will to learn from experience in a particular situation.

\section{Research Questions}

The main purpose of this thesis is to comtribute to a better understanding of how experienced teachers learn from experiences at the workplace. Six empirical research questions have been formulated for this purpose:

1. what learning activities are carried out by teachers duning their daily work schedule?

2. what is the rolle of reflection in teacher learning?

3. how do teachers regulate their learning?

4. how can a teacher's will to learn be described?

5. what situational factors influence teacher learning?

6. how should learming be fostered for those teachers who do not seem to have a will to learn?

\section{An overview of the studies}

This thesis includes four empirical studies. The first of these focuses on the manner in which teachers learn. Several accepted hypotheses on teachers" learning that are based on theoretical notions of adult leaming are also tested. The main question to be answered in this study is: in what way do teachers self-regulate their own learning processes (see research question three). However, this study also relates to research questions 1 (what learning activities), 2 (the role of reflection), the will to learn), and 5 (situational factors).

Study two focuses on learning activities that occur through interaction and compares the learning activities of teachers, police officers, and people working in the financial service sectors. The interactive learning activitios of both the learnen and his interaction partner across the spectrum of these octuptions are defined, and the study investigates whether the difforent manners in which these learning activities are employed can be explained on the basis of gender and hierarchical power. The main purpose of this study is to describe the differences in interactive learning activities between different occupations and, consequently, the study relates to rescarch questions 1 (what learning activities), 2 (the role of roflection). and 5 (situational factors).

The goal of the third study is to explore the concept of teachers" willingness to learn. The study consists of both a search for behaviors that indicace the apperarance or absence of a teacher's willingness to learn and a search for patterns that are common to a number of teachers in order to define parameters that manifest a teacher's willingness to learn. The findings are presented within the framework of the first four research questions (see above).

Study four describes the type of interventions that may influence teacher's will to learm. The primary goals of this study are: (a) to explore and describe the leaming and change process of teachers who do not seem to have a will 
to learn; (b) to ses whether it is posiblle to stmulate this group to start learming (again) using talor made interventions; (c) to explore the relationship between a teacher"s whillingess to leart and their selfefficacy. "The aim of this study is primarily to provide an answer to the sixth research question (how to foster a teacher" will to learn).

\section{Method}

The studies described in the following chapters stem from a qualitative or "interpretative" research paradigg (see, for example, Lincoln \& Gaba, 2000; Miles \& Huberman, 1994). Qualitative reseatch has often been advocated as the best. strategy for discovering and exploring new areas (Miles \& Huberman, 1994), and as wach it is very suitable for the studies presented in this thesis. Qualitative researchers are interested in the meaning people have constructed - that is, how they make sense of their world and the experiences they haw in it (Merriam, 1998). Although the complementary value of both qualitative and quantitative research paradigms is apparent and undeniable (Kelchtermans, 1998), researchers, policymakers, and practihomers still debate the relative advamtages and disadvantages of qualitative versus quantitative inquiries.

One still ongoing discourse 1 s that started by Hargreaves (1997) in which he argues that oducational research needs to be redirected towards the systematio development of a body of knowledge that is capable of informing teachers why they should $\mathrm{do}$ " $\mathrm{x}$ rather than $\mathrm{y}$ " or of finding the "size on the effect of $\mathrm{A}$ on $\mathrm{B}$ ". The purpose of this type of research is to let teachers and policymakers now just what works and why it works, and what is likely to be the most effective. As Hodgkinson (2000) points out. what Hargreaves is demanding is a clear-cut positivist conception of social science. Hammersley (2000) and, more recently, Rogers (2003) perceive Hargreaves cruticisms to be at odds with many of the current accepted ideas on the nature of the social world and how it can be understood. These two researchers adhere to a more 'enlightenmont model of social research instead of to the "enginering" model of Hargreaves. "Where the engineering model implies that research findings should have inherent and determinate practical implications about "what works", the enlightenment model views research as providing resonrces that practitioners can use to make sense both of the situations they face and of their own behavior, rather than telling them what it is best to do" (Hammersley, 2000, p. 1). The enlightenment model stresses the diverse orientations of people involved in social activities, the ways in which they actively make sense of then surroundings, and the resulting contingency of how this shapes what they do (Hammersley, 2000).

The studies presented in this thes is fit more closely with the view of the enlightenment model (as illustrated by the more numerous qualitative methods and fewer quantitative ones) than with that of the engineering model. Emphasis has been placed on the description and understanding of action, and not so much on the prediction of behavior, in relation to certain conditions (as is usually done in quantitative, positivist paradigms). 


\section{Research design}

What type of research designs are used in this thesis? Qualitative research is a universal term that encompasses numerous research designs, theoretical traditions, strategies of inquiry, and methodologies, with the exact terminology often depending on the researcher. For example, while Cresswell (1998) distinguishes biography, phenomenology, grounded theory, ethnography, and case study, other authors have their own individual taxonomies (see Jacob, 1987; Tesch, 1990; Wolcott, 1992). As comprehensive and clarifying as these taxonomies seem to be, to position a study, "they turn out to be basically ineommensurate, both in the way the different qualitative strands are defined and in the eriteria used to distinguish them" (Miles \& Huberman, 1994, p. 5). As an example, Merrian (1998, p. 20) shows that her typology (consisting of five types of qualitative reseanch) intrinsically comprises disciplinary orientation (ethnography, phenomenology), function (grounded theory), and form (case study or generic qualitative study). In addition, the types and tradition can, and often do, work in conjunetion with one another. Bearing this annotation on ypologies in mind, the first three studies in this thesis can be classified (in terms of Merriam) as explorative generic qualitative studies, whereby the data analysis of studies one and three is performed in a phenomenological manner, while the fourth study is an explanatory (multiple) case study.

\section{Data collection instruments}

The studies presented herein employ various instruments of data gathering, most of which are qualitative and some quantitative. In all of the studies, data gathering occurs by means of semi-structured interviews based on the two principles of the critical incident technique (Flanagan, 1954), namely, (a) the reporting of actual behavior as opposed to ratings and opinions based on general impressions and (b) the reporting of behavior that makes an important contribution in the learning incident (Flanagan, 1954). Consistent to the parameters of the qualitative paradigm defined in the preceding sections, the behavior incidents reported are explored in nore detail by asking questions on the intention, meaning, and consequences of the incidents in the context of the participating teacher.

The sem-structured interviews are not the only means of collecting the ritical incidents. Tn the first and second studies, the participating teachers are asked to keep an electronic diary as a means of collecting the incidents. In a subsequent semistructured interview these diary incidents are reviewed. In studies three and four, the critical incident technique is extended by means of classroom observations and a retrospective interview (in which the critical incident technique is used). In study four, data are also gathered - by means of a concepts map, a quantitative questionnaire, and the collection of field notes. 


\section{Validity and Reliability}

Numerous perspective exist on the importance of the parameters of validity and reliabinty in qualitatre research, their definition, and the procedures to be used to establish thern. The reason for this is that qualitative research still has to deal with the always pervasive areas of validity and reliability, and that in each strategy of inquiry (see above) these are dealt with in a different way. In the four studies reported here, they are discussed in the context of the more generally accepted terms: uteruall walidity, reliability, and generallizability". Nevertheless, we concur with the approach of Kincolm and Guba (1985), who use alternative terms that adhere strongly to the qualitative (naturalistic) axioms. We have applied a number of methods for paying special attention to the topics of walidity and reliability. Hirst, internal validity, or credibility in the terms of Lincoln and Guba (1985), is saleguarded by" (a) "peer examination" (Merrian, 1998) by other researchers or experts in the field, who commented on the findings as the emerged, (see studies two and four): (b) 'member checks' (Merriam, 1998), in which the data and tentative interpretations were taken back to the people from which they were derived, who were then asked if they were plausible (study four) (c) regular meetings between the researchers to discuss the interpretations of the studies (all studies). In addition, the foregoing paraguph has already mentioned the multiple methods that were used in the process of data gathering. This "triangulation" methodology strengthens the internal validity as well as the internal reliability.

Second, interval reliability or "dependability" (Lincoln \& Guba, 1985) is established, not only by triangulation methodology and peer examination, but also by the collection of data across a full range of appropriate situations, times, and respondents. In addition, the basic paradigms, analytical construets, or "theory" from which the studies depart are made explictit (Miles \& Huberman. 1994). If suitable, existing and validated (quantitative) instruments are used (see study four). One point of concern with respect to the internal reliability in studies one and three might be the absence of an inter-reliability check for the coding of the intervews.

Tho third issue is that of external reliability. Limooln and Gubasuggest thinhing whont the "confirmability" of the results obtained from the data, "That iss rather than demanding that outsiders obtain the same results, a researcher wishes outsiders to concur that, given the data collected, the results makes sense. In the pressnt studies this is nade possible by providing an "audit trail". The studies describe how data are collected, how calegories ane derived, and how decisions are made throughout the study. In addition, the basis on which the participants are selected and their ohvaterization are provided.

fourth, the generalization of qualitative studies is usually based not on an explicit sampling of a defind population to which the results can subsequently be extended but on the development of a theory that can later be extended to other cases (Maxwell, 1998). For those reasons, Guba and Lincoln prefer to talk in terms of "transferability" rather than 'generalizability' in qualitative research. To enhance the possibility that the results of the present studies are transferable, we use three strategies: (1) "rich deseriptions' from cases or described categories are provided (for example, most categories are accompanied by statements typical of the participating teachers): (2) sampling is random (studies one, two and three) or non-random (study 
four): (3) a multiple-case design (study four) is used instead of a singte case-study design.

\section{The context for the present studies}

The chronological order of the four empirical studies is identical to the order they are presented in this thesis; study two, however, was carried out concurrently with studies three and four. The studies are carried out at two different educationall levels - Higher Education and Secondary Education - as a result of the first author changing employer and thereby her occupational direction. The same fifteen teachers from three different Institutes for Higher Education in The Netherlands participated in studies one and two. Thus, the data that are gathered in study one are also used in study two, in which it is complemented with data gathered by other researchers within the framework of a study in the police and financial service sector. Fourteen secondary school teachers working in the secondary phase at the same school took part in study three. Seven teachers participated in study fonir, all of who are working in the lower levels at three different schools for secondary education. Although, the teachers work in different contexts and all teach different subjects, they have several factors in common in that they:

- work in a (constantly) changing environment, in which the change is directed towards more active and self-regulative student learning and, consequently, towards an increased coaching role for the teacher;

- a re experienced teachers (their years of experience range between 7 years and 30 years, and their age varies between 31 years and 58 years);

- have at least a bachelor's degree (most have a master's degree);

- have a minimum contract that is at least $70 \%$ of the Full Time Equivalent in which the teaching of classes is their main task.

\section{An overview of this thesis}

This thesis contains four empirical stadies that are presented in ehapters two to fivo (study one is presented in chapter two, study two in chapter three, and so on). The empirical chapters are articles that have either been publisted in international journals or have been submitted for publication. While each chapter is an independent entity in its own right, each also relates to the six research guestions that are formulated above. A summary of the findings based on the six research questions and a discussion based on existing literature and current developments in the ficld can be found in chapter six. A wew model that describes how teachers learm from experiences at the workplace is proposed. Furthermore, this final chapter discusses the implications of the results of the studies for the practical aspects of teacher learning and provides suggestions for future research. 


\section{References}

Anderson, J. A. (1980). Cognnitive psychology and is imaphicathons. New York: W. H. Freeman and Gompany.

Bakkenes, I, Hoekstra, A., Merink, J., Zwar, R. (2004). Leren wan docenten in de

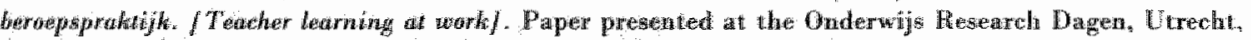
The Netherlenids:

Barab, S. A, Daffy, T. M. (2000) From practice fields to commonities of prathice. In J. D.

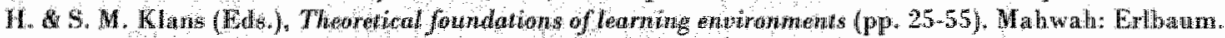

Berciter, $C$. Scardamalia. M. (1993). Surpassing ourseltes: an inquiry into the nature and implications of expertige. Chicago: Open Court.

Billetr, 8 . (2001). Compartipation affordance avid engagement at work. Tn T. Fenwick (Ed), Sockocultural perspecthes an learning rough work (Vol. 92, pp. 63-72). Sain Franisico: Jossey Bass.

Billet, S. (2002). Toward a workplace pedagogy: guidance partioipation and engagement. Adult Ed weation Quarterly, $53(1), 27-43$.

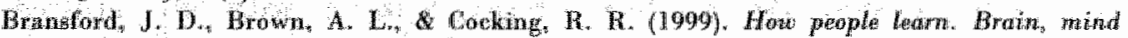
experience, and sthos whington D.C. National Academy Press:

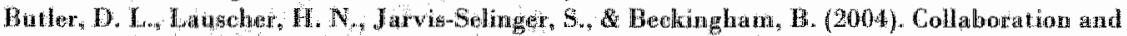
aelf regulation in teachers' professional development. Teacher and Teacher Edweation, $20,455.45$.

Cochan-Swith, M., \& Lytle, S. L. (1999). Relationships of knowledge and practicks Teacher leatring in commonities. Revien of Research in Education, 24,249-305.

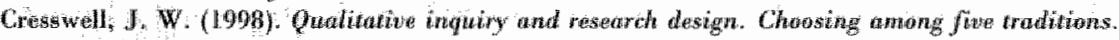
Thousand Oaks: SAGE Ptublications.

Eratit, M, (2000). Non-formal learning and tasit knowledge in professional work. British Journal of Eductatomal Psychology, $70,113-136$.

Fenwick, T. (2001). Thides of changes New themes and questions in workplace learning. In T.

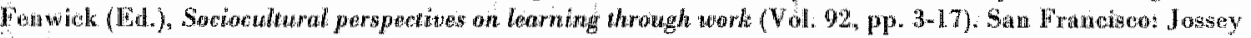
Basur.

Ferry, N. M., Rosw-Gordon, J, M. (1998). An inquiry into Schön's epistemology of practice: exploring links between experience and reflectiva practice. Adult Education Quarterly, 48(2), 98-112.

Flanagan, J. C. (1954). The critical ineident technique. Psychological Bulletin, 51(4), 327-358

Hammersley, M, (2000), The relevanee of Qualitative Research. Oxford Magazine of Educotion, $26(3-4), 393-404$

Hargreaves, D. H. (1997). In defense for research for evidencebased teaching: a rejoinder to Martin Hammersley. British Edurational Research Joumal, 3(4), 405-421.

Hodgkinson, P. (2000). Who wants to be a social engineer? A commentary in David Blanketts' speesch to the ESRC, 5 .

Holton, E. F, Swanson, 位. A. S Naquin, S. S. (2001). Andragogy in practice: Clarifying the

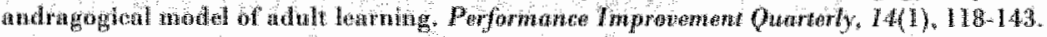

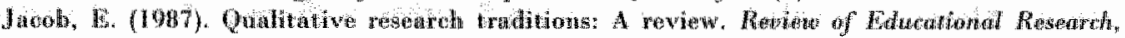
$57(1) .1 .50$

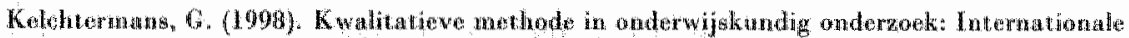
ontwikkelinguten de situatio in Vlataderen. Pedagogisd Tijdschrifi, 23(4/5), 221-234.

Kught, P.T. (2002), Learning from sellools. Higher Educotson, 47, 283-290.

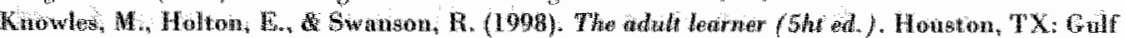
Publishing.

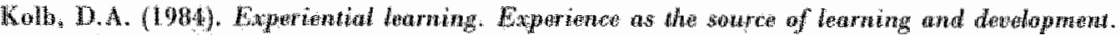

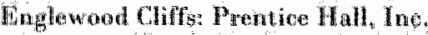

Korthagon, F. A. J. (1993). Two modles of rellection. Thather and Teacher Eduction, $9(3), 317$.

326.

Korthagen, F: A J., \& Keesels, J. P. A. M. (1999). Linking theory and practice: Changing the pedazogy of teacher education. Edweational Kesterefher, 28(4), 4-17.

Kwakman, K. (2003). Factors affecting teachers" learning participation in professional learning activities. Teaching and feacher Education, 19, 149-170.

Lavis, J., \& Wengew, E. (1991). Sutuated leauning: Leginiwate pwriphterial participation. Cambridge: Cambridge University Press.

Limonn. M. (2001), On the cognitive conflict as an instructional strategy for conceptual change: A oxitical appraisal. Learring and Instruction, $11,337-390$. 
Lincoln, Y., G Guba, E, G, (2000). Paradigmatic controviersies, contradiotions, what anetging

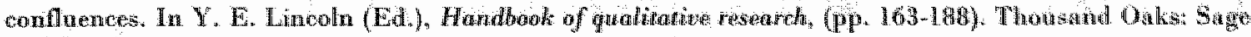
Publications.

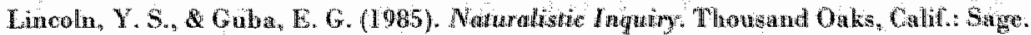

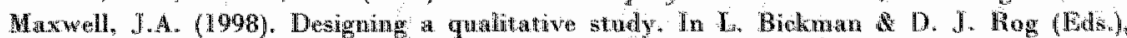
Handboot of apphied sociol research methods. Thonsand Oalks: Sage Publications.

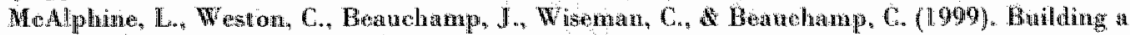
motacognitive model of reflection. Higher Educhtion, $37,105 \mathrm{~m} 13 \mathrm{I}$.

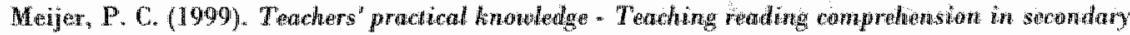
education. Leiden Universiry, Leiden.

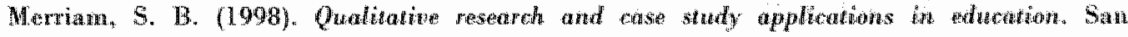
Franeisco: Jossey-Bass Publishers.

Miles, M. B., H Hulberman, A. M. (1994). Onahotite data andysis. Thonsand Oahs: Sage Pulblications.

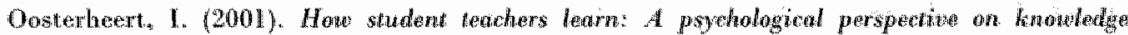
construction in learning to teach. Maastricht: Shaker Publishing.

Palincsar, A. S. (1998). Social constructivist perspeotives on teaching and lesaning. Annund Rovinent of Psychology, 40,345-375.

Putnam, R. T', \& Borko, H. (2000). What do new views on knowledge and thimking have io say ahout research on teachet learning? Educational Reserarcher, 29(1), 4-15.

Rogers, B. (2003). Educational Researelh for prolessional practice: more than providing

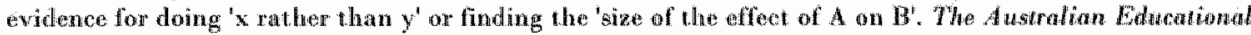
Researcher, $30(2), 65-85$.

Roth, W. M. (1994). Fxperimenting in a congtruetivist hight school physies lationatory. fournal of Research in Science Tauching, 3/(2), 197-223.

Schön, 1). A. (1983). The reflective prachioner. New York: Basio Books.

Schön, D. A. (1987). Educating the reflective practitioner. San Franciseo: Jossey Bass.

Teseh, R. (1990). Qualntative resenreh: Analysis types and sofhure tools. New York: Palinet.

Thomas, G., Wineburg, S., Grossman, P., Myhe, O., Woolworth, S. (1998). In the dompuny of colleagues: an interim meport on the development of a community of teacher learmers. Teacher and Teacluer Eiducation, 14, 21-32.

Verloop, N, Van Driel, J., \& Meijer, P. C. (2001). Teacher knowledge and the linowiledge busi of teaching. Intermational Joumal of Educational Reseands, $35,441-461$.

Vermunt, J. D. (1996). Metacognitive, cognitive and affective aspects of loarting styles and strategies: A phenomenographic analysis. Figher Edworion, 21, 25-50.

Vermmot, J. D., \& Verloop, N. (1999). Congruence and friction between learning and teaduing. Learning and Instruation, 9, 257-280.

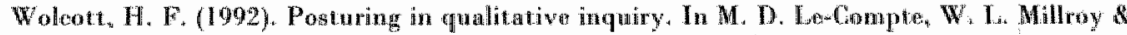

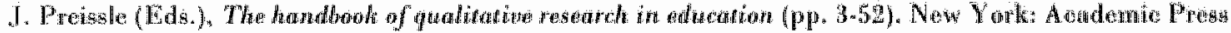

Zimmerman, B. J. (2000). Attaiment: of self-regelation: A social congivive perspective, lin M

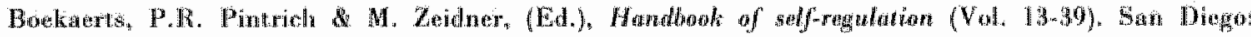
Andeanic Press.

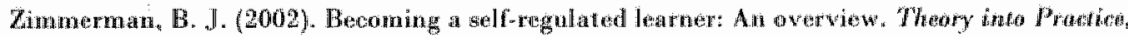
$21(2) \cdot 64-70$. 
The second dhapter will be published in Higher Education as:

I.M. van Eakden, Boshuizen, I.P.A, Vermunt, J.D. (in press). Self regulation in tigher education toudier learning. 


\section{Self-regulation in higher education teacher learning}

Various studies have focused on self-regulated student learning. However, little attention has been given to the self-regulation processes in teacher learning. In this study, we focus on the work-related learning processes reported by experienced Higher Edwcation teachers. The aim of this study was to discover whether teachers actively self-regulate their learning experiences (as their students are expected to do) and to examine how this regulation takes place in the workplace. We tested some generally held assumptions and conceptions regarding teacher learning. Fifteen experienced college teachers, from three differen colleges in the Netherlands, participated. Two semi-structured interviews and a (digial) diary study were used as the primary data collection methods. We collected 86 examples of veacher learning episodes. These were analyzed using a phenomenographic method. The results show that our teachers' learning experiences are not as self-regulated, planned, reflective, or spiral as some assume. Sometimes, the teachers' learning was planned (self. regulated), but mosily it occurred in a non-linear (both external and self-regulated) or spontaneous (externally regulated) way. We condude that our teachers do not always selfregulate their learning, but they mostly do self-regulate their teaching practice (with learning as a result).

\section{Introduction}

Institutes for Higher Education (HE) are increasingly striving for self-regulated student learming. In order to accomplish meaningful learning (as opposed to rote learning), students are supposed to actively self-regulate their learning proossses. Furthermore, students are expected to master lifelong learning akills in order to bo able to regulate their own learning once they are working in their fields of expertise.

As a result of this changing view with respect to the teaching alearning process (Verloop 2001), the teacher's role is nowadays changing from transmission of knowledge to supporting and guiding self-regulated student leaming (Vermunt and Verloop 1999). This requires substantially different knowledge and radically different skils than most teachers now have (Darling-Hammond 1997). Therefore, teachers themselves are also expected to self-regulate thoir learning in order to obtain this knowledge and these skills. How do HE teachers learn and more specifically how do they self-regulate their learning? Although not many sudies deal with self-regulation in Higher Education teacher learning, examples can be found in the field of Teacher Education (see for example Guilfoyle, Hamilton and Pinnegar 1997; Hamilton 1998; Tillema and Kremer-Hayon 2002). In this field it is recognized that it is important to prepare (student) teachers to develop their future pupils" regulation skills. 
Given that we expect students and student teachers to actively self-regulate their learning, we wondered in this study in what way experienced HE teachers themselveg actually learn and if and how they self-regulate their learning processes. As atarting point for our study we ased the three conceptions of how teachers learn as formulated by Cochran-Smith and Lytle (1999), in order to define the type of learning we wanted to investigate. In the first conception, teacher learing is seen as coming to know what is already known (formal knowledge). In this view, (expenienced) teachers learn from best practice examples in the literature, "how to teach" books, or training. In the second conception, teacher learning is seen as constructing practical knowledge by reflecting on experience. Here, it is assumed that teachers learn when they have opportanites to examine and reflect on the knowledge that is implicit in good practice. Learning takes place by consciously reflecting on the flow of classroom action. In the third conception, it is assumed that the knowledge teachers need in order to teach is generated when teachers treat their own classrooms and schools as sites for intentional investigation. The three teacher learning conceptions differ in the way learning is perceived: from a externally directed, passive, and knowledge-consuming process, towards a self-directed, active, and Knowledge creating process. While the first conception is still the basis of many professional development programs, the second and third conceptions relate more closely to the current, constructive wiew on adult learning. From this perspective, the learner learns from experience or might borrow ideas from others to scaffold the learning. In addition, it is the learner him/herself who is actively forming new knowledge and connecting it to an existing cognitive structure. Therefore, in this study, leaming was defined as an experience whereby knowledge, skills, new attitudes related to work are acquired and recognized by the teachers themselves. in this study, The acquisition of the new knowledge, skills or attitudes does, not imply that the existing knowledge must be replaced by new knowledge. Although we do not exclude these accommodative forms of learning, based on the literature of teachers" behiefs (Calderhead 1996; Pajares 1992), we agree with Hashweh (2003) that teacher learning at the workplace is probably assimilative most of the time.

\section{Teacher Horkplace learning}

Within our constructive view on aduh workplace learning, there are three perspectives on learning at the workplace, which provide a theoretical framework for this sudy.

First, within adult learning, self-directed learning (SDL) is seen as representing the mode of learning characteristic of adulthood (Candy 1991). It has been defined by Long (1994, p. 14) as: "the learner"s psychological processes that are purposively and consciously controlled, or directed for the purpose of gaining knowledge and understanding, solving problems and developing or strengthening a skill". SDL is often associated with setting goals, selecting learning resources, and managing time. Together, these characteristics suggest that self-directed learners reflect, assess, and evaluate rather than ancritically accept and internalise information (Confessore and Kops 1998). Moreover, self-directed learners are responsible for most of the detailed decision-making about learning, including choices about what and how to learn and at what pace the learning will occur" (Tough 1979). 
Second, experiential learning has a promment place in most of the literature om adult education (Kwakman 1999). Experientral Larning offers an integrative perspeetive on learning and combines experience, perception, cogmition, and behavior (Kolb 1984). Although there is not much empirical evidence to support the Kolb model, it is frequently used in adult education and m-company training (Bolhuis and Simons 1999). The description of experiential learning enplusizes, an active role of the learner and several phases in the learning proces. The learaer experiences, reflects, conceptualizes, and experiments, and starts experiencing again. Experiential learning assumes that the end of a learning process is the beginning of new learning process. It is a spiral model that aims at the improwement of the ongoing process of professional development.

Third, much attention is given to the reflection process in adulteacher learning. The notion of reflection as a way in which reathers learn has become something of a buzzword in education (Erancis 1995; Tillema 2000). Most of the existing general research elaborates or tests the reflection-in/on-action model developed by Schön (1987): The ALACT model (Korthagen and Kessels 1999) specifies five phases of teacher reflection on action: Action, Looking back, Awareness of essential aspects, Creating alternative methods of action, and Trial. Like the experiential learning spiral, the ALACT model assumes that learning can be more or less planned or predicted by following the spiral. Also like the experiential leaming spiral, behavior change (experiment or action) is a necessary part of the learning process.

The examination of self-directed learning and the views of expertential and reflective learning reveal (at least) five theoretical assumptions which might underlie self regulated learning at the workplace. These assmmptions "predict" how learning processes (should!) take place. Firstly, it is assumed that workplace leaming should be a self-directed and active process. Secondly, it has the choracteristics of a "purposively and consciously controlled" planned process. Thirdly, learning is represented as spiral. It is assumed that the end of a learning process is also the beginning of a new learning process. Fourthly, reflection as an important phase in the learning process is emphasized. Finally, since the learning and reflection oycles include "action" the fith assumption is that all learning should involve an (observable) behavional change or experiment.

However, some athors thave come to different conclusions about selfregulated learning at the workplace based on empirical evidence. For example, Candy (1991), Eraut et al. (1998), and Kwakman (1999) acknowledge the uneonscious character of work-related learning processes. First, according to then, most adult learners are not aware of themselves in the role of learner. Second, serendipity plays an important role in determining the direction that many learning projects take. Third, much learning arises from and seeks to resolwe a speific problem situation. Fourth, very few learning endeavours are entirely self-regulated, but instead depend on individual motives and interests shaped by interaction with other people. Fifth and finally, self-regulated leaming is rarely completely sollitary. Clearly, according to these anthors, the self-regulated learning process at the workplace is complex and unpredictable, and unfolds as it goes along. 


\section{Suden: self-regulated learning}

The conotruct of self-regulated workplace leaming becomes even more complex when wake into account the perppective of celf regulation in student learning. We consider this an important area for our study given that, as said in the introduction, HE teachers are expected to foster student self-regulated leaming and thas we might expect them to practice it themselves as well.

In the last two decennia, the characteristics of the students self-regulation processes have become more dear (Garcia 1999; Shuell 1980; Simons 1993). Zimmerman (2002) provides the latest overview. He presents (p.66) eight skills which are important to these processer (without necessarily being used all the time). These skills include: 1) setting specife proximal goals for oneself, 2) adopting powerfinl strategies for attaining these goals, 3) monitoring one"s performance, 4) restructuring one's learring environment to make it compatible with one"s goals, 5) managing one"s time effectively, 6) self-evaluating one's methods, 7) attributing results to causation, and 8) adapting foture methods. The overview of Zimmerman implies that self-regulated learners should not only have the ability to prepare and take the necessary steps in order to learn, but also have to take care of their own monitoring, motivation and feedback process during and after learning. The entirety of all these steps is called learning functions (Van Hout-Wolters, elt al. 2000), or leaming activities (Vermunt and Verloop 1999): Several authors have made overviews of the (micro) activities a student should undertake in order to learn (e.g. Vermunt and Verloop 1999, Pintrich 1994). Most of them (see also Winne and Perry 2000) make a distinction between cognitive, affective or motivational, and metacognitive learning functions.

However, as in the field of workplace learning (see above), some studies show that not all students seem to be capable of self-regulated learning. Vermunt $(1996,1998)$ found four qualitatively different (student) learning patterins in which the regulation and the strategies of learning differ. Within these four patterns, Vermunt distinguished four regulation types: 1) an experienced lack of regulation, 2) mostly external regulation, 3) self-regulation of one's own learning process, 4) both external and self-regulation. The study of Oosterheert and Vermunt (2001) in a teacher ducation context showed similar results. They describe five "orientations to learning to teach", which differentiate between an extermal, or self-regulated knowledge construction and performance improvement. Only a minority of the student teachers appeared to be fully self-regulated in both these processes.

\section{Self-regulated teacher learning}

"To conclude, by trying to define the concept of self-regulated teacher learning, it appears that over the past 30 years definitions of SRL have become increasingly encompassing (Paris and Paris 2001). Zimmerman and Schunk (2001) even identified seven different theoretical views on $S R L$. Their definition of SRL has oftern cited: "SRL encompasses the degree that students are meta-cognitively, motivationally and behaviourally ative participants in their own learning process" (2001, p.5). According to Zimmerman and Schunk (2001) SRL refers to selfogenerated thoughts, feelings and behaviors that are oriented to attaining learning goals. Based on the five theoretical assumptions underlying adult workplace learning and the student SRL perspective (see the two foregoing sections), we think that the core of self-regulated 
teacher learning is that the teacher independently and consiciously direots the process of attaiming leaming goals. The degree in which a teacher is able to do so makes the teacher more or less a self-regulated learner.

\section{Research Questions}

In order to discover more about self-regulated teacher learning processes and to test our assumptions about teacher workplace learning, the present study focused on the issues of the degree to which teachers actively self-regulate their learning and the ways in which they do so. To answer these questions, we went back to the micro level. We took a closer look at the work-related learning processes reported by experienced Higher Education (HE) teachers. The main goal was to empirically characterize the learning events of these teachers. To accomplish this, the following specific research questions were formulated:

- From what activities do HE teachers learn?

- With whom do HE teachers learn?

- How do HE teachers regulate their learning?

- What are the outcomes of HE teacher learning?

- What factors in HE teachers" environments stimulate or inhibit their learning?

\section{Method}

Given the difficulty of eliciting answers to questions about workplace-related learning (mostly informal), we examined two approaches used in previous studies in and outside educational settings. Kwakman (1999) collected a range of professional (routine) activities of secondary education teachers in which learning could evolve. She conducted a survey to determine how frequently weachers performed these activities. The disadvantage of this method was the exclusion of non-routine working/learning activities.

Eraut al. (1998) adopted another approach. They studied the ways in which business, engineering, and healthare professionals learn. They used an interview approach, in which almost all participants agreed to do two interviews. In the first interview, questions were asked about the nature of the job, the nature of the competence required to do it, and how these competencies were acquired. "The second interview focused on elaborating on the first interview and on factors affecting the amount and direction of learning. Eraut et al. (1998) indicate one important limitation of this approach: it was hard to elicit evidence for learning processes that, if not entirely tacit, do not readily come to mind.

To overcome the limitations of both the foregoing studies, we developed an alternative way to investigate work-related learning events, which included not only two interviews but also the keeping of an electronic diary. Within this descriptive qualitative approach, we used a phenomenographic method to analyse our data (see next section). 


\section{Porticipants}

Fifteen experienced teachers from three different colleges participated in this study. Each college awards a different Bachellor's degree; Information Technology, (Language) Teaeher Education, or Facility Management. The institutes were chosen on the basis of two criteria:

- at the thme they were involved in changing their programs or teaching concepts (in onder to ensure that the teachers would be in a changing envinomment. making it adaptive to learn)

- Wey had contrasting degree areas (for duferent kinds of teachers).

The heads of the institutes were asked to provide a lizt of all teachers with more than fore years teaching experience and a minimum contract of 0.8 Full Time Equivalent (almost fulltime teachers). From this, list, a randon shortlist was made with ten prospective panticipants. The head of each institute then asked the first five prospective candidates named on the list to participate. Only at the institute for language teacher education was it necessary to ask more than the first five. The main reason for refusing to participate was the amount of time involved in participating in the research. In the end, 15 teachers wh an average age of 45 years and an average of 17 years of teaching experience participated in the study.

\section{Materials}

Two semi-structured interviews and a diary study were used as the primary data collection methods. In the first interview, the teachers were asked to give examples of situations or activities from which they had learned something. These examples were explored using the five main research questions. Next, the teachers were asked how they would define learning and what learning goals (if any) they had for the following two monthe. The last question in the interview was about factors that stimulated or inhibited their learning in general. Second, the teachers were asked to keep a diary three times a week (during one month) by answering e-mails from the researchers. The e-mail received by the teachers listed the five main research questions. Third, in the final interview, the teacher and one of the researchers looked back upon the enails to summarize the way in which the teacher learned, to check interpretations, to discuss recurrent patterns in this learning if there were any" and 10 determine the degree of the teachers' satisfaction with this learning.

\section{Procedure}

At the start of the first interview, the interviewer explained the goal of the nterview: to get an impression of what and how the teacher learned and the factors affecting his or her learning. The interview scheme described above was then followed. At the end of the first interview, the interviewer explained the process of the diary stadies. Each interview took between an hour and an hour and a half. All first interyews were tape-recorded and transcribed verbatim.

Next, the teachers were requested to keep an electronic diary for a period of four weeks. During this period, they were to report to the researchers three times a week. In order to increase the chance that all teachers would make their diary entries regularly, they were asked to e-mail their diaries. To help the teachers with this task, each teacher received an e-mail from the first author on the (in the first interview) agreed thee days of the week. The teacher was asked to fill in the diary 
and reply mail at the end of the day. We did not respond to the e-ravils, except to give an oceasional word of encouragement to the entire group of teachers at the end of some weeks. Three teachers did not respond for a week. They were asked to give a reason (lack of time, siek) and they got baek into the rhythm the following week six teachers did write in the diary six times or more (half of what was asked of then). "The reason for this was mostly "no time to write" and, rarely, "I learmed nothing?.

Prior to the second interview, each teacher was asked to read through all their own e-mails. We also read the transcripts of the first interviews and all the mails. This reading provided us with questions for each participant for clarifications, checking of interpretations and confrontations. We asked, for example, "il see that you haven't reported any learning situations about the object of your field of study. Do you recognize that? How come?" The average length of the second interview was one hour. All second interviews were tape-recorded and transcribed verbatim.

\section{Data analysis}

A phenomenographic research methodology was used for the analysis (Marton 1986, 1990). In this methodology, the researcher describes the qualitative differences in the ways people perceive and conceptualize a phenomenon in conceptual categories. The central phenomenon in this study was the learning experiences of HE teachers". The data analysis started with a reading of all the material (both interviews and all e-mails). Next, all the emails were read again and, based on all learning episodes as reported in the e-mails and the (comments in the) interviews a summary was made for each teacher. The summary included all the answers to the five research questions. Another summary was made for each research question separately. These summaries were read again to develop initial categories of potential conceptualization related to each of our five research questions (thenes); from what activities do teachers learn, with whom, their way of regulation of learning, the learning outcomes and factors that stimulate or inhibit teachers' learning. Within these five themes, the initial categories were developed by grouping similar answers/citations into a (broader) category.

The next step was testing these initial categories within each theme by going back to the summaries and matching all the answers/citations to an cagory. If not all answers/ citations could be matched with the initial categories, a now category was developed or initial categories were changed. Also it could happen that a category was identified while working on a categorization for another theme. The newly identified categories were again tested in the summaries. The reading, categoriaing, testing, and recategorizing process for each theme was repoated several times until all diversity in the summaries seemed to be covered, in other words until "saturation" occurred. After reaching this stable grouping in the categorical system, ultimate descriptional categories for each theme were formulated, representing the essential characteristics of the groupings that were found. Each category was illustrated with typical statements. In addition, the decision rules for assigning quotations to a category of description within each theme were formulated. These rules describe the conditions under which quotations were labeled with a certain category.

As the final step in the analysis, for each teacher we looked, based on the decision rules, for the category or categories in which their learning incidents as 
reported in the enails $(\mathrm{N}=86)$ would fit (which eategory matched which teacher?). This procedure resembles the procedure described by Marton (1986, p. 34). Each quote had two contexts in relation to which it had been interpreted first the interview [learning imeident] from which wis taken and second the pool of meanings to which it belongs". Sometimes, a quote matched several of our five thenes. In this case, the quote was copied several times and put into the categories of each theme in which it fitted.

\section{Results}

\section{How do towahers learn?}

The firt research question concerned the activities from which the teachers learned. While analyzing the interviews and e-mails, four categories were defined (see Table 1). As has already been said, some quotes matched two pools of meaning. As a result, the total number of frequencies is higher than the total sum of learning incidents $(N=86)$ as reported in the emails. Each category is illustrated with a quote and a code between brackets. This code refers to an abbreviation of the institute: Information Technology (IT), Teacher Education (TE), Facility Management (FM), and the identification number of the teacher. 
Table 1: Teacher learning strategies and the frequencies with which they occurred in the emails

Teachier learning strategy

1. Larning by doing

The teacher leams by doing a task (mostly) alone. This involves figuring somothing Trequency out by trial and error, for example, a formala, an ICT applioution, preparing a dass, writing a paper, or conectimg homework. "I was translating a paper about constructive learning. While doing that, I compared ny leaming to student learning, I saw a lot of similarities" (THE).

\section{Learning in interaction}

A. The teacher learns in interaction with students, both in and outsole dassonom situations. For example, a student explains to a teacher how something works, sonnething unexpected happens in a classroom stution, or the teacher gans an insight. "Today, during practical work, I asked the students if they knew how I shonld download MP3 files from the Internet. They thad wonderful ideas" (IT3).

B. The teacher learns in an (mostly) informal, unplanned interaotion with a colleague: For example, answering e-mails from colleagues, asking collestugess for opinions or explanations, hawing a chat at the coffer machine, or attending a colleague's hesson, "I Was writing a paper and all of a sudden I understood thanks to a short explanaton from a colleague, what ICT tools I don't understand and showld work on (TE4).

C. The teacher learns by participating in a (mostly) formal or planed meeting with several colleagues or external experts. This inchdes traning, meetings, supervision, conferences, etc. "Today, I was in a meeting with my colleague coaches from the institute. I learned two things: first, my opinion matters and is shared by others, and second, I should state my opmion in a more relaxed way and present it with hurror" (TES).

\section{Learning by reading (a newrpaper, a book, an article)}

The teacher learns by self-study.

sarloday, I read the bography of Nels Bohr. It made me think about the individual teaching stylles (TTS) of teachers" (FMS).

\section{Learning by thinking}

The teacher takes time to reflect and think about school matters while doing something else (working in the house, driving from house to school, trying to sleep,

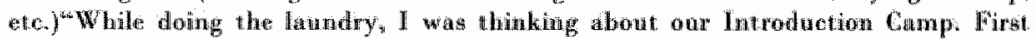
about the camp and making pictures, then making video and, all of a suddon I thought about a multimedia ad-rom" (ITS).

Of all learning activities, leaming by reading and thinking wer reported least in our emails. Learning in interaction was reported most frequently, followed by learning by doing. While the importance of interaction was very clear in our study (see next section), the role of conscious and structured reflection as supposed by most. reflection theories was not so clear. For example, only one teacher mentioned learning by supervision, planmed ways of collegial consultation were not mentioned at all. Some teachers used the process of writing a diary as a way to reflect, whille others disliked it. One teacher wrote: "I realize with pleasure that, as with supervision, to be forced to reflect works very well" (TE2), while another teacher took an opposite position about the writing in the dairy, "(...) you have to reflect, you have to think, and that's something I don't like. I try to avoid that. I don't have time for $\mathrm{t}$. That means that I find other things more important than thinking about myself, about my own learning" (IT2). 


\section{With whom do teachers leam?}

The interaction category ag divided into three main parts: interaction with students, informal interaction with colleagues, and formal interaction in meetings. Our teachers learned most frequently from colleagues or experts in formal meetings. They mentioned students and informal talks with colleagues less often as learning situations.

Most of our teachers were enthusiastic about their meetings with students who were interns. The metings with those students and external tutors were very worthwhile for them. "This morning, I visited an intern. Her mentor at that company said something about "the three functions of Huben". After our conversation, I asthed her what she meant (.). In this lind of conversation, I chect my ano knowledge: I read this... is that right... are you also busy with..." (FM3).

Only one teacher gave an example in which the manager played a role in the learning. When asked about this, most of the teachers said that it was not necessary. "I haven't spoken with my manager in the past month. In my profession, my subject, I cannot learn from him. I also don's have a need for it. He has to manage the big picture and shouldn't inferfere wh my learning. He infuences our learning indireculy by initioting change programs in our institution in which we have to partictpate" (FM5). With this, we answered our second research question.

How do veachers regulate the learning?

The third research question concerned the way teachers self-regulate their learning. Based on our data, three different types of regulation can be distinguished: spontaneous learning, non-linear learning, and planned learning (See Table 2).

About two thirds of the learning situations mentioned in the e-mails were unplanned (spontaneous and non-linear). While analysing the teachers" remarks about setting goals, we noticed that these confirmed this unplanned character of our teachers" learning processes. In the first interwiew, the teachers were asked to mention learning goals or things they would like to improve upon. Very few teachers reported learning activities in relation to these learning goals in their e-mails. One teacher, when asked aboult this unplanned learning pattern, said "That's right. I constantly ask my students to set learning goals and I also ask them to reflect on them in then reports. But I don't do it myself This is quite an insight" (FM2). Another teacher said, "I have a general idea of what I want to learn. While I'm working on that, I ancounter problens that make it clearer to me what I want to learn. In this way, I also encownter other things which are much more fun to learn. As a result, I quit he original things (IT3). 
Table 2: Three different types of teacher regulation in learning and their frequencies

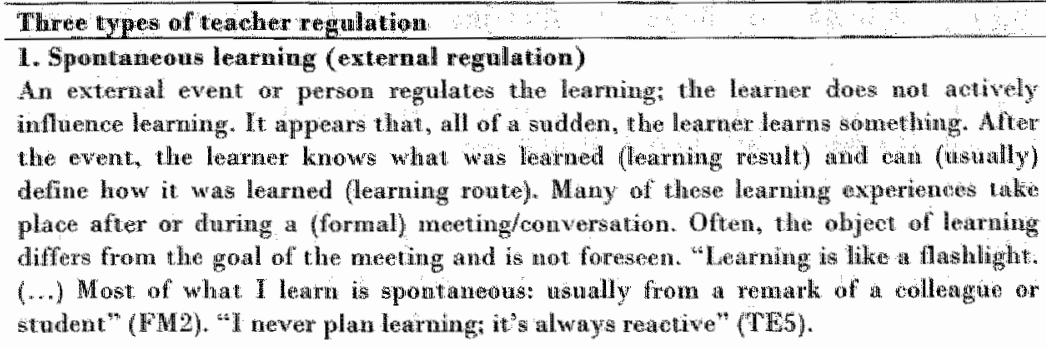

Fequengy

\section{Non-linear learning (external/sell-regulation)}

This form of learning is the (monpected) result of achedy doing something: performing a task ar solving problent. The problem or task emanites fram an

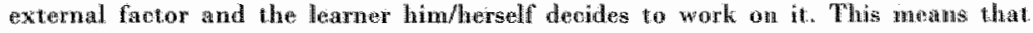
leaming is regulated both extermally and intermally. The lewmor does not know beforehand what (no learning goal) and how (no learming route) is going to be lowned. Although the learuer does mot define a learning goal, there is a "working" goal fto solvo the problem, to do my task). "T tonscionisy solve problems. The learning that aceurs. as a result is unexpected" (IT5). Non-hinear learnimg can be dompaned to lasaning from surfing on the internet. One often starts with a question but whiles surting wno may and up with a complecty different insight.

\section{Planded learning (self-regulation)}

The loamer knows beforehand what and how one is going to learn. The lewarme is solfregulated. The leatner ereates bishers own leaming aetivity; not only the learning goal, but atso the llearning route is known beforehand. The learnet consciondy tries at different behavior, skill, something which he/her the mot tried before, for the sake of mastering that behavior or skill (imstead of for the sake of solving a problom): The learner may also plan a conversation with someone else in order to ask for help or dinectiona. "I have things learning goals- in my head which make me more alert to possibilities in my enrroundings, a kind of selective pereeption" (FM3). "Every chanse I get, I try to work on themingl goal" (TE2). "Letroing to use ICT" tools is planned: I make thine for that in the whings (IT)

In sum, one third of the learning experiences mentioned in our sudy were planned. In the rest of the sintuations; learning took place without planning as a result of an extermal or problem based type of regulation. With this, the third rescareh question was answered. 


\section{The result of lewring}

The fourth reacarch question dealt with the issue of whether teacher learning involves a behawioral change. The data was processed in order to discover whether the teachers reported "a behavior change" or "getting an insight". Four categories could be distinguished (see Table 3 ).

\section{Table 3: Outoomes of leanumg and heir frequencies}

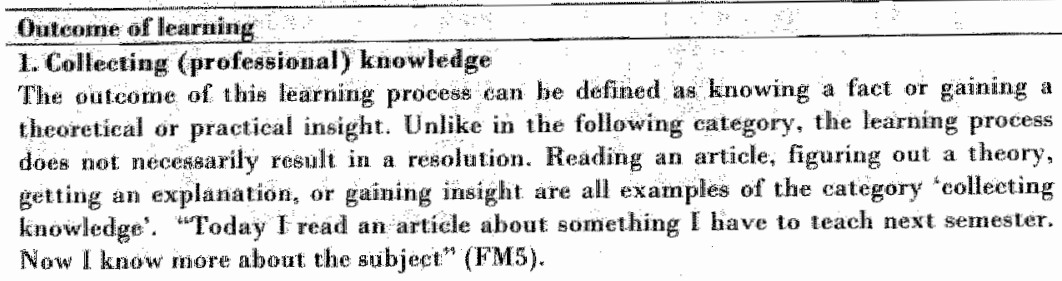

Frequency

1. Collewing (professional) knowledge

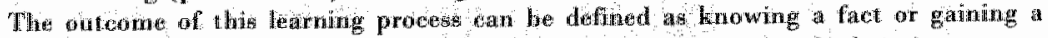

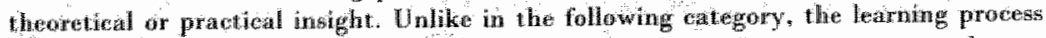

2. Minking at resolution for the mext time

The oukome of 1 his learting proces is a resolution for the next time the teachie encounters the same type of stontion. The tencher decides no (1) repeat the same

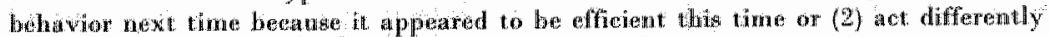

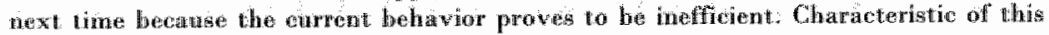
type of learning (ats componed to the last two categorizs) is that the teacher does not seom tio carry out this resolution (at sort notice). "I was teaching stadents a new

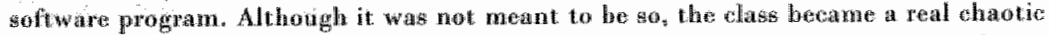
mess. Fath student wont his own way while discowerng the program. I learned that it is much more efficiont to sillow students to explore an application by thamselves, instead of giving them ditect wastruction. They worked paratel and learued from each othar" (TT3). "I loarnod today that from now on, I will be very strict about the deadlines I set for seheol papers. I granted one stadent a delay after which all stadents

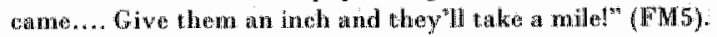

\section{Claanging social behaviour}

This categary is scored when a teatuer is consciously trying a new type of soeval

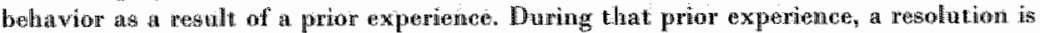

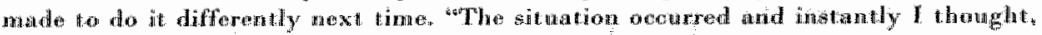

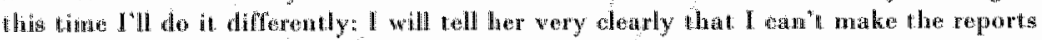
anywore. And so I dit. She agred immediatoly" (FMis.

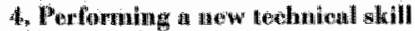

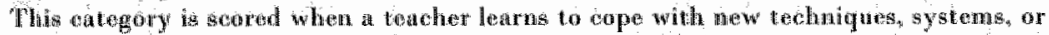
applieations "I was busy putting the grades into the systen. While doing this, 1

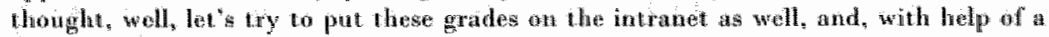
colleagras I did" (TT6).

The first two categories can be characterized as "getting an insight"; the last two as types of 'behavior change'. Most learning situations that were reported by the teachers in this study concerned the two "insight" categories. In these categories, there was no sign (yet) that a new behavior had been developed. When asked about this pattern, one teacher said, "We only reached the step of consciousness, of talking about it and telling each other how bad we are, but that's it. We reach the stage of confession and God may do the rest. (...) As a result, I can leam something ten times and do wrong the same number of times" (TE5). "I also make the same mistake more than once. I think it is a habit. I also don't really think beforehand: 'Let"s do it 


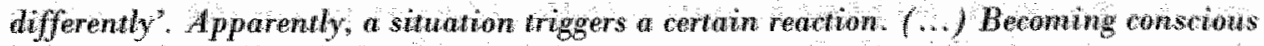
is only the first step. Hoes not guarantee a change of behwior" (TM2).

We let the teachers themselves judge whether they had learned anything, According to them, they had learned. However the learning of most of our teachers did not appear to be spiral. They only appeared to go through one two or three phases of the experiential leaming cycle. Most of our teachers seldom actively searched for or created sitnations in which they could test their rosolunions. According to the learning and reflection cycle (see Introduction), this is what they should do in order to learn. A few teachers did finish these cyeles. They reported the next step: actively trying the resolution in a new setting. Three ont of the fifteen teachers reported the third category more than once (ohanging socual behavior). As might be expected, the gromp of IT teachers often reported learning situations matching the "performing a new technical skill cattegory.

What factors stimulate or inhibit learning?

The last theme we investigated concemed the factors that stimulate or inhibil: teacher learning. Two teachers were completely satisfied with their leaming during the research period. More than half of the teachers were not at all satisfied with their learning. As a result, the total list of stimulating and inhibiting factors was long.

"No Time' appeared to be the nost inhibiting factor. Most of our teachers complained about their work load. "My day is filled with meetings. I go from one meeting to the next. I"m a teacher! There are days that I don't even turn on my computer and, as a result, I do the work at home at night" (IT5). On the other hand, some teachers did not see this as an inhibiting factor: "I don't have the feeling that I have too little time for my own learning. It just depends on the amount of time I nake for it: (TT3).

Some teachers did not feel motivated to learn from or in thein work. "I give myself assigmments in my private life. Here at the institute, I only have organizational assignments. Those are not very inspiring" ( $\mathrm{X}^{\mathrm{l}}$ ). "I learn so much more outside my work that I wonder why I still do this work" (X). "Right now, I"m such an expert in my field that I'm erosing the goals of the institute. I can't expect students to learn everything 1 know. (...). But why should I learn when I can't pass it on to the students anymore (...)? I also don't have aparing partiner at the Institute. If find that difficult" $(\mathrm{X})$.

The autonomous position of our teachers is another inhibiting factor: no demands are made of them and they are not corrected at work. "One of my learming goals is to be a betrer coach: wo guide instead of teach students. But the more I explain to the student, the happier he is. I am rewarded for the opposice behaviour! And nobody secs it. If somebody was situng next to me, I would not ant this way, but nobody corrects me" (FM2).

As a stimulating factor, many of our teachers said that they leaned a lot from interms or from students" final projects. Apparently, those external contacts are important for teacher tearning. "I leam a lot from external people. For example, I am visiting an intern and when I talls wh the intern's tutor or when I speak wh people whom I know are experts in my field" (FMS).

\footnotetext{
To guarantes complete anonymiry, we did not include the codes of the participants here.
} 
The results confronted us with something of a puzzle. We couldn"t elicit a clear picture of the factors: there were so many and some were even contradictiory. For instance, the factor of room/officemates. Ome teather liked sharing an office in order to ask a colleague questions, the other would rather have an office for oneself in order to have a quiet enviromment. Thus, some factors were mentioned as both stimulating and inhibiting. Apparently, the factors are very individually based. A previous study done by Kwakman (1999) might offer an explanation for this phenomenon. Kwakman concluded that teachers perceive the task and work environment very subjectively and that these differences in perception are caused by the differences between individual teachers.

\section{Conclusions and Discussion}

In this study we raised the question of whether and how teachers self-regulate their learning. Due to the limited number of learning experiences reported, the use of selfreponted data, and the absence of observational data in our study, it is difficult to generalize the results. Furthermore, with respect to the influence of the research on the teacher learning process, it must be said that all teachers reported that the study itself inlluenced their learning. All said that they were more conscious of their learning than normally. However, they also stated that their ways of learning (in terms of their learning activities, with whom, planned or not) were not influenced. Acoording to the teachers, they were doing their job as usual, but they noticed more easily when a learning situation occurred. Finally, we do not claim to study "what there is in the world" (reality) but we do claim to study "what there is in people"ss conceptions of the world". By adopting a phenomenographic approacla we have studied the perception of teachers about their learning. The benefit of this approach is that these conceptions, which are identified in the context of this particular study, ane related to each other in a structure of categories such that, in the words of Renstrom. Andersson and Marton (1990), "the relations between the categories are of a logical character, and the categories have been ordered into a hierarchy in terms of inclusiveness [in which] they are progressively differentated and integrated". These categories maly indicate several patrems which might direct future studies in order to "decontextualize" our findings.

In the section on teacher workplace learning, we listed five assumptions about learning. In short, learning üs udeally a (1) self-regulated, (2) planned, (3) spriral, (4) reflective process and (5) involves a behavioral change. We will start by determining whether these assumptions were confromed in this study.

Based on the reported learning episodes, three types of regultation could be discerned: external regulation, both extemal and self-regulation, and self-regulation. Nevertheless, we acknowledge the fact that our teachers" learning experiences are never completely self or externally regulated. When a learner decides to learn something (self-regulation), this is usually because something in the environment triggers it on leads the way (see also Candy 1991, Bolhuis 2001). Notwithstanding, when something in the enviromment triggers the learning (externally regulated), this is because the learner decides to pay attention to that something. For instance, during a meeting with two graduating students, one of our teachers got a sudden 
insight into the way a certan subject should be tanght. The teacher got this insight because one of the students stated the solution almost literally. The other teacher who was at the meeting did not pay attention to the student remark because that teacher did not have to teach that subjeet. So, although this leaning experience was defined as externally regulated, the learmer still had an role in it by recogning it as an important remark. With this we underline the view of Oosterheert and Vermunt (2003), who conclude that learning can only oceur-ultimately under the internal control of the learner.

Aceording to the participating teachers, most of their learning situations were unplanned (see Assumption 2). These were called sontaneous of non-linear learning experiences. These findings are in line with other studies on teacher learning. For example, the study on the learning process of high school teachers (KWakman 1999) showed that most learning is not goal-directed but the result of working activities of situations. Others have also found that adult learners rarely pre-plan their learning. They have reported that adults" learning activities none often than not arose ont of some "triggering event" (Spear and Mocker. 1984). More specifically, Danes and Tremplay (1985) found that the learning experienoe does not conform to either a linear or a spiral sequence. The present study also contirms the findings of Oosterheert et al. (2002) concerning student teachers' learning. "They found two types of learning activities and regulation: active, intentional learning versus reactive, non-intentional leaming. We support their assumptions that, besides deliberate processing, spontaneous insights also play an important role in learning. Apparently, the learning experiences of this particular (and small) group are not always as planned and consciouslly controlled as described by the experiential and reflective spirals we refered to in the introduction. Rather, they appear to be spontaneous and non-linear learning forms.

As a consequence of the unplanned and unstructured eharacter of most learning experiences of our teachers, we also conclude that leaming experiences, like the ones of our leachers, might not (always) be spiral (see Assumption 3). Sahön (1987) explains this conclusion as follows. Teachers are not instrumental problem solvers who select the technical means best suited to particular purposes. In many cases, a teacher has to improwise. Most situatione are unigue, and, acoordingly, nost solutions to these situations differ. This has an important impact on learning. Because of this non-technical rationality of work, it may be difficult to approach learning from the technical perspective prescribed by experiential and reftective models. In most teacher learning situations in this study, our teachers did not reognize a short-term possibility to test a new solution or behaviow fand thus continue with the last and first step of the cycle). If the opportumity had arisen, it might have been unexpected (and thus the teacher may have been unprepared) or slighty different (and thus have required a different approach). An exception to this conclusion is made for the IT teachers in this study. While exploring a new IT program, they went though the experiential learning cycle several times.

From what activities do teachers who participated in our study learn? This cpuestion relates to the fourth assumption about the role of reflection in the learing process. Four categories were distinguished. Of all the leaming activities learning by reading and thinking were reported least. Learning in interaction was reported most frequently, followed by learning by doing. While many athors (see Introduction) 
emphasize the importance of reflection, this emphasis was not found in bur empirical data. All our teachers looked back upoin their experiences. In this sense, they reflected. However, very lew of the teachers reported a planned or structured form of reflection, swch as the ALACT modell (Korthagen and Kessels 1999) presented in the introduction. Some teachers even disliked the idea of reflection. And because of the apparently non-spiral character of most learming experiences, (often) nothing was done with these reflective thoughts. Similar findings were reported by Knight (2002) and Kwakman (1999). According to Knight, reflection is not a sufficient condition for learning, because "any kind of thinking of one's practice tends to get described as relleetion" (p. 293). K wakman conduded that reflection only seems to appear in coaching situations, where it is more or less organized. This might suggest that teachers, like students, need guided and sustained opportunities to reflect on their practice, and to consider and try alternatives.

While investigating the outcones of the teacher learning expeniences (see Assumption 5), it was noticed that most learning experiences resulted in obtaining professional knowledge" or 'making a resolution for the next time'. Surely, not all the reponted learning episodes resulted in a behavioral change (during our study). Nonetheless, the teachers concluded that all these episodes resulted in learning. This finding might be influenced by the way we defined learning (see introduction). In this study, we were satisfied with assimilative learning processes in which the existing knowledge structure does not need to alter fundamentally.

Placing these findings (concerning the five assumptions) in the context of the student self-regulated learning literatwre we referred to in the introduction, the following conclusions can be drawn. Like students, our teachers seemed to differ in their abilities to self-regulate their learning. Only some of them used some of the skills identified by Zimmerman (2002, see Introduction). For instance, some teachers had difficulty with formulating their learning goals for the coming month. "I never plan learning; it is ahoays reactwe". Others did not plan their learning, but did solve conseiously their problems: "I conscionsly solve problems, the learning that occurs as a result is unespected".

Like students, not all teachers in owr popalation showed the ability to aotively and oonsoiously self-regulate their learming experiences. But all teachers were involved in spontaneous and non-linear learning. 'The teachers in our sample, who involved in spontaneous or non-linear learning, maybe were not self-regulating their learning, but our findings indicate that they did self-regulate their teaching practices. That is, they reported (see also Table 1 , teacher learning strategy) that they constructed instruotional strattegies based on specific goals for their students; they enveted them in their classrooms, they monitored the ontcomes, they solved problems and they made resolutions in order to revise instruction accordingly. The same argument (teachers self-regulating their teaching practice) is made by Butler (2003). Butler $(2003$, p. 5) states that "when professional development is situated in practice, teachers actively eonstruct approaches to teaching (...), and when they focus on their own learning in that context (with opportunities for goal setting, active learning, reflection and self-assessment), they simultaneously revise knowledge about learning and teaching". We therefore want to add something to our definition of SRL (see Introduction). We now think that the core of self-regulated 
teacher learning is best defined by: "independenty direoning the process of improving teaching andior attaining learning goals".

Finally, we return to the three conceptions of how teachers learu put forwand by Cochran-Smith and Lytle (1999). Our findings were quite different from what we expected based on those conceptions. Our teachers seldom participated in training. reading, or other types of study (see the first conception). They seldom reported that they were engaged in conscious en structured reflection in order to eonstruct practical knowledge (see the second conception). None of the teathers wrote us about intentional (systematic) investigation (third conception). Based on the lindings of our small scale study, we would like to add a potential fourth conception of how teachers learm.

In this fourth conception, it is recogmiged that there are several ways in which teachers regulate their learning experiences. Teachers learn by all kinds of day-to-day teaching experiences without planning this. For example, they spontaneously learn by taking note of remarks made by students or colleagues. They also learn in a non-linear way by solving problems. These proesses might not be self-regulated in order to learn as such, but firstly regulate (their improvernent of) their teaching practice. Besides this self-regulation of their teaching practice with learning as a result, teachers also deliberatelly set time aside for self-regulatod learning experiences. With this description, the fourth conception may acknowledge the specific context of teacher learning processes at the workplace.

\section{Further research}

There is clearly a need to verify the conclusions of the small scale qualitative study presented here. Future research could look into the processes of the non-linear learning, because this type of learning seems to connect with the learning of modern multimedia (think of surfing on the internet). How are decisions made about what to learn or what to do in this learning process? What makes people quit non-linear learning: how do they decide that they have llearned enough and that it is time to move on to a different subject?

Futare studies might take into account the two critiques as formulated by Webb (1997) considering the phenomenographic method. Basically Webbs" (1997) concerns relate to the "prejudices" of phenomenographers as they construct and interpret categories of understanding ( $\mathbf{p} .200)$. According to Webh. categrores are not just "simply there" but are, when constructed, influenced by the historical and social experience of the researcher. In addition, one of these categories often displays the "correet meaning" as judged by the researcher while the others "anre recapitulations of earlier, now supposedly discredited accounts" (p. 20l). Following Webb it seems likely that phenomenographic researchers will tend to report the history of a discipline as it is understood by them instead of secing new conceptions. In order to handle these critiques Webb suggests a more hermeneutic approach, in which a deeper understanding may be reached for example by involving the research participant in the conversation in which categorization and judgment lakes place. This is in line with the solution given by Linder and Marshall (2003) no similar problem. They plea for a) a frequent and deliberate "shifting in focus" whille constructing the categories $(p .280)$, since there is a rolation between the focus and 
meaning given to a certain object of learnimg; and b) a "inindful searching for variation to explore an ohyect of learning" (p. 282) in order to see what has not be secn before:

\section{References}

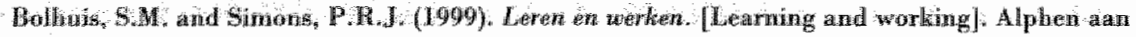
de Rijn: Samion.

Autler D.t. (2003). Self-regulation and collaborative leaming in teachers" professional development. Paper pesented at the 2003 aninal inetings of the European Association for Researeh in Leaming and instruction (GALI). Tonly: Padua.

Calderhead, J. (1996). 'Teachers: Beliefs and knowlegde', in Berliner, D.C. and Calfee, R.C. (Eds.). Handbook of educational psychology. New York: MacMillan, pp. 709-725.

Candy, P.C. (1991). Solf-dinection tur lifetong learning. A comprehensive guide to theory and practice. San Irancisco: Jossey-Bask

Coehran Smilh. M, and Lytle, S.L. (1999): 'Relatiomships of knowledge and practice: Teacher leatning in towmunities", Review of Researeh in Education $24,249-395$.

Confegsore, S.J. and Kops, W.J. (1998). "Self-directed Learning and the learning organization: Examining the connection between the individual and the learning environment, Fuman Rescource Developmen Quaterly $9(4), 365-375$.

iDanes, Ot and Tremplay, N. (1085). "Critical andlysis of aduht learning principles from a self-

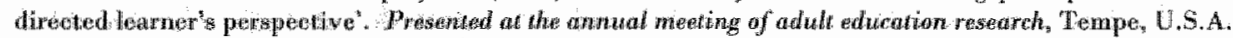

Darling- Hammond, I. (1997). School reform at the crossiroads: Confronting the central issues of teaching diducational Policy $11(2), 151-166$

Frant, $\mathrm{M}$. Alderton, $\mathrm{J}_{\text {, }}$ Cole, $\mathrm{G}$. and Senker, $\mathrm{P}$. (1998), Development of knowledge and skills in amployment. Brighton: University of Sussex.

Francis, D. (1995), "The reflestive jourial: A window to pre-service teachers" practical knowledge", "Taching and Twacher Education $11,229.241$

Garcia, $\mathrm{T}$. (1999). "Mainaining the motivation to learn An introduction to this special issue of 1earniagand indwidual differsnces', Learning and Individual Differences $11(3), 231-232$.

Guilfoyle, K., Haniltou, M.I. and Pinnegar, S. (1997). "Obligations to unseen dhildren", in

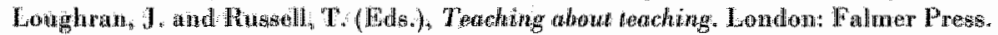

Hamilton M.t. (1998). Reconceptualuzing teaching practice; self study in theacher edneation. London: Falliner Press.

Hothweh, M.Z. (2003). "Teacher accommodative change", Teaching and Teacher Education 19, 421.434

Knight, P.T'. (2002), 'Learning form sthools', Higher Education 44, 233-298.

Kolb. D.A. (1984). Experiential learaing: Experienws ats a source of fearning and dlevelopment. Fingle woed chiffs, NV: Prention Hall.

Konthagen, F.A.I. and Kessels, J,P A.M. (1999). "Linking theory and practiee Changing the

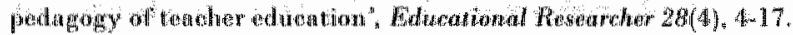

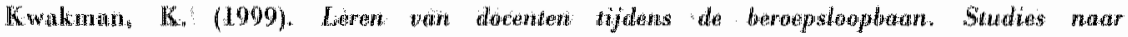

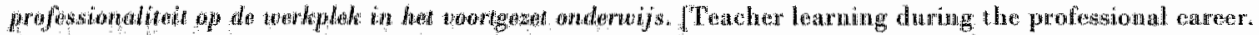
Studies to the professionatiam at the workplace in secondary edncation]. Doetoral dissertation. Nijmegen Universily.

Cinder. C. and Marshall. D. (2003). Relection and phemomenography: towands theoretieal and eduteational development postibilities", Learnang and Instruction $13,271-284$.

Long, H, B. (1994). "Resources related to overcoming resist tance to self-direction in learning", in Hivnstha, R. and Brockett, R. (Eds.), Overcoming resistance to self directed learning in ad ul learning. New: dinechons for Adult and conturningy Education, no. 64. San Franeisco: Jossey-Bass.

Martion, $\mathrm{F}$. (1986). Phenomenography - A research approah to understanding different understatudings of reality", Joumal of Thonght $21,28-49$.

Marton, $F .(1990)$. The pheomenography of learning - a qualitative approach to educational research and some of its implications for didactics", in Mandll, H., De Cortey E., Bennett, S.N. and Friedmich, H.F. (Eds.), Leoming and Instruction - European research in an international context. Volume 2.1 Oxford: Pargamon Press, pp. 601-616. 


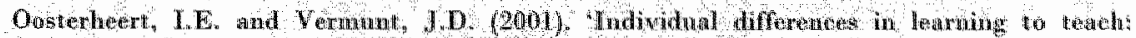

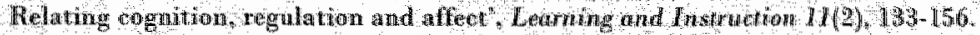

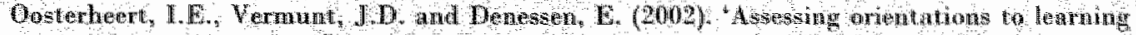

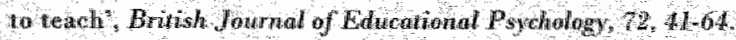

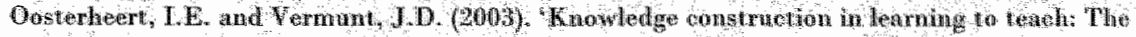
role of dynamic sompes. Teachers and Teathing, Theory and Practice, $9,15716$.

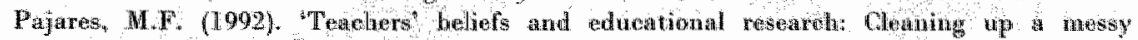

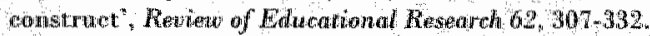

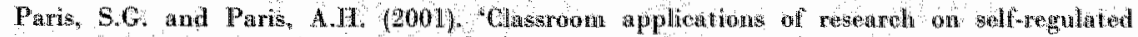
learning, Educotional Psychologist $3602,39-101$.

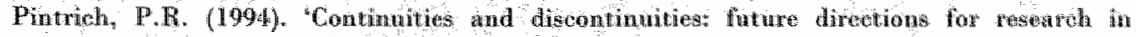

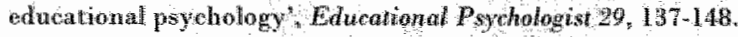

Renstrom, 1., Andersson, B and Harton. F. (1990) "Students" coneptions of matter" Jourmal of Edicational Psychology $82,555-569$.

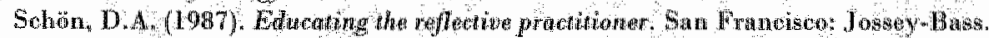

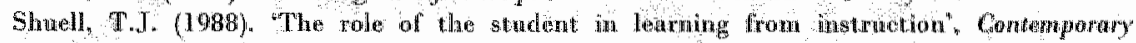
Educational Psychology 13, 276.295.

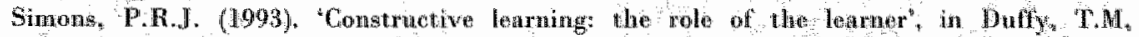

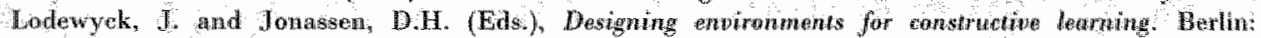
Springel, PP. $291-313$.

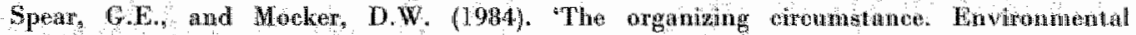
determinants in self directed learning" Aduh Lawcanon Quaterly $35,1,10$.

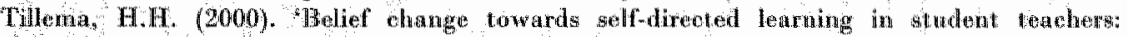

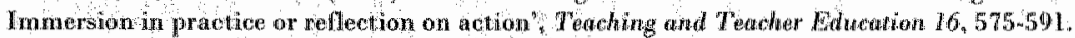

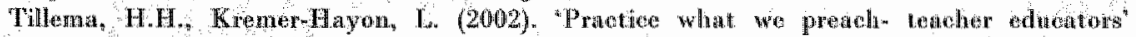
dilemunas in promoning selfregulated learning a cross case comparison", Teather and Teacher foluchtion $19,593 \cdot 607$.

Tough, A (1979). The aduit learning projects (2nd ed.). Tononto. Olst.

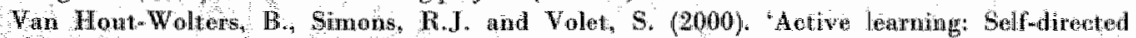

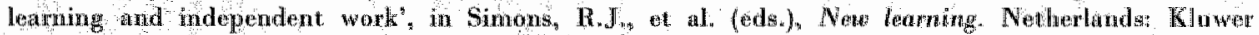
Acadentid Pablisheirs, pp. 21-36.

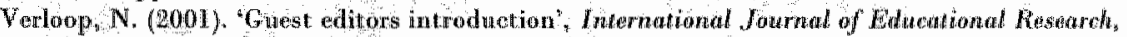
$35,435-440$.

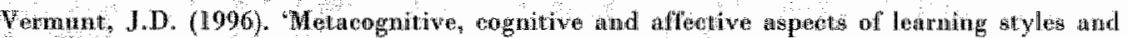
strategies: A phenomenographie analysis", Higher Education 31,25 .50.

Vermunt; J.D. (1998). "The regulation of constrotive leaming procesiess", British fournal of Ediucational Psychology 68, 149-171.

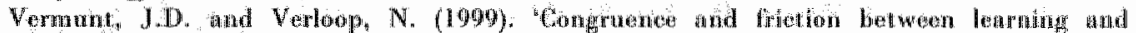
teaching', Learning and Imstruction $9,25 \%-480$.

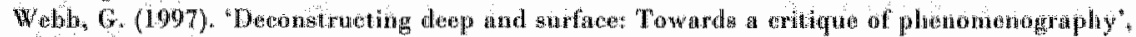
Higher Eatueation $22,195-212$.

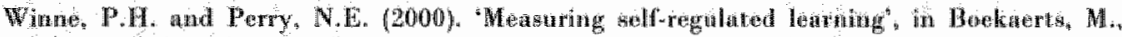

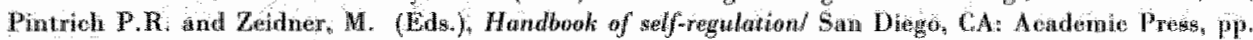
531.566.

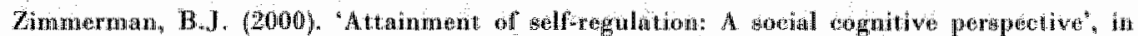

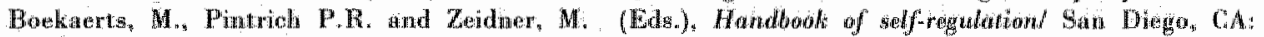
Acendome Dress, pp $13-39$.

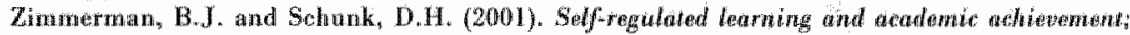

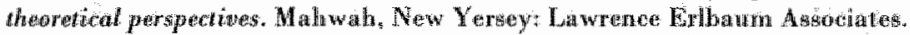

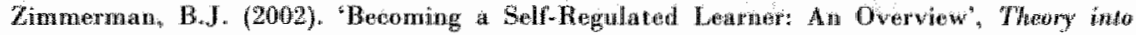
Prantice $21(2), 64-70$. 


\section{THREE}

A condensed version of this third thapter has leen sulunitted to Human Resource Development Qunterly ass

Downhos, A.J. Van Cokelen, I.M, Koopmans, H. It takes tumo to tango: why not invite both partners to dance? 


\section{It takes two to tango: why not invite both partners to dance?}

Adult learning that arises from interactions at work is the focus of the present study. More specifically, the concrete activinies of adult leaners and heir interachon portners were of interest because such learning activities largely determine the quality of leaming outcomes. The results of the study are summarized in the form of a typology of interache learning behaviors for adult learners (ie., workers) and then interaction partners at work. The similarities and differences between three ocenpational groups (tid teachers, financial service professionals, and police officers) were examined and explanations were sought based on the nature of work, gender, and power. The results can help adult learners and their interaction partners enter into a more equal, dyadic, and reciprocal learning process and thereby contribute to a critical HRD perspective.

\section{Introduction}

Understanding how adults learn at work is quickly becoming a major issue for both schollars and practitioners within the field of adult education (Fenwick, 2001). As a result of being involved in work situations, adults must also sometimes change how they think, act, and interact with others (Dalley, 2001). In fact, most of the ongoing adult development of skills occurs via work participation. For adult learners as well as educators, thus, it is critical that awareness be raised and learning at work be better understood (Billetr, 2002).

The importance of interaction for adult learning at work is also being increasingly emphasized. Research shows peoplo to often be asked to work elosty with others within the work organization to develop ereative new solutions to various challenges (Marsick \& Volpe, 1999). In a broad qualitative study of learing within the fields of engineering, business, and bealth care" "learning from other people and the challenge of the work itself proved to be the most important Himensions of leaming" (Eraut, Alderton, Cole, \& Senker, 1998, p. 37), Daley (2001) sxamined how knowledge becomes meaningful for different professional practices and - consistent with Eravt el al. - found work experiences and interactions with solleagues to contribute most to the continual development and refinement of knowledge. On the basis of an examination of worker experiences and wiews, Billet 2002) similarly identified three key contributors to the learning of individuals hrough everyday work activities: (a) engagement in everyday work tasks, (b) direct guidance from cow workers, and (c) indirect guidance provided by the workplace itself and others in the workplace. And when Van Eekelen, Boshuizen, and Vermunt (in sress) created an inventory of how teachers learn, leaming in interaction was eported most frequently, followed by learning by doing. 
The alm of the present stady is to contribute to the field of adult education via the extension of our knowledge of how adults learn at work. Along these lines, Holman. Fintropaki, and Ferwe (2001) have pleaded for such atudy and observed that research "needs to be conducted in a wider range of learning strategies, including behavioral strategies that are concemed with discuszing and sharing knowledge" (Holman et al, 2001, p. 680). While former studies have shown interaction to be an important source for the ongoing development of workers, the present study takes this finding one step further and investigates the types of adult learner and interaction partner activities that actually generate workplace learning. The present study can thus add to the empirical basis for determination of how workplace learning should best proceed and to the construction of a workplace pedagogy (Billett, 2002). From a practical point of wiew, the present study can help adult educators to better understand not only their own practices as adult learmers but also their practices as an interaction partner for adult learners.

Finally, the present study can contribute to the field of Human Resource Development (HRD) and the emerging stream of critical HRD (Fenwick, 2004) by revealing how various workplace practices either impede or foster learning. More specifically, learning opportunities are not always distributed evenly across the work force, which means that certain workplace practices reproduce workplaee inequities and relations that tend to marginalize women, non-native speakers, migrants, and employees low in the organizational herarchy (Bierema, 2001; Billett, 2002). In other words, different occupational contexts and different organizational infrastuctures may promote or discourage adult learning, and it is to the benefit of HRD personnel to know as much as possible about the characteristics of these contexts and struetures (Bierema, 1996).

\section{Theoretical notions related to adult learning at work}

The present study builds on a number of theoretical notions related to adult learning at work. Of particular interest are notions stemming from learning theory, theoretical insights regarding informal learning, and notions related to the interactive, social context of learning.

To start with, the learning theory of John Dewey (1938) is drawn upon to nnderstand individual meaning-making within the workplace. From such a perspective, the adult learner is assumed to construet a personal understanding of a problen on the basis of his or her experiences and reflection is assumed to play an important role within this meaning-making process (Schön, 1993). Other significant proponents of this view are Kolb (1984) who understands learning in terms of personal engagement, learning experiences, and a four-stage cycle and Jarvis (1987) who extends Kolb's model with the outlining of nine possible responses to life experiences.

Theoretical insights into informal learning are also drawn upon within the context of the present study and to better understand adult learning at work. The results of sondies conducted during the past decade suggest that $60 \%$ to $80 \%$ of adult learning in today"s workplace occurs unintended and informally (Marsick \& Wavkins, 1990). Informal leaming is the result of natural opportunities to learn and thus situations or interactions occurring during the individual's everyday working life. However, the close connections between working and learning make it difficult 
to distinguish informal learning from working (Erat, 2000). Stated differenty, adult learning - and perhaps learning in general _ is dearly situated whin the activity in which it takes place (Lave \& Wenger, 1991). And along these lines, Marsick and Watkins (1990) have extended the acthon science nodel of Argyris and Schön (1978) to characterize informal learning and the interactions of individuals with the environmental context. In fact, the perwasive influence of the learning context is explicity incorporated into a later version of the model (Cseh. Watkins, d Marsick, 2000) and seen to provide triggers for learning, potential opportunities for learning, and sometimes barriers to the solution of problems and thos learning.

Finally, the importance of the sociall context for understanding the nature of informal adult learning in interactive work situations is also reoggnized. We assume adult learning within the workplace to be inherently social in two respects. First, work situations often involve other people either directly or indirectly. Second, not only the behavior of the adult leamer but also the behawion of the "other" within an interactive work sitwation can make the interaction either didactic or not.

Based on the experiential informal, and social aspects of learning at work, adult learning is thus construed within the present study as: 1) an activity whereby knowledge, skills, or attitudes are acquired, revised, or relearned and recognized as such by learners; 2) an activity that does not take place within the context of or follow from a formally organized learning program or event; and 3 ) an activity in which the adult leamer is involved in an interactive work situation.

\section{The interaction partner in worlplace learning}

In the present study, the "other" within an interactive work situation is referred to as the "interaction partner" or the person whose activities contribute to adult learning. All kinds of people can directly fulfill the role of interaction partner. Think, for example, of colleagues, managers, clients, family members, and friends. The role of interaction partner can also be indirectly fulfilled via written materials or artifacts (Salomon \& Perkins, 1998); think, for example, of books, websites, newspapers, accupational magazines, ete.

Direct interaction can take place in one-to-one conversation or in groups. And in this conneetion, Eravt, Alderton, Cole, and Senker (2002) identified three chusters of leaming from others involving different contexts: 1) organized learning support such as mentoring, coaching, rotations, wisiting, shadowing, and designated experts; 2) consultation and collaboration within the working group, including ongoing consultation, observation, spesial groups assignments. and feedback within the group; and 3) learning from people outside the working group such as secking help or critical information from people in parallel positions when needed.

While Eraut et al, have provided insight into the different types of interaction partners and contexts, Salomon and Jerkins (1998) provide insight into the process of social learning and the specific behaviors that appear to evoke such learning. Review of the educational research literature revealed different forme of socalled social learning". In the case of the socially facilitated acquisition of knowledge and skills, for example, a facilitating agent" helps the learner (Salomon \& Perluns, 1998, p.4). The facilitating agent provides information, informative feedback, approachable but challenging tasks, encouragenent, tips, and hints. In the case of participatory knowledge construction, learning products are constructed and 
distribured by all of the individuals involved and not just a single mividual. Finally, there ss the case of indirect help from artifacts such as tools and information sources that carry the "wisdon ard hidden assumptions that went into their design" (Salomon \& Perking, 1998, j, 5).

\section{Gender and power in workplace learning}

In addition to the roles of adult learners and interaction partmers in workplace learning, the roles of gendrex and power will allso be examined (Hanscome \& Cervero, 2003). We agree with Billet (2002) who argues that the workplace shapes learning via different activitivs and the access provided to learning activities for different learners.

The literature on gender and learining contains a number of constructs that differentiate between men and women (Severiens, Ten Dam, \& Nijenhuis, 1998). One of these constructs is "cooperative jearning" and the preferences for such observed amoug women and - to a leser extent - men who show a greater preference for competitive and individual learning (see for example Hughes, 1995 ). Women are found to consider the perspectives of others, the making of conmections with preers, and the establishment of a collective perspective to be of considerable importance within a collaborative learning setting (Baxter Magolda, 1994). Men, in contrast, are more often concerned with their own learning and thus prefer working indiwidually over working collaboratively. These two patterns reflect the distinction between "connection" and "autonomy" as described by Belenky, Clinchy, Goldberger, and Rarule (1986) and - by examining the differences between men and women working in interactive situations within the present study - we hope to supplement this body of knowledge.

An examination of power reflects individual, interpersonal, organizational, and societal levels of analysis (Ragins \& Sundstrom, 1989). For the individual level of analysis, power is defined as the individual's ability or perceived ability to influence another or change the behavior of otthers. For the interpersonal level of analysis, power is defined as a dyadic and reciprocal process in interpersonal relationships. For the organizational, more maero, and thus less psychological level of analysis, power is defined as a property of the structure of the organization and its resoures. Finally, at the societal level of analysis, power is defined as the fuid relations between the various groups within a society. In sum, power can be delined as the influence of one person over another als a result of individual characteristics, interpersonall retations, position within the organization, and membership within a particular social group (Ragins \& Sundstrom, 1989). For the present study, association with the same organization and hierarchical position within the primary workplace are considered key power eloments. D'abate, Eddy, and Tanmenbaum (2003) speak of the organizational location of an interaction partner in relation to the learner. The interaction partner can be associated with the same organization as the learner (i.e., an insider) or associated with a different organization than the learner (i.e. an outsider). Furthermore, the interaction partmers within an organization can have different 'relative positions in the social hierarchy" in relation to the employee (i.e. adult leamer): they can be higher, equal (i.e. peer), or lower (Levy, Collins, \& Naill, 1999, p. 723). 


\section{Research Questions}

Interaction with others within the workplace thus constitutes a major source of adult learning. But do all of the interactions within the workplace lead to learning? And what, exactly, makes an interaction didactic? The purpose of the present study was to gain insight into what employees and their interaction partners actually do during interactive work situations that lead to learning.

The following research questions were formulated for examination.

1. What activities on the part of adult learners appear to generate learning in interactive work situations?

2. What activities on the part of the interaction partmers of adult learners appear to generate learning in interactive work situations?

3. What are the differences between the activities of adult learners and their interaction partners in interactive work situations and how do these vary - if at all - for the different occupational groups?

4. Do the differences in the activities of adult learners and their interaction partmers in interactive work situations vary depending on gender?

5. Do the differences in the activities of adult learners and their interaction partners in interactive work situations vary depending on power?

\section{Method}

In order to gain insight into the concrete activities that generate learning between an adult learner and his or her interaction partner, an interpretative paradigm was adopted (see for example Lincoln \& Guba, 2000; Patton, 2002). We were more interested in understanding human interactions in specific cases than generalizing across time and space. The nature of the present study was largely descriptive and therefore based on the principles underlying the critical incident technique (Ellinger \& Watkins, 1998; Flanagan, 1954). More specifically, the following two basic principles were followed: (a) actual behavior was reported as opposed to the collection of ratings or opinions reflecting general impressions and (b) behavior that appeared to make an important contribution to the learning incident was selected for closer consideration (Flanagan, 1954). It is frequently argued that verbal data have greater validity when based on actual events and changes in behavior than on hypothetical situations (Ericsson \& Simon, 1984). Semi-structured interviews were therefore undertaken (Kvale, 1996). With neither an existing typology of adult workplace learning activities nor a clear nodel of how interaction partner and adult learning activities relate to each other, it was necessary to create our own inventory of activities from the ground up. And for this purpose, extensive interviews were undertaken with employees in very different employment settings.

\section{Research participants}

In order to obtain as diverse a mix of participants as possible, three different occupational groups were selected for study, namely: teachers, linancial service professionals, and police officers (see Table 4). It was assumed that the analysis of the learning incidents and interactions for these three groups would provide a rich 
array of dlata and thereby insights applicable to other employees and other occupational settings.

Table 4: Research Participants

\begin{tabular}{|c|c|c|c|c|}
\hline$:$ & $\begin{array}{l}\text { Teachers } \\
\text { (Higher } \\
\text { Fidncation) }\end{array}$ & $\begin{array}{l}\text { Finamcial service } \\
\text { profestionaly }\end{array}$ & Polize officers & Toital \\
\hline Partictpant: & 15 & 8 & 10 & 33 \\
\hline Gender & $\begin{array}{l}7 \text { mente: } \\
\text { D forratile }\end{array}$ & $\begin{array}{l}5 \text { miale } \\
\text { 3temale }\end{array}$ & $\begin{array}{l}9 \text { male } \\
1 \text { female }\end{array}$ & $\begin{array}{l}21 \text { male } \\
12 \text { female }\end{array}$ \\
\hline Age & $37-53$ years & $25-41$ years & $28-49$ years & \\
\hline Working experience & $12-30$ yeara & $2-18$ years & $1-30$ years & \\
\hline Educational lewel & Higher education & Higher eductation & $\begin{array}{l}\text { 3. Higher eductition; } \\
2 \text { Serior secondary general; } \\
5 \text { Junior general }\end{array}$ & \\
\hline Employment & Min, $0,8 \mathrm{FTE}$ & Full time & Full time & \\
\hline
\end{tabular}

Note: Of the 8 financial service professionals, 4 were managers, 2 were programmers and developers, I was a salesman, and 1 was a rish calculator.

Teachers were selected by the heads of three post-secondary Institutes of Higher Education. Given three lists with all of the teachers with more than five years of teaching experience and a contract for a minimuna of 0.8 FTE, 15 prospective participants were randomly selected for each institute. The head of each institute was then asked to invite the first five prospective candidates on the list to participate.

The financial service professionals were selected from an internal professional education database for which access was obtained via the human resource department. The financial service professionals all had a higher educational level but varied with respect to age, tasks, work-related problems encountered, and responsibilitios within the work domain.

The police officers were selected via three chief inspectors, who were sent a letter of invitation with an overvew of the entire research project and the purpose of the interviews to be andertaken. The three chief inspectors were asked to select three police officers with street duties, at least a year of work experience, differing ages, and differing police ranks 10 participate in the interview. This resulted in nine participants while a tenth police officer became involved via the interview with a colleague: The interview arose his interest, and his offer to take part was also thus accepted.

\section{Dowa collection and interview guide}

The interview data were available from three separate research projects in which the authors of this article were individually involved (Doornbos, Bolhuis, \& Denessen, in press; Eekelen, Boshuizen, \& Vermunt, in press; Koopmans, 2002). All of the interviews were aimed at gaining insight into informal kinds of learning incidents within the workplace. All of the interviews were andio recorded and transcribed verbatim. Some sample unterview questions are as follows. "What do you do 
differently now compared to a lew years ago?" What have you learned?" "Can you describe some situations in which you have found yourself to be nore wiser than before? "What were the leaxning activitus?" Whth whom did you learn / wore you interacting with? " How do you solve problems in your work" The data collected in such a manmer was very rich and clearly suited for our research purpose.

The literature guidelines for the use of existing data to answer new research questions were adhered to (Heaton, 2002, Hinds, Vogel, \& Clarke-Steffen, 1997). First, the content of the data from the different studies was shown to be compatible as all of the studies were aimed at gaining insight into informal types of adult workplace learning using exploratory or semi-structured interviews. Second, the analysts for the present study conducted the initial analyses as well and also had access to all of the original data.

\section{Data analysis}

In order to answer the specific research questions, the data were analyzed in three broad steps. First, the transeribed interviews were examined for workplace lenrning incidents. Second, the learning activities of the employees and the interation partners were analyzed. And third, the different oceupational groups, gender groups, and power groups were compared for different patterns of employee learning and interaction partmer activities.

For the first step in the analyses, "workplace learning incidents" were selected as the unit of analysis becanse such incidents contain the information needed to answer the research questions. We selected workplace learning incidents based on (1) an employee learning activity in relation to (2) an interstion partner and (3) a learning outcome. Statements regarding learming outcomes played a critical role in the selection of the learning incidents for andysis as we did not want our conclusions to be based on general comments, which have been shown to be less trustworthy in terms of actnal learning and the inpact of such on work performance. The learning outcome could vary from clearly identifiable and observable behavioral changes to minimal adjustments in attitudes, which were not evaluated further by the researchers. This first step resulted in three liste of learning incidents that were chedked for their authenticity with the other two researchers (Lincoln \& Guba, 2000). Authenticity is the "rellexiwe consciousness aboul one"s own perspective, appreciation for the perspective of others, and faimess in depicting constructions in the values that triggered them" (Pation, 2002, p.546). The descriptive validities of the employee leaming activities, the activities of the interaction partners, and whether the learning incidents generated a learning outcome or not were similarly determined with the other two researchers (Maxwell, 2002).

In the second step of the analyses the specific content of luw learning activities of the employees and the interaction partners was examined and subsequently coded. Each researcher initially examined the learning incidents for one of the groups of participants for the specific activities of the adult learners and interaction partners. This resulted in six lists of specific learning activities: three for the adult learners and three for the interaction partners. The identification of the activities was grounded as much as possible in the language of the participants and their own descriptions of the activities. In consultation with the other researchers, 
the thee lists of adult learner activities were then integrated into a single list and the interaction partnet activities were similarly integrated into a single list. These two lists were subsequently used to code the entire set of interactive work situations, and several coding rounds were needed to attain sufficient inter-subjective agreement (Glaser Strauss, 1967). Given more or less comparable types of content, the activities of the learing employees and meraction partners were also categoried. The gender (male, female) and hierarchical position of the interaction partner relatwe to the learning employee (higher, peer, lower) were also coded when sach information was avallable. We did not code how powerful a learning incident may have been as this could not he rigorously deduced from the interviews and was not critical for eomparison of the learning incidents:

The third step in the andyses was undertaken to answer the remaining three research questions. Do the activities of the adult learners and their interaction partners in interactive work situations differ and, if so, do these differences appear to depend on the occupational group, the gender of the interaction partner, or the hierarehical position of the interaction partner (i.e., power relations)? Chi-square tests were used to compare the leaning employees and interaction partners activities with regard to occupational group, gender, and hierarchical position.

\section{Results}

Examination of the 33 interview transcripts revealed a total of 231 interactive workplace situations (i.e., learning incidents). For the teacher group (T), a total of 97 learning incidents was found; for the groups of financial service professionals $(F)$, a total of 52 ; and for the police group (P), a total of 82 . Given that working and learning are so closely intertwined (see Introduction), we would like to emphasize that the activities we define as learning activities can also be interpreted as work activities that generate a learning ontcome.

\section{Activities of adul learners}

The first research question concerns adult learning activities in interactive work situations. In Table 4 , the percentages for 15 different adult learmer activities per ocompational group are presented. Note that the activities are not performed in isolntion but in interaction with the activithes of the interaction partneir. And on the basis of comparable types of content, five general types of activities could be identified: (1) Regular job, (2) Application of something new, (3) Information seeking. (4) Exchange of information, and (5) Thinking about work expertences. In Appendix A, the specific activities inchaded in each category are described in greater detail.

The results show the leamer"s activity to involve "asking a specific question" in $21 \%$ of all the learning ineidents. Most of the questions are knowledge related (e.g.s concerned with logislation, concerned with the features of an insurance product) or skill related (e.g., how to use one of the other ICT product). Most of the questions also required a simple (i.e., unambiguous) and/or relatively quick answer. The following quotations illustrate the type of questions posed by the adult learners. "I wanted to make a web-page. Before I started, I asked a colleague how I should do that. I made some sample pages and showed them to colleagues who gave me suggestions for a 
differen layout" (T). "I wanted to know exactly how much the social security benefit for the elderly is this year. My colleagues only gave me an average. I therefore looked it up on the Internet or called the Home Offuce to ask them" (F). "We one found a truck trailer at a bus stop. I wondered what offence I should fine for. You ask someone, get an answer, and you never forget" $(\mathrm{P})$.

The results further show the learning activities of "observation" and "performing occupational task" to be mentioned relativelly often as well - in $13 \%$ and $11 \%$ of all the learning incidents, respectively. For the teachers, performing occupationall task' means - for example - the use of educational approaches. For financial service professionals, 'performing occupational task' means - among other things - the circulation of a service catalogue, discussion of results with the manager, or e-mail solution of a problem. For police officers, "performing occupational task' means taking action to solve a crime, reporting of offences, or for example - participation in quality improvement projects. Learning activities involving "checking information' or "answering a question" were mentioned on only a very few occasions. 
Table 5. Pereentage of Adnlt Leamer Activities in Interactive Work Stuations for Different Oecupatonal Groups

\begin{tabular}{|c|c|c|c|c|}
\hline Adult Learne Aetivity & $\begin{array}{r}T \% \\
(\mathbb{N}=97)\end{array}$ & $\begin{array}{r}\mathrm{F} \% \\
(\mathrm{~N}=52)\end{array}$ & $\begin{array}{r}p^{3} \% \\
(N=82)\end{array}$ & $\begin{array}{c}\text { Total \% } \\
(\mathrm{N}=231)\end{array}$ \\
\hline Regrealar joli: Performs customary work & 6 & 23 & 27 & 17 \\
\hline Perfornưg oceupational task & 1 & 12 & 23 & 11 \\
\hline Answering a question & 5 & 0 & 1 & 3 \\
\hline Preparfing for wouk-related actwities & 0 & 12 & 2 & 4 \\
\hline \multicolumn{5}{|l|}{ Appilication of something new: } \\
\hline Wnudertalkes unconventional work & 14 & 4 & 14 & 12 \\
\hline fixperiment & 8 & 0 & 6 & 6 \\
\hline Replication & 3 & 0 & 6 & 4 \\
\hline Holdirigg on to personal wision. & 3 & 4 & 2 & 3 \\
\hline \multicolumn{5}{|l|}{ Information seckling: } \\
\hline Attenupts to expand knowledge (one-way) & 25 & 39 & 29 & 30 \\
\hline Askimg a specifite queention & 18 & 19 & 26 & 21 \\
\hline Chesking information & 0 & 12 & 0 & 3 \\
\hline Aequiring knowledge in a training or workshop & 7 & 8 & 4 & 6 \\
\hline \multicolumn{5}{|l|}{ Exelluatigge of information: } \\
\hline Converses with interaction partner (two-way) & 20 & 17 & 6 & 14 \\
\hline Discussion & 7 & 4 & 2 & 5 \\
\hline Brabsutorming & ) & 0 & 1 & 4 \\
\hline Conversation & 3 & 14 & 2 & 5 \\
\hline \multicolumn{5}{|l|}{ Thinking about work experitences: } \\
\hline Thinks about work-related topics & 35 & 17 & 23 & 27 \\
\hline Observation & 19 & 2 & 11 & 13 \\
\hline Rehection & 5 & 6 & 7 & 6 \\
\hline Rereiving feedback & 10 & 10 & 5 & $\mathbb{8}$ \\
\hline Totat $1 \%$ & 100 & 100 & 100 & 100 \\
\hline
\end{tabular}

$T=$ teacher, $F=$ financial service employee, $P=$ police officer

\section{Achuines of interaction parthers}

The second research question comecrned interaction partner activities that appear to generate employe learning in interactive workplace situations. The participants in the present research mentioned valus interaction partners as contributors to their letrning: not only colleagues, managers, clients, family mombers, and friends but also neighbors, interns, study partners, and experts from other companies or institutions. The suthors of written materials (e.g., books, internet articles, nowpapers, occupational magazines) were also sometimes mentioned for their indirect role in adult learning. In Table 5 , the percentages for 19 different interaction partner activities that generate employee leaming are presented per occupational group and for the entire group. The activities could be clustered into five groups: (1) Response to adult learmer's work, (2) Role model, (3) Provision of something. (4) Fixehange of information, and (5) Learning support. In Appendix B, the specifio activities included in each category are described in greater detail. 
Table 6: Percentages of Interaction Partner Activities in Interactive Work Situations for Different Occupational Groups

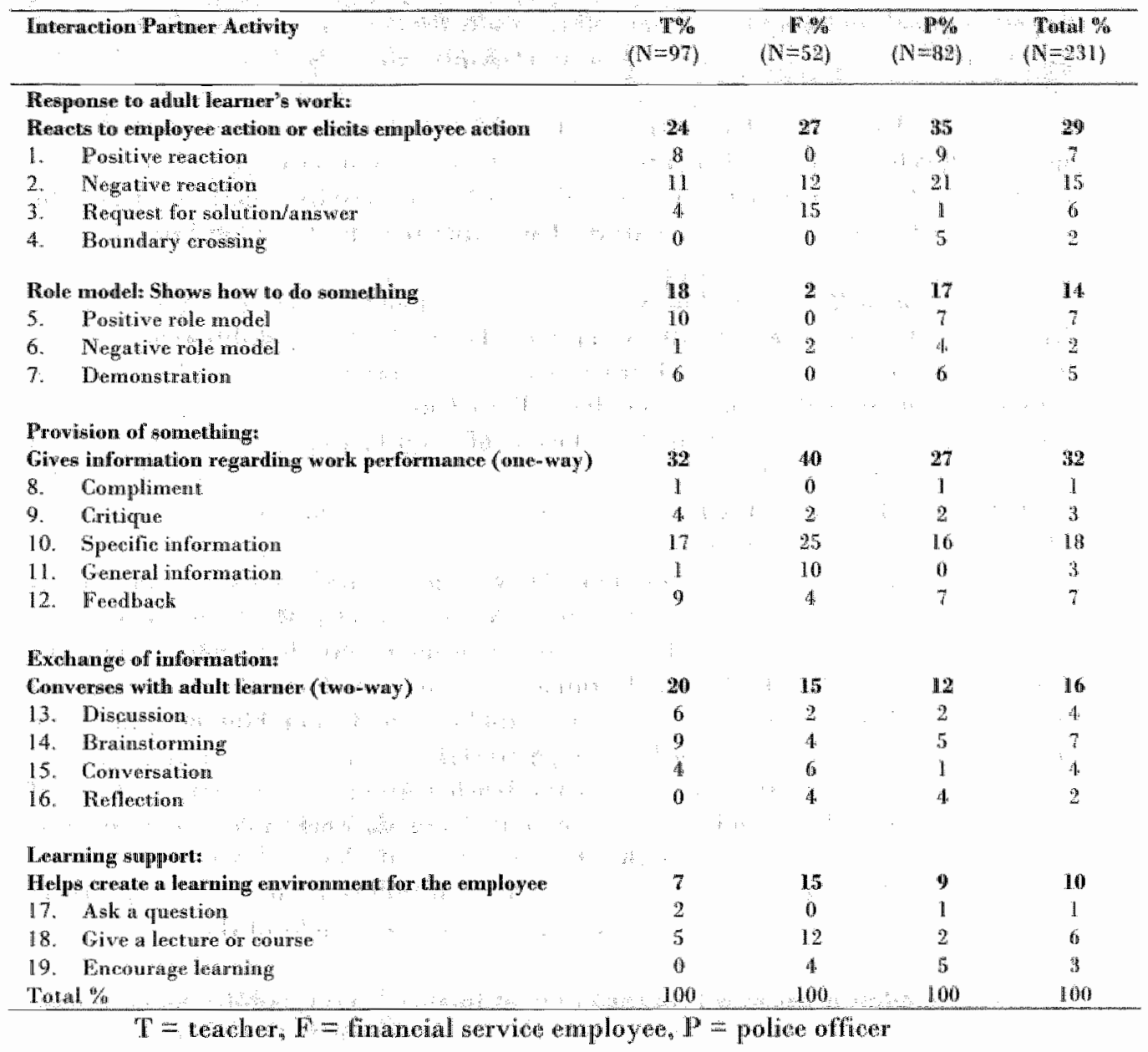

In $18 \%$ of the 231 learing ineidents, the interacton partiner provided specific information" for the employee to learn from. This high score parallets the high score of $21 \%$ for the adult learner (i.e., employee) activity of "asking a specific question". In $15 \%$ of the 231 learming incidents, the interaction partwer provided a "negativas reaction" to the work of the adult learner. Consider, for example, the following statemont from a financial service professional. "In one of my projects, I had to deal with a project member who was always asking questions and nevar formulating answars on her own. I found that problematic because it look a lot of time and particularly because most of the questions were already dealt with during an earlier stage in the projed. In the end, I laarned how to dew with her" (H).

Further inspetion of the learning incidents shows the interaction partuers to rarely "compliment". or 'ask a question' for purposes of promoting employes learning (only $1 \%$ of all learning incidents, respectively). A police officer mentioned 
the receipt of a compliment from an interaction partner and how this helped him realize that he could really mean something to a client and showed him that he was "on the right track". "Once I went to an accident. Victims think they are the most importate people in the thorld. At that point, I really felt that I meant something to them, particularly because they gave that back to me when they said: "Thanks for the good work"s" $(\mathrm{P})$.

A wider variety of activties was found for the interaction partners (19) than for the adult learners (15). The interaction partwers are not only concerned with the elicitation of employee aetivities bat also with the activities performed by the employee, which produces a wider array of activities than for the adult learmers.

\section{Similaritics and differences in learning activities whih and between occuparions}

Inspection of Tables 5 and 6 with respect to the similarities and differences in the activities of not only the adult learners and the interaction partners but also the different occupational groups themselwes allowed us to answer the third research question. The distributions of the five clusters of adult learner activities were found to differ depending on the occupational group $\left(\chi^{2}(\mathrm{~d} . \mathrm{f}=8, \mathrm{~N}=231)=28.9, \mathrm{p}<.05\right)$ while the distributions of the five clusters of interaction partner activities did not ( $\chi^{2}$ $(d . C=8, N=231)=14.9, p>, 05)$.

Within the teacher group, adult learners mentioned "thinking about work experiences" in $35 \%$ of the interactive work situations (i.e., 34 of the 97 learning incidents). Due to the high incidence of "brainstorming" and discussion" among the teacher group, $20 \%$ of the 97 learning incidents involved the exchange of information". The clusters "regular job" and "application of something new" involved fewer learning incidents ( $6 \%$ and $14 \%$, respectively).

For the interaction partners in the teacher group, the activity clusters of "provision of something" and "response to adult learner"s work" were reported most. frequently (i.e., in connection with $32 \%$ and $24 \%$ of the 97 learning incidents, respectively). Teachers reported relatively few instances of interaction partners "supporting learning" (i.e., only 7\%", which is surprising in light of the fact that the core business of teachers concerns learning.

The adult leaners within the group of financial service professionals scored catively high with regard to the cluster of one-way information seeking activities with $39 \%$ of the 52 learning incidente reflecting such (e.g., the financial service professional asks something and the interaction partner replies). Low frequencies wore found for the cluster application of something new with only $4 \%$ of the 52 leatrning incidents refecting such activities as "experiment", replication" or "holding on to personal vision" (see Table 5). Compared to the other two oceupational groups, "thinking about wok experiences" was mentioned lles often (i.e., in only $17 \%$ of the learning incidents).

Just as for the teacher group, the interaction partner activities of "provision of something' and 'response to adult learner"s work' were reported most often by the financial service professionalls (i.t., in $40 \%$ and $27 \%$ of the 52 learning incidents, respectively). Particularly low frequencies were found for "role model" with only $2 \%$ of the loaming incidents The behavior of the interaction partners is perceived more negatively than positively, as indicated by the seores produced for "positive/ negative reaction", "positive/negative role model", and "compliment/ critique" (see 
Table 6). Fually, "learning support $(15 \%)$ was provided by the interaction partners of financial service professionals mostly in the form of "give a locture" and relatively more often than in the other occupational groups.

The gromp of police officers seored particularly high with regard to the chusters of "information seeking" and "regular job" with $29 \%$ and $27 \%$ of the 82 learning incidents reflecting activities falling into these clusters, respetively. In contrast, the group of police officers scored relatively low with regard to the "exchange of information' with only $6 \%$ of the learning ineidents reflecting such activities.

Just as for the other two occupational groups, the interation partiner activities of "response to adult learner's work" and provision of something" were also reported most often by the police officers (i.e., for $35 \%$ and $27 \%$ of the 82 learning incidents, respectively). Within the cluster of "response to adult learner"s work" the particularly high score for "negative reaction" stands out. Apparently the police officers we interviewed regularly receive a negative reaction regarding their work performance from interaction partners.

\section{Comparison of adult learner and interaction partner activities according to gender}

In Table $7 a$, the distributions of the adult learner activities according to the gender of the adult learner are presented. The Chi-square test showed the distribution of the activities across the different activity clusters to vary depending on the gender of the adult learner $\left(X^{2}(\right.$ d. $\left.f .=4, N=231)=10.2, p<.05\right)$.

Table 7a: Distributions of Adult Learner Activities across Five Cilusters according to Gender of the Adult Learner (percentages)

\begin{tabular}{lcccccc}
\hline $\begin{array}{c}\text { Activity } \\
\text { Gender }\end{array}$ & $\begin{array}{c}\text { Regular } \\
\text { jol }\end{array}$ & $\begin{array}{c}\text { Application } \\
\text { of some- } \\
\text { thing new }\end{array}$ & $\begin{array}{c}\text { Information } \\
\text { seeking }\end{array}$ & $\begin{array}{c}\text { Exchange of } \\
\text { information }\end{array}$ & $\begin{array}{c}\text { Thinking } \\
\text { about work } \\
\text { experienees }\end{array}$ & Total \% \\
\hline Male $(\mathrm{N}=149)$ & 22 & 11 & 32 & 12 & 23 & 100 \\
Female $(\mathrm{N}=8 \mathrm{~g} 2)$ & 9 & 14 & 26 & 17 & 3 & 100 \\
\hline
\end{tabular}

Males appeared to learn more from their "regular job" than females, who altenatively learned more from "thinking about work experienoes" than males. These findings may be explained in part by the nature of the occupations held by the males and females, with particularly the police group involving mostly males. When Chi-square tests were condueted for the occupational groups separately no significant results were found. This means that within the occupational group of teachers and financial service professionals, males and femalles do not differ with regard to the types of learning activities undertaken in interactive work situations. Such analyses could not be conducted for the group of police officen due to low cell frequencies for females.

In Table $7 \mathbf{b}$, the distributions of the activities of the interaction partners according to the gender of the interaction partner are presented. Of the 231 learning incidents, 86 occurred in a group situation and were coded as "group". Learning incidents including other than a humain interaction partner such as tools and information sources were coded as "resources" to involve solely the "provision of 
something". These 12 incidents were therefore excluded from the present analyses involwing gender. The gender of the interaction partner was simply unknown for an additional 39 learning incidents, which were therefore also excluded from the present analyeses.

Table Tb: Distrbutions of Interaction Partner Activities across Different Cluters atcording to Gender of the Interaction Partier

\begin{tabular}{|c|c|c|c|c|c|c|}
\hline $\begin{array}{l}\text { Activity } \\
\text { Gender }\end{array}$ & $\begin{array}{l}\text { Responsie to adult } \\
\text { learner's wouk }\end{array}$ & $\begin{array}{l}\text { Role } \\
\text { model }\end{array}$ & $\begin{array}{l}\text { Provistion of } \\
\text { glomething }\end{array}$ & $\begin{array}{l}\text { Exchange of } \\
\text { information. }\end{array}$ & $\begin{array}{c}\text { Learning } \\
\text { supporl }\end{array}$ & $\begin{array}{c}\text { Total } \\
\%\end{array}$ \\
\hline Male $(N=77)$ & 29 & 12 & 35 & 17 & 7 & 100 \\
\hline Female $(\mathrm{N}-17)$ & 24 & 11 & 4 & 18 & 6 & 100 \\
\hline Group $(N=86)$ & 42 & 12 & 21 & 20 & 5 & 100 \\
\hline
\end{tabular}

The findings for the remaining 180 interactive work situations showed the male interaction partners, female interaction partners, and group of interaction partners to not differ significantly with regard to the occurrence of the different types of activities reported by the adult learners $(X,(d . f .=8, N=180)=7.8, p>05)$.

Comparison of occupations and interaction partner activities according to hierarchical and organizational position of interaction partners

In Table 8 , the percentages of the interaction partners with a higher, peer, lower, or outside position relative to the adult learner are presented per occupational group. Interactive work situations with written resources were again exchuded from the analyses. The Chi-square test showed the hierarchical (i.e., power) and organizational position of the interaction partner and the oceupation of the adult learner to be related to each other $\left(X^{2}(d . f=6, N=217)=34.0, p<.001\right)$. This means that the adult leamers from different occupational groups learned from interaction partners with a different hierarchical position. Teachers differed from financial service professionals and police offers in that they did not report learning from interaction partners with higher herarchical position. Conversely, teachers reported relatively more learning interactions with peers than the financial service professionals or police officers. Police officers differed from teachers and financial service prolessionals in that they reported more learning interactions with both interaction partners with a higlier or llower postion. Furthermore, they reported relatively fewer outside interaction partners than the teachers and financial service professionals. 
Table 8: Percentages of Interaction Pantners with Higher, Perer, Lower, on Outside Position per Occupational Group

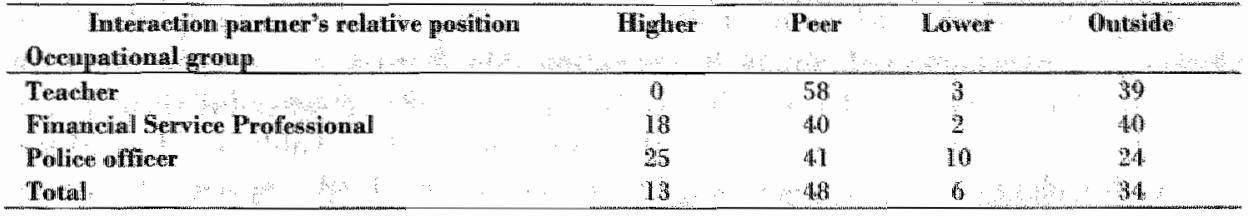

In Table 9, the distribution of the activities of the interaction partners aceording to their power position relative to the adult learners is presented. Interactive work situations with resources were again excluded from these analyses. The Chi-square test showed the relative position of the interaction partner to be related to the types of activities found to generate adult learning $\left(X^{2}(\mathrm{~d} . \mathrm{f} .=12, N=217)=57.6, p<.001\right)$.

Table 9: Distribution of Interaction Partier Activities that Generate Learning according to Power Position of the Interaction Partner

\begin{tabular}{|c|c|c|c|c|c|c|}
\hline 8 & & $\begin{array}{l}\text { Response to adult } \\
\text { lesrner's work }\end{array}$ & Rolle model & $\begin{array}{l}\text { Provision of } \\
\text { something }\end{array}$ & $\begin{array}{l}\text { Bxeluange of } \\
\text { information }\end{array}$ & $\begin{array}{l}\text { Luraring } \\
\text { sumport }\end{array}$ \\
\hline Highther & & 43 & $\overline{7}$ & 32 & 0 & 18 \\
\hline Peer: & & 14 & 25 & 35 & 28 & 1 \\
\hline Lower & & 67 & 0 & 25 & 8 & 0 \\
\hline Guttinde & & $\therefore \quad:$ & 6 & 19 & 15 & 18 \\
\hline Toutal & 8 & 30 & 15 & 29 & 17 & 10 \\
\hline
\end{tabular}

As can be seen, interaction partners higher in the organizational hierarchy appear to provide a "response to the adult learner"s work" and 'learning support' but do not exchange information with the adult learner. Note that this only holds for the police officers and financial service professionals as absolutely no interactions with managers were found for the teachers (see Table 8). Peer interaction partmers mention predominantly being a "role model', the "proviaton of something", or the prowision of "learning support. Lower level interaction partners mostly provide a "response to the adult learner"s work" and were not mentioned as at "role model" or for the 'exchange of unformation'. Outsiders were frequenty mentioned to provide a "response to the adult learner's work", to be contacted for the "provision of something", and to be consulted for the "exchange of information".

\section{Discussion}

In the present study, a number of juestions were addressed with regard to the activities of adult learners and their interaction partners in interactive work situations reported to generate adult leaming. The first and second ressarch questions concerned the types of activities generally carried out by adult learmers and their interaction partners. Overviews of the different learning activities are presented in Tables 5 and 6.

Inspection of the types of activities undertaken by adult latrners and their interaction partners in interactive work situations confims the clusters of learning 
from others formulated by Erat at al. (2002) and the forms of social learning formulated by Salomon and Perking (1998). However, the results of the present study also show the behavior of the interaction partner within a work situation to not alway be experienced as positive or encouraging. Most studies speak of the interaction partner as predominantly providing information, encouragement, tips, and hints. The resulte of the present study, however, also show adult learners to benefit from the negative reactions of whers on acasion (see Table 5). Most of the learning incidents reported within this category involved surprise that the interaction partner did not react to something. The interaction partner behaved in an unexpected on unpleasant manner according to the adult learner. In addition to the report of megative reactions, there was a striking absence of interactions partmers providing a compliment: This was done in only $1 \%$ of all the reported learning incidents.

The question that now arises is how this pattern of negative reactions and very few compliments within interactive work situations can be explained. Are compliments simply not a part of Dutch culture, less recalled than negative information or something that does not foster employee learning? Unfortanately, we cannot explain the frequency of negative reactions and little or no complimenting on the basis of the present data alone. Information on all informal learning incidents whether interactive or noninteractive - and all compliments - whether contributors to learning or not - must first be attained. While a wide variety of learning incidents was examined in the present study, not all learning incidents have been considered. It is conceivable, for example, that interviewees only recall the most salient examples of learing and particularly those in which their actions led to mistalkes with high impact consequences (i.e. critical incidents). Learning under such circumstances may be much better recalled and therefore explained in terms of negative reactions from others. In other words, the low frequencies found for certain activities in our research do not necessarily mean that the participants did not perform these activities; such activities were simply not mentioned within the context of an interview regarding learning incidents. Future research should at tempit. to shed greater light upon the occurrence of less salient learning activities. In addition, there is a ived to verify the present results using a larger group of respondents and respondent representing other ocenpations. Future research should also address the question of which specific activities on the parts af adult learners aud their interaction partmers appear to be most helpful and thus most promising for incorporation into a workplace pedagogy. It is conceivable, for example, that negative reactions have a greater impact on adult learning than compliments.

\section{Occuparional groups}

The third research question addressed the similarities and differences in the activities of the adult learners and their interaction partners according to occupational group (i.e., for the teachers, police officers, and financial service professionals). Given the specific contexts associated with a particular occupation, a person's job can provide certain learning situations or not. The results of the present research revealed considerable variation in the learning activities undertaken by the adult learners and interaction partners within the different occupational groups. 
Of all the ocoupational gromps in the present research, the group of teachers most frequently reported thinking about work experiences in interaction. Relative to the other two occupational groups, moreover, the teachers irepont at greater "exchange of information (two way) and fewer "information seeking" (one way). This two way information-related prevalence may be related to the process of knowledge construction associated with the teaching profession. That is, learning to teach or teach better does not so much involve the application of factual knowledge, such as regulations, bat the ereation of knowledge in the form of what works for a particular teacher. For the unexpectedly low incidence of interaction partner activities that "encourage learning, we do not have an explanation.

Financial service professionals and their interaction partiers were found to score high with regard to the request for and provision of information (see Table 4 and 5). In contrast, however, they scored low with regard to the "application of something new. This pattern of results is very consistent with the type of work and context of the work performed by financial service professionals. The individualls involved in such anowledge intensive occupation must engage in frequent meetings, search for information, and apply regulations within all kinds of reports. Often a specific piece of information is the key to the solution of a problen, which explains the relatively high oecurrence of checking information". Just why the behaviour of the interaction partner is more often experienced as negative than positive, however, cannot be explained.

Finally, the growp of police officers in the present research showed more learning activities in relation to the performance of their actual job than the other two occupational groups. This can be expected and explained by the characteristics of the occupation. Police officers have jobs with many active "do" tasks. Much of their learning thas occurs on the job. Another learning activity that is very much in keeping with the characteristics of police work is "boundary crossing" (see Appendix B). In addition, the group of police officers studied here reported nore negative reactions from others than the groups of teachers and financial service professionals, which suggests that police mistakes are hard to discuss and may even lead to trouble at times. The low frequencies for the general exehange of information" however, are difficult to explain.

In sum, the results of the present research show learning behaviour in interactive workplace situations to be partly explained by the context of the occupation involved although some major questions still remain with regard to why certain behaviors are reported more often for one occupation than for the other. Future research should thus investigate the extent to which the social and cultural contexts of differing occupations can explain the relatively rare or frequent occurrence of specific learning activities.

\section{Gender}

The fourth research question addressed the similarities and differences in the accurrence of various learning activities depending on the genders of the adult learners and their interaction partners. Previous studies have shown a preference for individuality and autonomy on the part of males and a preference for cooperation and connection on the part of females. Based on this distinction, the male participants in the present research were expected to display relatively more 
ativies associated with the duster of information seeking/provision (one way) and the formale participants expected to display relatively more activities associated with the exchange of information cluster (two way). However the present results and the resulte of other studies (see Severiens, Ten Dam. Nijenhuis, 1998) do not confirm Whe prevous differences observed in male versus female learning. The observed lack of a significant difference may be due to the small soale of the present study - that is, not every male or fernale displays stereotyped behavior - and the preferences cannot be inferred from the activities.

\section{Power}

The final research question involved an examination of the similarities and differences in the leaming activites undertaken in interactive workplace situations with respect to the hierarchical (i.e. power) and oxganizational position of the interaction partmers involved. The teachers do not report activities involving interaction partiners with a higher position but do report relatively more activities involving per interaction partners than the police officers and financial service professionals. Whis finding is explained by the relatively flat organizational wharacteristics of Duth Instutes of Higher Education. Conversely, police officers report more interaction partuers who are either higher or lower within the orgamization and fewer interaction partners from outside the organization when compared to teachers and financial service professionals, which is partly explained by the very hierarchical structure of the Dutch police force.

The different interaction partners within an organizational hierarchy all play their own, unigue role in the workplace learning of adult learners. Most of the activities performed by the interaction partners appear to stem from theix relative postion within the relevant organization although some clearly missed chances were also observed. As can be expected, for instance, interaction partners higher in the organization appear to provide a "response to the adult learner"s work" and "learning support but do not, unfortunately, engage in an actual exchange of information'. Similarly, the interaction partners lower in the organization often provide a "response to the adult leamer"s work" but rarely serve as a "role model" or provide "learning support". We thus conclude on the basis of the present findings that the position of the interation partner can clearly prevent the occurrence of certain leaning atotivities at times, which has mitor practical implications.

\section{Practical implicaions of the present findings}

One pratical implication of the present findings is that the promotion of optimal adult learning involving interaction partners from different levels of the organization may require extra effort on both the parts of the adult learners and the interaction partners. Such extra effort may require that both partners recognize the supporting role to be played with respect to the other. Up until now, the role of the "intenction partner" with respeet to the "adult learner" has been examined. However, the "adult learner" can also support the learning of the 'interaction partner' in many ways. That is, the learning involved in interactive workplace situations may wen be mutual! Extra effort also requires the interaction partners to take responsibility for the occurrencellack of learning activities outined in Tables 4 and 5 . For example, the interaction partner higher in the organization may devote greater attention to 
the "exchange of information" in light of the observed absence of such while the adult leamer may stand more open to the possibility of an mberaction parther lower in the organization serving as a "role model' in light of the observed non-ocourence of this In such a manner, a more equal, dyadic, and reciprocal learning process involving individuals from different levels of an organization can develop.

A similar process of awareness raising may be more generally welcome within the fields of adult education and HRD. Although inspection of this possibility is beyond the scope of the present study, it is nevertheless plausible that differences in the positions of the adult educator or HRD professional with respect to the adult leamer may impede the occurrence of critical learning activities at times. In order to ameliorate this problem, the adult educator or HRD professional and the adalt learner nust both: a) recognize that they are learner and interaction partner at the same time and b) take clear responsibility for the occurrence and nonoccurrence of varions learning activities (see Tables 4 and 5 ). In such a mamer, a more equal, dyadic, and reciprocal process of learning can be stimulated with diagnosis of the interaction process using the information presented in Tables 4 and 5 as a possible starting point. In addition, both interaction partier and adult learmer should decide whether they are satisfied with their roles and, if not, discuss the types of learning activities in need of greater or less attention. Such an emancipatory disconrse may help adult educators, HRD professionals, and adult learners to transform workplaces and HRD prantices towards greater justice, fairness and equity. And with the emergence of a critical pedagogy, both partners should be invited to dance.

\section{References}

Argyris, C. \& Sellom, D. A. (1978). Organizatomal learning: A theory of action perspective. San Fransiseo: Jossey-Hass.

Baxter Magolda, M. B. (1994). Past-college experienee and opistemology, Rethew of Hight Educathon, 18,25-44.

Belenky, M. T., Clinchy, B. M. "T., Goldberger, N. R., d Farule, J. M. (1056). Women's Ways of

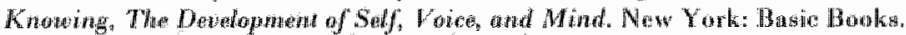

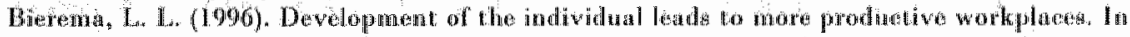

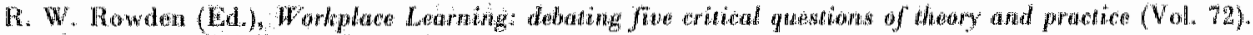
San Fransico: Josson-Bas Publishers.

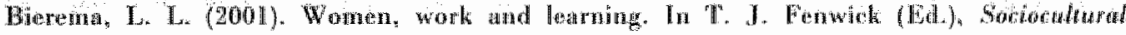

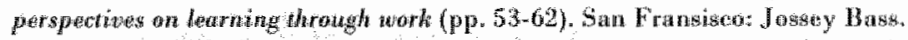

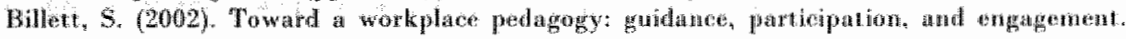
Atule Edueation Quarterily, $53(1), 27-43$.

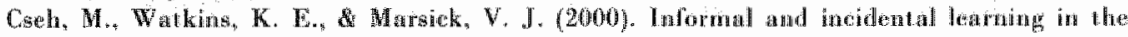

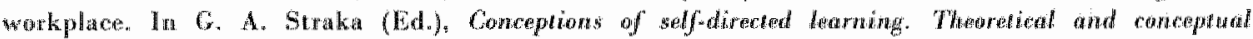
considerations. Mïnster: Waxmami.

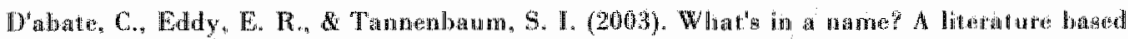
anppoach to understanding nentoming coaching, and other construets that degicribo develophental

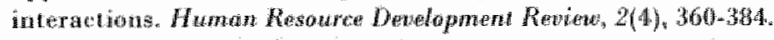

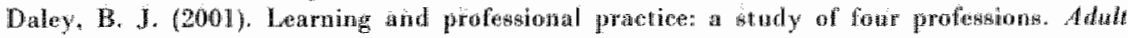
Education Quarterly, $52(1), 39-54$

Dewey, J. (1938). Experience and Edwention. Natw York: Gollitar Books.

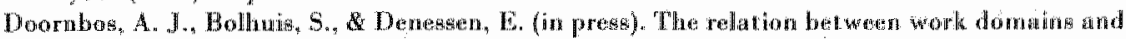

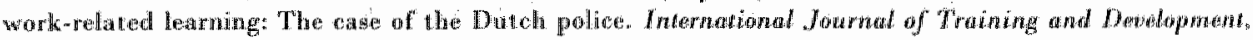
8(3), 174.190. 


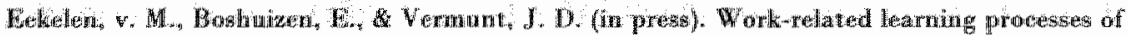

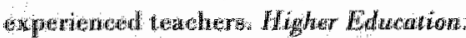

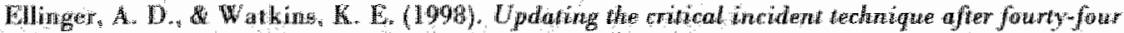

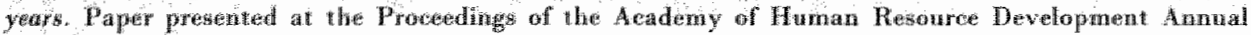
Conference, Chichago.

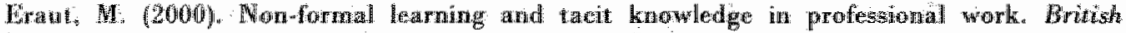

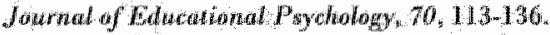

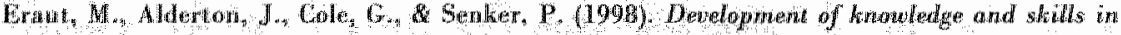

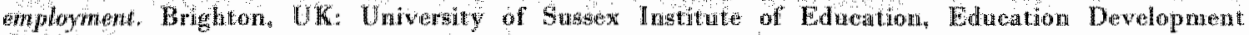
Wuiloing

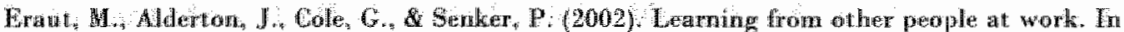

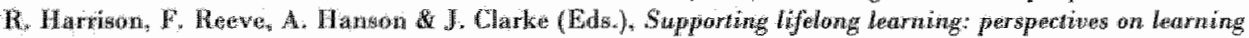

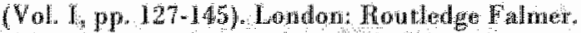

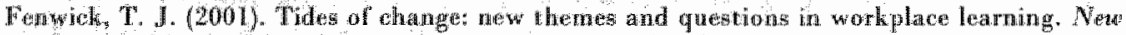

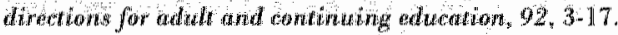

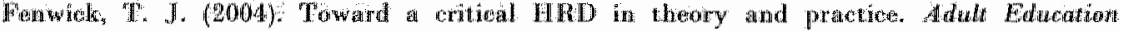

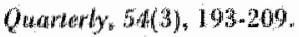

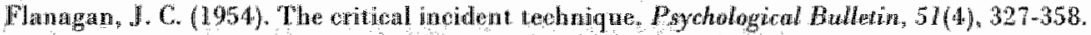

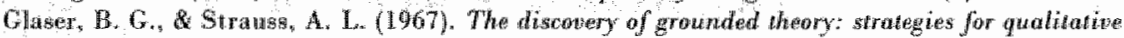
rasewoh. Chougo: Aldine.

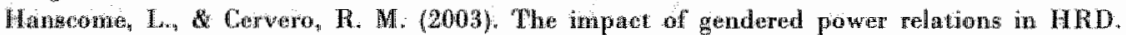

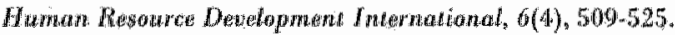

Hexton, J. (2002). Secandary andysis of qualiwate data, Retrieved 16-12-02, 22, froth

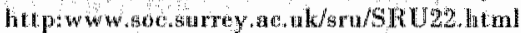

Hinds, P. S., Voged, R. J. \& CJarke-Steffen, L. (1997). Thie possibilines and pitfalls of doing a

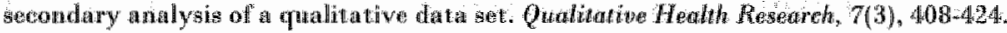

Holman, D, Epitropala, $0, \&$ Fernie. 5 . (2001). Undersanding learning strategies in the workplace: * factor analytie investigation. Journal of Occupational and Organisational Psyatholog, 74,675 . 681 .

Hughes, K. P. (1995). Feminist pedagogy and feminist epistemology. Internathonod Journol of Lufelong Ldusution, $14,214 \mathrm{~m} 230$.

Jarvis, P. (1987). Aduh ledraing in the social context. New York: Croom Helm.

Kall, D. A. (1984). Experintial lewning. Experience as the source of learning and development. Englewood Clifts: Prentice Thall, Ine.

Koopmans, H. (2002). The balame in teaming. Paper presented at the Academy of Haman Resonaree Development, Honolulu.

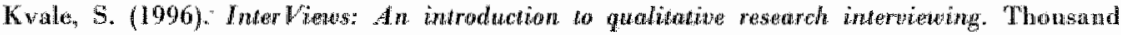
Onkis, CA: Sogre.

Lwy, D, A., Colline, B. E, Nail, P, R. (1099). A new model of interpersenal influenee

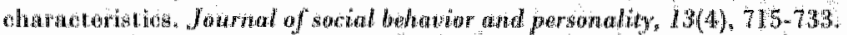

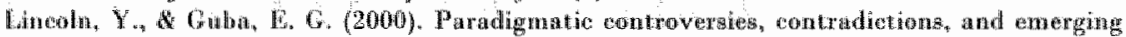

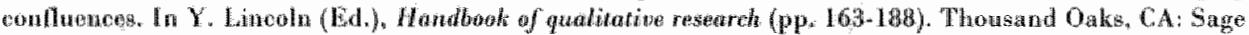
Publications:

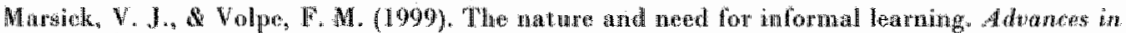
Dowelophing Homar Resourefs, 3, I. 9 .

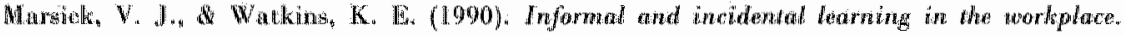
I:sondom: Rontledige.

Maxwoll, J. A. (2002), Understanding and validity in qualikative pesearch. In A. M. Huburman

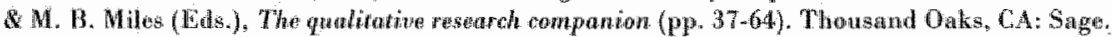

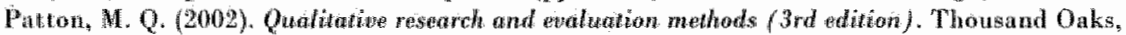
R.: Sage.

Ragino, B. Rin Sunktrom, E. (1989). Gender alad power in orgamiations: A longitudinal

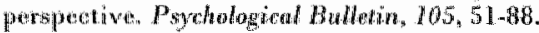

Sallomon, G. \& Perkins, D. N. 1998\%. Tudividual and social asperts of leaning. Review of Research in Education, $23_{2} 124$.

Schôn, D. A. (1993). The reftetine practionter. New York: Basic Books.

Severiens, S. Then Dam, O., \& Nifjenhuis, E. (1998). Ways af knowing and patterns of reasoning: Women and men in adult secondary education. Gender and Edwcation, 10(3), 327-341. 


\section{Appendix A}

Adult Learner Activities in Interactive Work Sinations

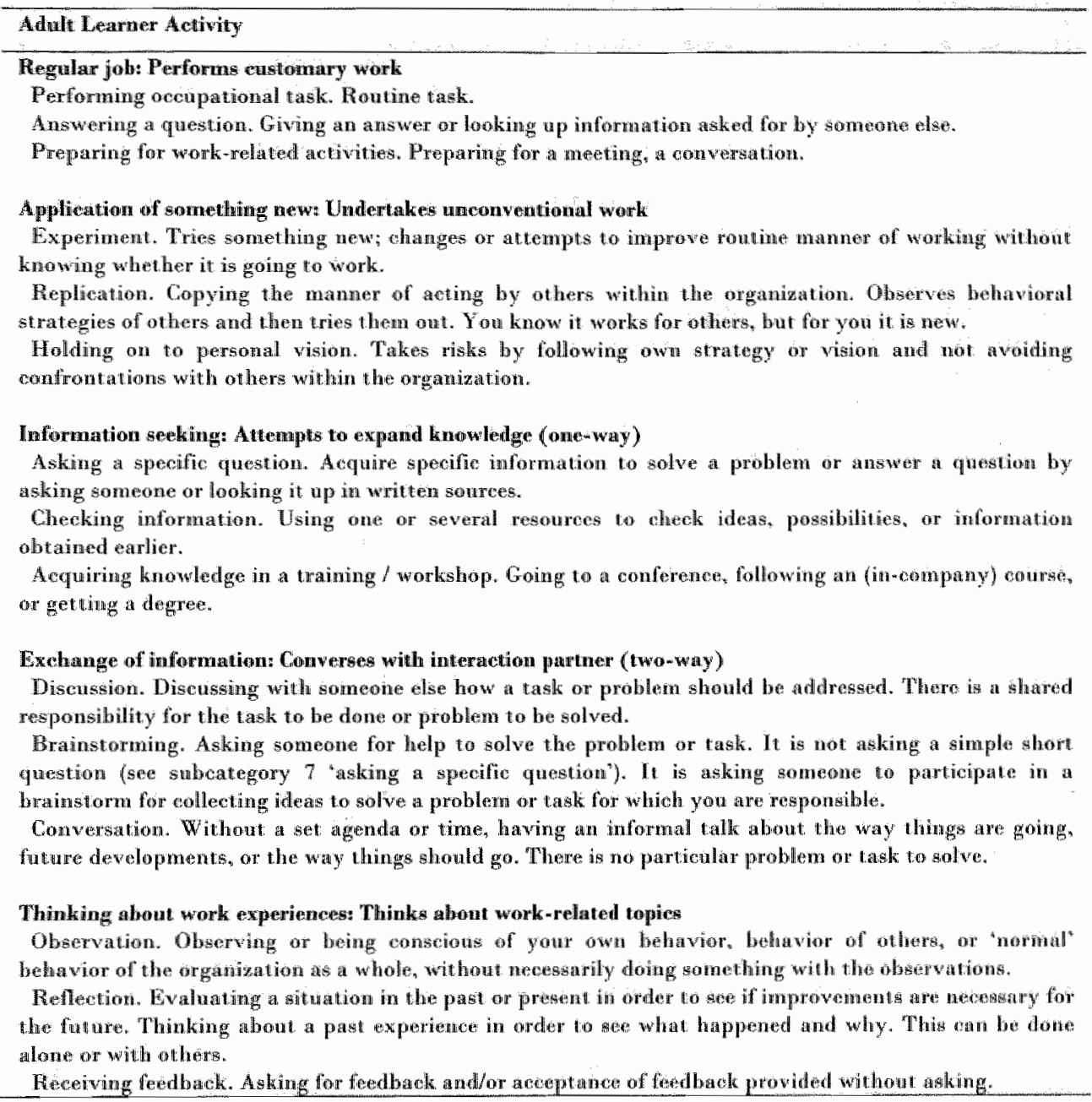




\section{Appendix $\mathbf{B}$}

\section{Activites of Interaction Partiners in Imeractive Work Situations}

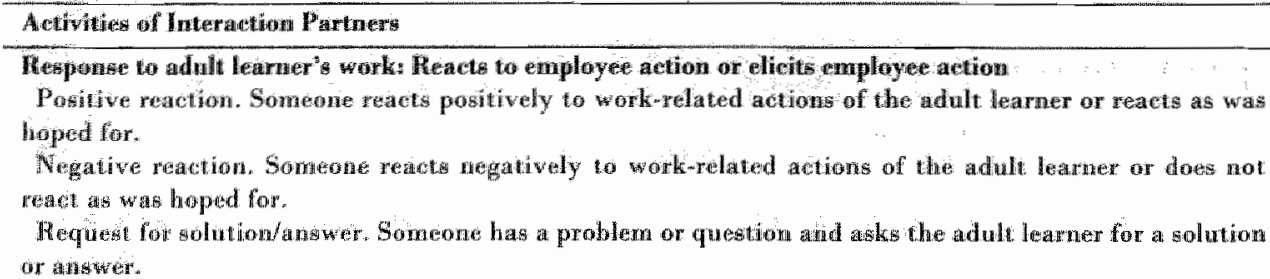

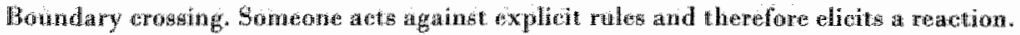

\section{Arole model: Shows how to do something}

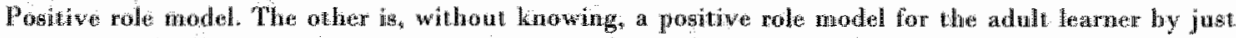

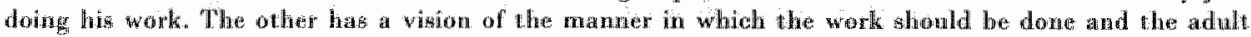

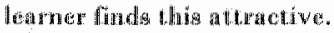

Negative rote model. Simply by doing job, the other is an example of how the adult learner showld not work. "The onthe is usually unaware of this.

Deanonstation. The other demonstrates a curtain skill to the enployee.

\section{Prowision of something: Gives information regarding work performande (one-way)}

Complinemt; short positive rematk regarding employ performance or wanner of acting.

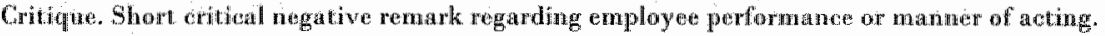

Specific unfomation. Prowision of specife information to answer a panstion; explanation of how to do something without demornstration.

General information. Provision of general information when the employee has no specifoc question.

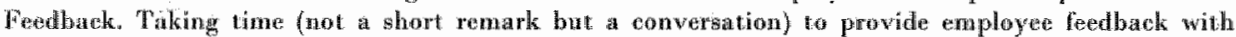
regard to bohevior: provition of suggestions for improvement.

\section{Exchange of information: The other and the anployee are aetively inwolved an a converwation (two way)}

Disewssicun. Discussing with the employe how a task or problem should be addressed. The other is also responsiblo for the task to be done oup problem to be solved.

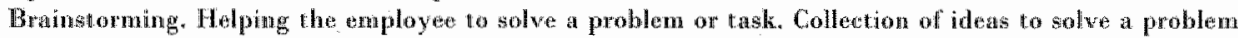

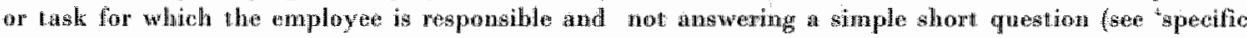
iriformation

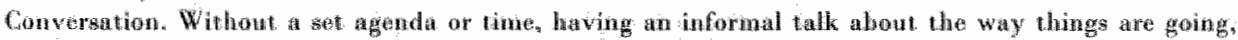

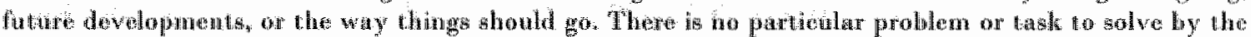
ampiloyeo of oblot.

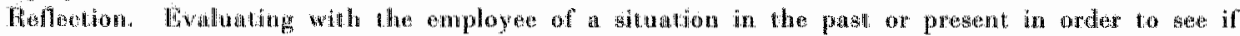

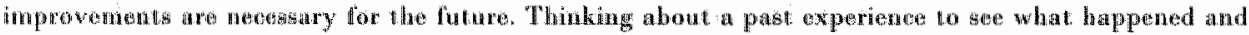
why.

\section{Hearning support: Helps create a learoing environment for the amploges}

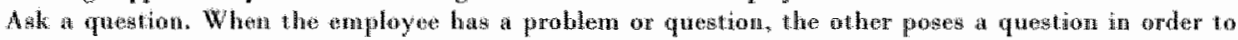
Whet lip.

Give a lowture or course. The ofher arganizes or gives a coursellecture.

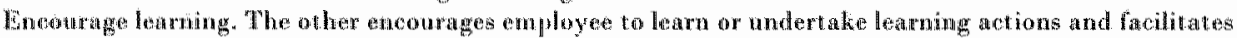
suich. 


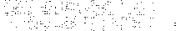

ब्य

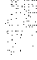




\section{FOUR}

Whe fourth chnpter has been submitred to Teading and Teacher Edneation as:

Van Bekelen, I.M., Vermunt, I.D, Boshuizen, H.P.A. Exploring teachers's will to learn. 


\section{Exploring teachers' will to learn}

In this study, it is assumed that "a will to learn" mast be presen before teachers engoge in actual learning activities. In onder to explore teachers' will to bearn in worlaplace situations, a small-scale qualitative study was conducted using a semi-structured interview, abservation, a retrospective intenview, and a phenomenographic apporoad to the analysis of the data. The results showed the following behaviors to be andicative of a will to learn among teachers: having the ambition to discover new practices, being open to experiences and other people, being pro-active, attribution of successes and mistakes to internal causes, question-ashing after performance, undertaling action to learn, and recognition of learning processes and results. The resulis also showed three differen manifestations of the will to learn to characterize the teachers studied here. The following groups of teachers could be distinguished: those who do not see the need to learn," thase who wonder how to learn; and those who are eager to learn. The results of the present study contribute to fields concerned with teacher learning and the motivational aspects of learning.

\section{Introduction}

Just as all individuals, teachers are expected to embrace life-long learning (Knight, 2002). And although continued professional development may be a necessity, it cannot be taken for granted. Within the field of professional learning at the workplace, for example, Kwakman (2003) recently took inventory of the degree of participation in several professional learning activities and found poworful opportwities tor teachers to learn at their work to go unued. Recent atudies concerned with educational innowation have similarly shown the majority of andu innovations to fail becanse the teachers - even after a considerable peniod of time and change - simply abadon the new behavior and return to comfortable old routines (Verloop, van Driel \& Meijer, 2001). In other words, professional learning is not self-evident and there are clearly occasions on which teachers gimply do not learn.

The phenomenon of "not learning" can possibly be explained by various personal and contextual factors. A significant personal factor has been irevealed, for example, by the study of teacher cognitions and educational beliefs (Calderhead. 1996). The beliefs that teachers hold about what constitutes good stodent leaming and good teaching have been found to strongly influence teachers behavior. Such beliels are formed, moreover, during the early stages of a teacher"s career and therefore found to be self-perpetwating and even immune to contradictions cased by reason, time, schooling, or experience (Pajares, 1992). Several other personal factors have been found to influence teachers" workplace learning and development, including the following: the teacher"s biography (Beijaard, 1995: Duffee \& 
Aikenhead, 1992): perceived sense of self-efficacy (Bandura, 1997; Whitaker, 1993): such personality traits as openness to experiences, tolerance of uncertainty, conscientioustess (Button, Mathien \& Zajac, 1996" Huber, 1995) manner of emotion regulation (Oosterhert \& Vermunt, 2001); manner of knowledge growth regulation (Oosterheert \& Vermunt, 2003); and reflection on experience (Korthagen \& Kessels, 1999).

In addition to these personal factors, teacher learnimg and also "not learning" are influenced by aspects of the work context. The professional development of teachers is obwowsly situated within the classroom and the school and partially within the professional learning enviromment outside the school. In other words, most teacher learning is situated in exeryday activities or the so-called commmnity of practice (Hargreaves, 1997; Lave \& Wenger, 1991). And just as for other work contexts, it is difficult to separate teacher learning from teacher work (Eraut, 2000). Nevertheless, a large number of workplace conditions has been shown to be either conducive or obstructive to the professional learning of teachers and school improvement (Smylie, 1994). For instance, Hargreaves (1997) has shown professional learning to occur when: a) teachers pursue it collaboratively and not individually; b) the learning addresses issues of interest to teachers and not issues raised by others; c) the learning is connected but not necessarily restricted to the ongoing priorities of the school; and, finally, d) there is long-term and sustamed commitment to learning as opposed to short-term, episodic commitment. In addition, Eraut (1998) has found the following workplace factors to affect learning: a) how a person is managed (e.g, allocation of work, appraisal and feedback, manager as developer of staff, etc. ; b) the micro-culture within the workplace (e.g., collaboration, learning climate, focus on quality, ete.); and c) the exact nature of the organization itself (e.g.. appraisal systems, recruitment, etc..).

In sum, the results of prewious studies show several personal and contextual factors to influence teachers" workplace learning and development. The focus of the present study, however, is on a personal factor that has received very litle attention to date, namely "teachers" will to learn". A will to learn is considered a necessary prerequisite for workplace learning and development to occur for, although the workplace may constitute a powerful learning enviromment in theory, it is not uways in actual practice (Kwakman, 2003). Teachers must take an active role in order to learn, and a "will to learn" typically precedes such active involvenent. In other wordss several factors may influence teachers" prolessional development and in the pregent study a will to learn stands central among these.

In the present study, the question of which behaviors of experienced teachers within the workplace indicate the presence or absenee of a will to learn will be explored. In addition, the possibility of different patterns in the various behaviors indicating a will to learn will be considered. The identification of a will to learn and greater understanding of such in the professional learning of teachers constitutes an important issue within the field of teaching and teacher edtcation for a variety of reasons. First, the theme is clearly of current interest as reflected by the title of the $10^{\text {th }}$ Biennial Conference of the European Association for Research on Learning and Instruction (Earli) in 2003: "Improving Learning, fostering the will to learn'. Second, vast amounts of money are spent worldwide to stimulate the professional development of teachers, which means that explicit examination of any factors that 
foster or interfere with the workplace leaming and development of teachers to merited. As many other studies withm the freld of teacher education, the present study is specifically concerned with how to foster or improve this professional learning. However, this study explicity acknowledges that teachers do not always learn and explains this by their "will to learn". Third, thorough description of the phenomenon of teachers" will to learn may help school directors, adult educators. and change consultancs identify the presence or absence of a will to learn and thereby approach teachers in a nore personal and differentated manner. Finally, it is not clear how the will to learn relates to such other areas as intentional learning, self-regulated learning, the ability to learn, and interest or motivation to learn. Given that a body of knowledge" specifically concemed with the will to learn does not exist as yet, varions domains will thus be called upon to provide a defintion for the notion of a will to learn (see next section).

\section{The will to learn}

The term "will to learm' is taken to refer to a psychological state in which the learner has a desire to learn. Such a psychological state appears to be a prerecuisite for actual workplace learning to occur (Bollnwis \& Simons; 1999). In the words of Oosterheert and Vermunt (2001, p. 9): "Teaching experiences fail to be educative when existing knowledge is taken for granted and the desire to see something new is absent. Then the perception of classroom events tends towards self-confirmation." Conversely, a clear will to learn may lead to whot Dunn and Shriner $(1999, \mathrm{p} .647)$ call deliberate practice, which is the approach of nomal teaching activities in a deliberate manner: "It may be fully mindful during these activities, mindful of what was effective, what was not, of ellanges that may lead to improvement. It may be choosing to be effortful, making changes when teaching seems to be going well, trying to find an even better way, nying to reach a particular child, trying to solve a particular problem." A clear will to learn may also lead to the process of teacher "tinkering" as described by Hargreaves (1999). Teacher tinkering represents the testing and modification of an initially good idea for more systematic validation. Sehools that are involved in more or less systematic tencher tinkering may establish and disseminate professional knowledge more easily than other schools. And the "ireadiness of teachers to tinker" (Hargreaves, 1999, p.151) may be thus the equivalent of teachers" will to learn. Finally, a will to learn may influence reflectionon- action, as described by Schon in the Reflective practitioner $(1983,198,0.28)$ : "We think up and try out new accions intended to explore the newly observed phenomena, test our tentative anderstandings of them, or affirm the moves we have invented to change things for the better." However, teachers do not always meet the theoretical expectation of reflection. That is, the results of many previous stadiess show reflection, just as learning, to not be self-evident (Booth, Hargreaves, Bradley, \& Southworth, 1995; Oosterheert, 2003; van Eekelen, Bowhizen, \& Vermunt, in press). And when such reflection does take place, it does not always lead to practical, how-to-do insights and not so much in a deeper understanding of teaching and learining.

A will to learn should not be confused with the intention to learn. Eraut (2000) has created a typology of unformal learning processes based on intention to learn. At one extreme is the now widely recognimed phenomenon of implieit learning 
with no intention to learn and no areness of the learning when it takes place. Next comes the category of reactive loming, which is almost spontaneous and largely unplanued the learner in aware of the learning but the level of intentionality may wary and is often unclear. This type of learming occurs most often at the workplace in the form of spontarieous reflection, the incidental notation of facts, or the recognition of learning opportanities occurring within the workplace. Thirdly and finally, there is deliberative learning, which involves explicitly setting time aside. Examples of this intentional form of learning are systematite reflection, rewiew of past actions, and engagement in planned (in)formal learning. In our wiew, however, there must be a basic underlying will to learn before a learner engages in any of the Wree aforementioned types of informal learning.

"The same holds for self-regulated hearning for which three types of leaming activites have been discerned: cognitive, affective; and meta-cognitive or regulative (Vermunt, 1996; Zimmerman, 1986, 2000). A will to learn precedes each form of these activities. In addition., affective learning activities relate closely to the will to learn as such activities involve the building of a will to learn (Vermunt $\&$ Verloop, 1999). However, in nost descriptions of affective learning activities, the will to learn is almost exelusively considered in situations where obstacles to the ongoing learning process are eneountered and the explicit exercise of a will to learn must exist to insure the implementation of the relevant learning activities. Once again, however, we assume a will to learn also to precede most any learning process.

The will to learn should also not be confused with the ability to learn. Inportant aspects of the ability to learn are: reflection upon a situation, making learning moments explicit, generalization, transfer, formulation of learning goals and learning routes, and the use of available leaning resources (Onstenk, 1997). Ability to learn also involves goal directiveness and an intention to learn, which are different than the psychological state of openness associated with the concept of the will to learn.

Finally, both interest and motivation are important concepts but not bynonymous with the will to learn. The energizing aspect of the two concepts refers to the fact that one tends to be more alert, more responsive, and exert greater ffort when oue is interested and motivated. According to Hidi (2000), moreover, there is a psychological state involwing focnsed attention, increased cogritive functioning, persistence, and affective involvement in oases of personal or situational interest. And when we think of a will to learn, we typically think of someone who is alert and fully mindlial:

However, motivation and interest have a directional aspect that may interfere with the will to learn at times. The drectional aspect refers to the fact that, when one is motivated or interested, a specific kind of motivation is usually involved or a specific object is of interest. This specificity can lead to selective action, striving; and attention such as being eager to learn about only a specific subject (Ferguson. 2000). We consider the person who is willing to learn as someone with "an open mind" and a desire to seo something new. Interest and motivation appear to have a narrowing function, which is thus at variance with our perspective on the will to learn.

Most motivational theories are, in addition, goal directed. For example, in many motivational studies, the expectancy value model is used to characterize the 
motivation to learn (Garcia, McGan, Thmer, \& Noska, 1998). Theorues along these lines include the notions of achievement motwation (Button, Mathen, $7 \mathrm{Zaja}$, 1996; Dweek, 2000, Ellot \& Chureh, 1997, Heckhausen, 1991), self-conoept and seileffeaey (Bandura, 1997. Sehunk 1991), and (perceived) locus of control (Skimer, Zimmer-Gembeck, \& Connell, 1.998). However, teachers cone to sclwool first and foremost to teach. Their learning is therefore typically reactive; near-spontaneous. and unplanned (Kwalkman, 1999; Lohman, 2000; van Eekelen, Boshminen, \& Vermunt, in press). And given the unplanned character of such informal and unintentional learning, the expectancy value model cannot be used to explain the motivation of those involved. How can one expect" or "value" something unplanned?

Given the specificity of motivation and interest and the goal-directed nature of motivation, we conclude that motivation and interest are not the same as the will to learn. We can certainly draw upon the theories concerned with these concepts but should avoid the complete equation of motivation or interest with a will to leam.

In sum, teachers" willingness to learn does not involve intentional, goal-directed, or self-regulated leaning but precedes such learning. The will to learn is thus in our opinion, a psychological state that involves a desire to learn, experiment, and see or do something that has not been seen or done before. Given that the meaning attributed to experiences is assumed to shape the learning of teachers, we adopted a constructivist perspective on the actual teacher learning itself. Learning is defimed as a workplace experience that results in the "re-etablishment" or "more or less change" of knowledge, skills; or attitudes with the teacher recognizing that the process constitutes a learning process. With "re-establishment", we mean that teachers can relearn things that they once knew (e.g. "Today, I again realized that it is important to: ") With changed," we mean - in terms of Hashweh (2003) - transactional learning outcomes (e.g., live with unresolved cognitive conflict), conservative learning outcomes (e.g., alteration of some ideas and preservation of other ideas or practices), and progressive learning outcomes (e.g., accommodative change; a profound shift of paradigm, conceptions, beliefs, and/or practices).

The research questions guiding the present study were as follows.

1. What behaviors of experienced leachers in the workplace appear to indicate a will to learn?

2. Is it possible to discem different patterns of behavior (i.e., indicatorg of a will to learn) and thereby different manifestations of the will to lean?

\section{Method}

\section{Research methodology}

Giver that the workplace learning and development of teachers has yet to bo thoroughly explored, there is no shared tradition of inguiry. Nevertheless, in general five qualitative methods or traditions can be distinguished (Cresswel. 1998), namely: biography, phenomenalogy, grounded theory, ethrography, and case study. Given that the focus of the present research is on teachers" experiences with respect to a particular phenomenon (see research question one), we opted for a phenomenological methodology. While phenomenology typically makes a distinction between immediate experience and the conceptualization of this experience, we do 
not make such a distinction. We are only interested in teachers" perceptions or wonceptualizations of their learning experiences and therefore did not even try to distinguish "actual" learning from pierceived learning. Furtherwore, phenomenology often fouses on the "esserce' of experience while phenomenography investigates the different ways in which people experience or think about phenomena (Marton, 1986 , p. 3). A phenomenographic approach was therefore construed as particularly wellsuited to our second research purpose, namely to idemtify the variability in how people's. willingness to learn manifests itself (see research question two). Phenomenongraphic researchers categorize subjeets descriptions of phenomena, and this is primarily what our sudy is about: The categorization of behaviors indicative of a will to learn and the development of categories of indicators to discern any qualitative variation in the will to learn.

\section{Research sontext}

The research was conducted within a single Dutch high school. The first school that we approached proved willing to participate in this small-scale study. The school had 1200 students and 100 teachers, and it was Iocated in a middle-class neighborhood where most of the students also lived. At the time of the study, the school was busy with the implementation of a new nationwide program aimed at fostering active and selfregulated learning among students in the latter phase of their pre-university education (i.e., students aged 15 to 17 years). This large-scale imnovation project requires teachers to shift from a traditional teaching role to a more process-oriented coaching role.

\section{Partictpants}

A total of 28 potential participants were selected on the basis of the following three criteria:

- they were working in the innovation program;

- they had a minimum of seven years of teaching experience (i.e.s they were experienced teachers): and

- they had contract for at least 20 hours with the school in question.

Of the 28 potential participants, 15 were randomly selected for final inclusion in the study: 9 males and 6 females combing from different subject areas participated in the end. Their mean age was 47 years, and their teaching experience ranged from 10 to 31 years.

\section{Dala collection}

A semi-structured interview, an observation study, and a retrospective interview based on the observations were used to collect the data.

The goals of the semi-structured interview were as follows:

1. to collect samples of situations in which teachers do and do not learn from the past, and the present,

2. 10 get aequainted with the teacher and establish sufficient rapport for classroom observation.

The interview protocol consisted of several open-ended core questions and a number of suggestions for possible follow-up questions, such as: "Can you give an example, in relation to the new program, of something that you have now mastered 
but could not do or did not know how to do before?" "Can you decall a situation that was important for mastery of that skill, for the creation of the necessary insight?" What did you feel in that particular situation?" "What did you think about the other, yourself, or the situation itself?" and "What did you learn or do as a result of the situation??

The goal of the observation study was to collect examples of possible learning sitnations from an ordinary work day. For this purpose, any change in the activities of the teacher was noted by the observer in a logbook along with the time of the change. Examples of the activities noted are" walking through the classiroom, listening to a student, encouraging a student to work, and explanation of something to a student. In such a manner, a chronological record of the day was created. Special attention was paid to so-called "incidents" or times when something unexpected happened (e.g., the teacher had to deal with an angry or overly enthusiastic student or group of students; a classroom disruption; brief meetings with colleagues, etci).

The purpose of the second - retrospective - interview was to have the teacher reflect upon those incidents that occurred during the observation day and to determine whether the teacher learned something from the incidents or not. Both the teacher and researcher could mention incidents, and the following types of questions were posed to prompt further reflection or elaboration: "What happened at that particular moment?" What did you feel in that particular moment?" "What did you think about the other, yourself, or the situation itself?" "Did you llearn something from the situation? If so, what did you learn or what are you going to do as a result? If not, why was this situation not instructive for you?"

\section{Procedure}

Prior to the start of the study, all of the teachers were informed via a presentation about the object of the study (i.e, to learn about the learning processes of teachers) and the data collection procedures. "This was done again at the beginning of the first interview. The participants were reassured that the study was unrelated to any form of evaluation and that their names would remain anonymous. The interview was then conducted, and a date was set upon completion of the interview for classroom observation.

On the observation day, the researcher briefly introduced herself to ouch of the teacher's classes. According to a few of the teachers some of the classes reacted to the appearance of the researcher. All of the actions of the teachers and, when necessary, those of the students were written down in chronological order. And after each class, the researcher marked the incidents to be reviewed during the retrospective interview.

The second interview took place at the end of the observation day. Firstion the teacher was asked to look back on the day and mention any unexpected incidents, which were then reviewed with the teacher using the interview protocol described above. Second, the researcher described any unexpected incidents and asked the teacher to review these using the interview protocol described above. 


\section{Data analysis}

All of the interwew were audiotaped and then transcribed verbatim. Dhe to technical problems, the second interview for one teacher was not reeorded. This ceacher was therefore excluded from the data analyses, which left atal of 14 participants and 28 transcripts to be analyzed (14 initial and 14 retrospective interwiews).

The data were analyzed in three main steps. First, all of the interviews were read, rewead, and broken down into separate fragments (i.e., sentences, staterrents, or paragrapts) that tell us something about the behavior of the teacher with regard to his or her willingness to learn. Each fragment was given a temporary label such as "talks about experimenting", "talks about own learning process", or "talks about how to reach ehildren". With these temporary labels in mind, we found Calderhead's (1996) overview of teachers" beliefs (see Introduction) to be particularly helpful for the grouping of the fragments and construetion of a preliminary categorization scheme. The categoriation scheme was next tested on the interviews by coding some of the interviews and adjusted several times until a stable coding scheme with a discriminative combination of eategories and subcategones was established. The wategories were described as accurately as possible in order to represent the essence of each category and all were labeled with letters. The sub-categories were also described, and numbered. This way an overview with decision rules for assigining quotations to a (sub)-category of description was established. Later on this seheme would serve as a basis on which we could answer our first research questions.

In the second step of the analyses, all of the 28 interviews were coded using the categorization seheme. First, the topic of the interview fragment was identified (see Table 1). Next, the fragment was assigned to one of the categories from the categorization scheme. And thereafter, which behavior (i.e., subcategory) from the categorization scheme best fit the fragment was determined (see Table 2). In such a manner, each fragment was coded using a topic number, a category letter, and a subcategory number. $\mathbb{B}$ y adding all the subcategory numbers, it was possible to determine which behavior occurred most frequently within each category for each of the 1.4teachers. When multiple fragments addressed the same event or incident, only the first fragment was considered; when the sane fragnemt occurred on more than one occasion in the intervitew, only the first occurrence was considered. And in such a manmer, quatitative profile of each teacher's will to learm was established (see Appendix).

In the find step of the analyses, the profiles of the 14 teachers were compared with each other. "The teachers" profiles were rank orered one to fourteen from "very willing" to "not willing' to learn. And on the basis of comparable types of content, three different patterns or clusters could be distinguished.

\section{Results}

The first research question was what workplace behaviors of expentenced teachers appear to indicate a will to learn? However, the analyses of the teachers" behaviors showed their willingness to learn to clearly depend on the learning object. For example, some teachers were not eager to learn about the classroom use of computers but eager to learn more about the subject they teach. The six topics 
occurring most frequently in the interviews were therefore examined forther and described in Table 10 .

Table 10: Six topics that teachers were most willing (or wnwilling) to learn about

1. The organization of the classroum prowess. The teacher is (not) nilling to learin about the dassoon process and the decisions that he or she and about the lessons. Statements about how the teacher wews the class as a whole or a cohort of students are placed in this category as well.

2. Individual or small group of individuals. The teacher is (not) willing to learn abont and hind vidual and

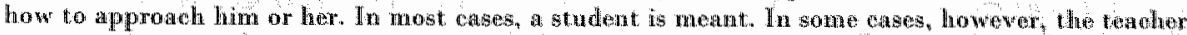
means colleague, manager, or some other extenal person. Statenents abow how tho hadher views these individuals are plated in this category as wall.

3. The content of the teacher"s subject. Statements about (not) being willing vo learn mone abont the content of the subject being taught are planed in this category.

4. The tencher him/herself The teacher is (not) willing to learn about his or her personal charatumition personality traits, purgormance while wonkug, etc.

5. The sethooledueational system. The teacher is (not) willing to leatn about how to impore the sohool system, school management, or the educational system as a whole.

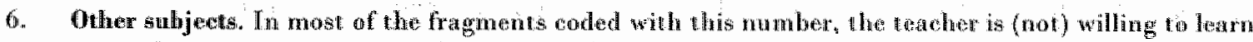
about Information Communication Teehnologs, but athen stabjects which do not fit the athove categories are also placed here:

As can be seen from Table 11, six general categories of behavior that indicates a willingness to learn at the workplace could be distinguished on the basis of the present data. Each of these categories could be further divided into two to four subcategorites of behavior, with a low number indicating a low will to learn and a high number indicating a high will to learn.

Table I1: Main categories and subcategories of a teacher's behavior indicating the will to learn

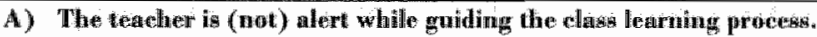

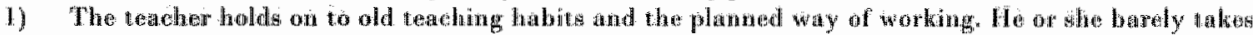

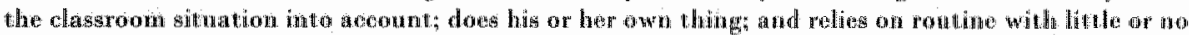

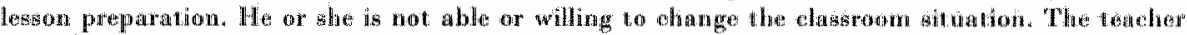

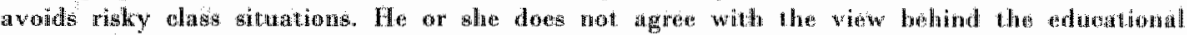

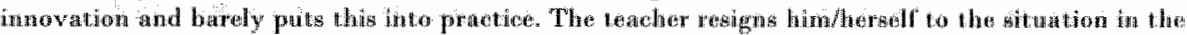

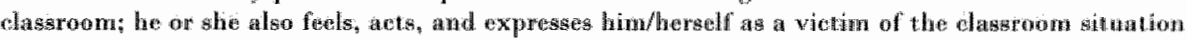
and/or the eductional innowation.

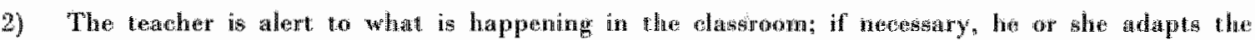
program. Earlier experiences with the gwowp are taken indo asoown, and the teacher atapts his os

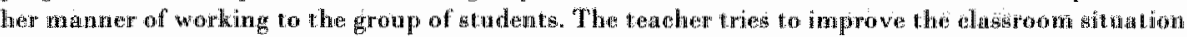

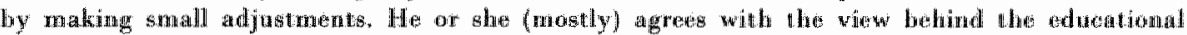
inmovation. The teacher is working on the educational inmovation.

3) Although the teacher has wonsiderable expentence, he or she devotes extrat time and effort lo the preparation of lessons and ries to improwe on the textbok. Difficult or risky situations ate not

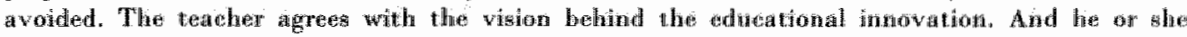
vohntarily wes to improve upon the dassrom simation and odocational inmovation by experianenting with new methods or approaches. 


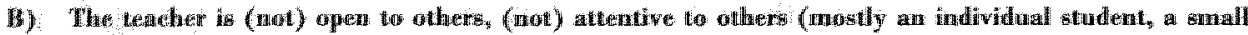

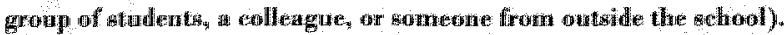

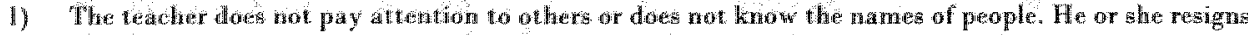
himilherself to not reahng or heng able to help others and is not willing or able to put energy inte helping others. The teather frets, aets; and expresses hinhersedf a victim of the situation in interation wh others. He or we dow not keep an open nind when talking or thinking about Mhetit?

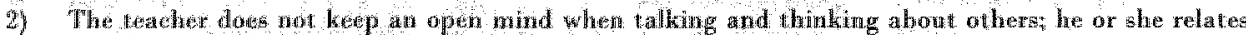
why ho of one winke that others do what they do.

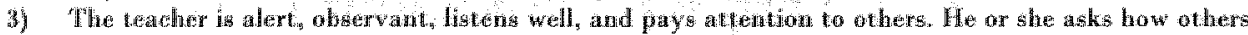

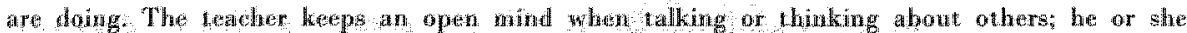

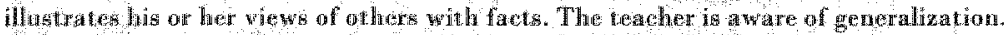

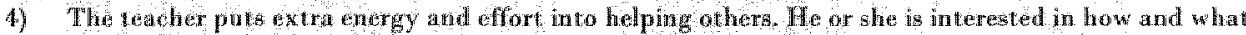

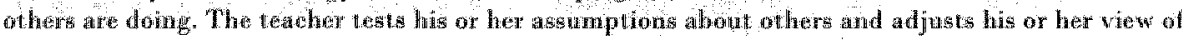
others, when necesantry.

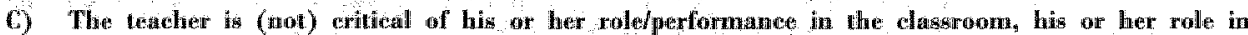
interateion with otheps, his or heb subject knowledge, him/herself as a persow, his or hew role in the argatumathoul, wete.

1) While thalking about a critical inchdetw, whe tedcher dons not take his or her own role/performance into acomm. He of she atributes the canse of the problems to a sonce ontside himberself. The weroher feets, acts, and expreses him/laverself as wictim of the educational system or school system.

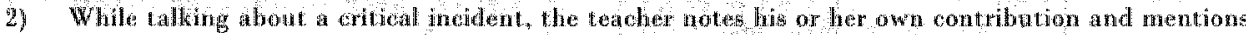
whar was offectwe and what was not. The tocher is able to state his or her qualities and learning

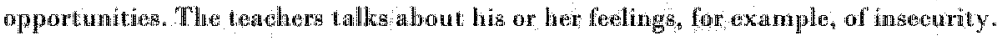

D) The bacher asks him/hersetf (no) questions with regard to how to deal with eritical situations in the

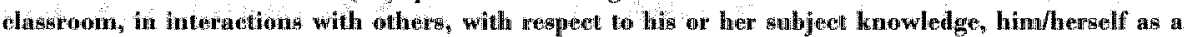
person, his or her wole in the organization, etce.

1) The teachrer does not susk him/herself goestione before, during, or after an ineident. The teacher gimply states that he or she does not need collegial visitation. The teacher also states that he or she does not ned to leam any more about certain subjects. The teacher is unable to formulate either current lonatug goale or goals tor the forture.

2) The temoher ans him/hersolf questions before, during, or after an incident. He or she refleftis upon incidents. The teacher is able (when asked) to formulate a learming goall. He or she asks for lieedback from others.

D) The thacher wakes (no) resolutious and/oi pults (no) sweh resolutions into action.

1) Tha disther wans to improve his or her performance bat does not know how to do this or how to

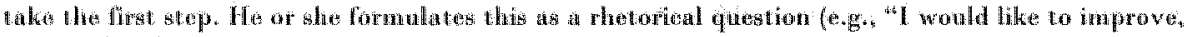

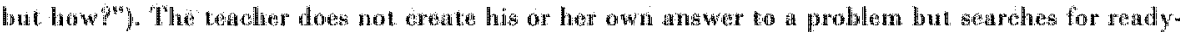

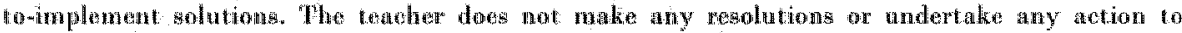
improwe lis on the performanes, situation, knowledge, or skills.

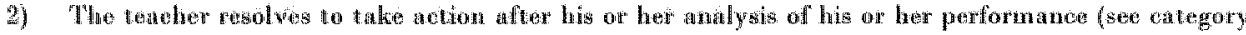

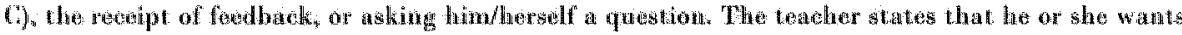
lo learn and develop contintuondy and that ho or she wants bo face new challenges.

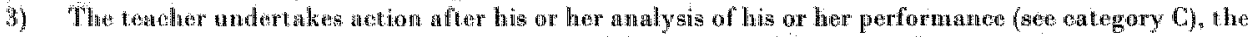

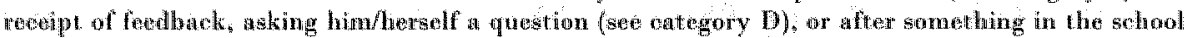
gystem dans not work for him or her. The teacher keeps track of tevelopments in his an her subject

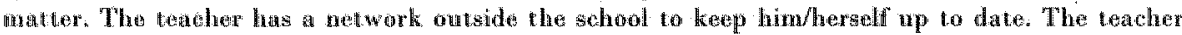

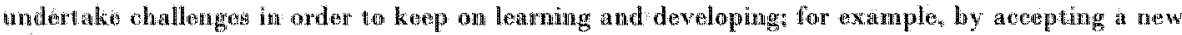
Pinction or task.

F) The teacher leame (does not learn)how to deall with enitical clasgroom situations, others, new knowledge of his or her suhject hiwherself as a pergon, his or her role in the organization, ete.

1) The teacher is barelly ahle to describe learning experiences. The teacher states that he or she did not lesurn thing from a critical situation in the past.

2) The teachen is able to deseritbe explicit lesaning experiences the teacher clearly learns. 
Three qualitatively different manmers in whoh teachers exhbit a willingness to Learn were next disceined. See the Appendix for explication of how the different pattems of behavior (i.e., manners of behaving) were identifed. Suffice it to sity that the three manifestations of the will to learn clearly differed with regerd to the six general eategories of behavior described in Table 11. The three mantestation of a will (or no will) to learn can be labeled as follows:

1. not seeing why there's a need to learn;

2. wondering how to learn; and

3. eager to learn.

Some teachers showed features from more than one manfestation, however they could all be placed in one of the three manifestations. In the following subsections, the different groups of teachers exhibiting the different manifestations of a will to learn will be considered; the boundaries on the different manfestations will be stipulated; and some characteristic statements (translated from Dutch) will be presented to illustrate each pattern of behavior (i.e.s group of teachers). Note that each quotation is accompanied by the teacher identification number and the code assigned to the fragment: topic number from Table 10; general category letter from Table 11; and behavior number indicating relative willingness to learn from Table 11 .

The "not seeing why there's a need to learn' group

Four features were found to be most characteristio of the "not seeing why there"s at need to learn" group of teachers: 1) the teachers hold on to established habits of: teaching (category A); 2) they do not appear to have an open mind for others (category B); 3) they often blame students or the educational system for things that go wrong and are seldon exitical of their owin performance or role (category C) and 4) they find it hard to describe any leanning restalts (category $\mathbf{P}$ ).

The teachers in this group hold on to old teaching habits and stick to established mamers of working (A1). "That child (code 2B1) whom I sent away during class actually dared to ask if he could work on the computer. But I don't find working on the computer useful for this group. Tr only causes at of unest because they don"t know what to do with it..." (3, code $\mathbb{A} \mathbf{A})$.

The teachers in thils group are not open to others (B1-2). Quote after lesson observation: "There are so many mentally retarded students in this class ...." (3, code $1 \mathrm{BI}$ ).

While talking about a critioal inejdent, the teachers in this group do not take their own role/performance into account. They dearly atribute the cause of problems to a source outside themselves. They feel, act, and express thengelves as if they are a victim of the educational system or the school (CI). "The gentemen in The Hague the means the Duth governmen/ detide which direction we must go, we - as foot soldiers - must follow that direction. But are we waiting for all that traning? Ard will working in education be more atractive to us then?" $(1$, code $5 \mathrm{C} 1)$ "The problem is that I am constanily busy wh students who are watring at my desti. At that woment, there is a distance between me and the group. And although I hear whe notse in the background, I am busy with a student and then the others are supposed to do what they should do, but they don't. That is big problem" $(2$, code $1 \mathrm{CI})$ 
These same teacherg do not ask themselves about how to deal with diffroult situations. They also smply state that they need not learn any more about certain subjects and that they need not be visibed by colleagues (DI). "There is more to life than working in ducaion. They ast a lot of my time, it is enough. When you are young, you can whe on a lot. Now I know what I an capable of: My students have to graduate, and that"s $i^{4 y}$ (1, code IDI)

The teachers in this group make no resolutions and therefore put no resolutions into action. They do not search for their own answers to problems but simply seck ready-made solutions instead (El). Interviewer: "So, two differen ways of instruction were used by the trainers during that professional development meeting. Why was th that he sicond one was not so usefulp" "Teacher: "I really missed the ready-to" implement suggestions. Tell me what I should do in order to improve my relations with the students:" (12, code $1 \mathrm{E} 1)$.

Finally, the teachers in this group barely describe a learning experience (FI), "What did I learn? ....(silenee) somewhere, sometime, you can probably say: "oh yes, I ghowld think about that," but for the rest...you just keep on moving..." (1, code FII.

\section{The "wondering how to learn" group}

Unlike the first group of teachers, the theachers in this group are a bit more open to others (category B) and critical of their owm performance and rolle (category C). The teachers in this group can also clearly state what they have learned at times (category F). The essence of this group is that the teachers want to improve their performance but do not always know how. As a result, these teachers do not make any learning resolutions, let alone implement them.

The teachers in this group have less open relations with others than the following group (category B) and they are not allert to student concerns or very nexible with regard to the guidance of the learming process (category A). "Sometimes you lose. Last year, I had a class, the first lesson on Monday and the last hour on Thursday. On Mondays, they had to discuss the weekend with each other, and on Tharsdays, why were too tired to concentrate. It was truly a disaster. At a certain poim, I decided to los it go, and decided that they could worry abou their results themsolves. From that point on, I was just trying to keep it "nice" for myself and for them." (6, IA1, IBI)

They do not have an open mind when talking or thinking about others. They can, however, relate why they think others do what they do $(B 2)$. "It is rare that studenus give me the feeling that I should shut up. Very rare (...). Nent time, I

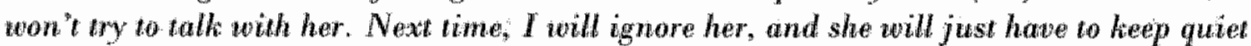
or leave. I don"t have the feeling that being reasonable gets me any further." (4, code 2B1).

While talking about a critical moident (C2), these teachers may note their own contribution to the situation and mention what was effective and what was not. In the following, a teacher describes the impact of the implementation of an educational innovation: "At that time, I seriously thought about quitting teaching. I told myself that if I performed this bad next year too, then I should stop. " (4, I C2)

The teachers in this group do not ask themselves questions before, during, or after an incident (D1). In their opinion, they do not need collegial visitation and do not need to learn. "I have been teaching for many years now. When something does 
not go so well, I try this or that. I have several solutions, and there is not much to wall to that." (5, code 1D1). "One of my frustrations is the requirement that we hate to get our ICT (Information Communication Technology) license. I'm absolutely not indensted in ICT and I don't feel the studying for that." (4, code 6DI)

Although they may clearly want to improwe their performance at times: these teachers do not know how to do this or how to take the first step (E1). All of this may be conveyed in the form of a rhetorical question (e.g. "I wonld like to improve, but how?"). They do not create their own answers to problems but search for ready-to-implement solutions instread. "I wowld tille to change a lot of things in my teaching, but that does not work. I sill think that the students do not worl hand enongh (IBI). For example, in this morning's elass, 12 out of the 27 had not fone their homework. And they kept on taking during the lessanl! I didn't get that right. I hept on, tery dwll, checking their exercises and $I$ ashed 6 twes of they wanted to bisten $(1.11), \ldots I$ am not satisfied at all. I really think I gave a bad lesson (1 C2), but how do I tmprote that? I don't know how to improve that." $(5,1 \mathrm{E} 1)$

Nevertheless, these same teachers can describe exphicit learning experiences (F2). "I noticed that it is much more effective to approach students low-profile, carefully, especially the older students. When a student is not cooperative, this works much better." $(6,1$ 1 2).

\section{The 'eager to learn' group}

Unlike the first and second groups, thïs group undertakes action in order to learn

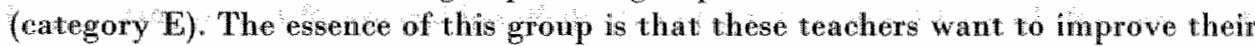
performances and undertake action in order to aecomplish this.

The teachers are critical of their own role/performances in every possible situation (category C). They have insight into their good and bad qualities, and they can mention explicit learning opportunities (Category $D$ and $F$ ) "I know who my qualities are and also what I cannot do very well. For example, I am not so good in aerobics although I have tried it for years." (11, code 3C2)

The teachers in this group ask themselves questions about how to deal with critical situations (D2). "There is a student who is really good. He constuntly challenges me with difficult questions. And when I look over my own ghoulder, I think, "yes, he did ask me that question" and "yes, I had to give that answer." Did I do that to intimidate or just do explain some algebrap" (12, code 2D2)

These same teachers resolve to undertake action in order to loarn (E3). "I have a student who is visually liandicapped, and I want to know how do deal with him in the classroom. I therefore went to a course that dealt with this specific subject" (12, code $2 \mathrm{E} 3)$.

These teachers learn (F2). They are able to describe specific learning experiences. Interviewer: "Can you explain what you have learmed since the second phase program was introduced?" Teacher: "I learned mainly about the new content of the program; there are different requirements now for the graduation." (L3, code 3F2)

Within the third group, we also see that the teachers are alent to what is happening in the classroom and that they adapt the program wen necessary. They (mostly) agree with the view behind the educational innovation (A2). "The second phase program is implemented in a top-down manner. I wonder whether it is really that 
useful, espatally for the lesg han fweroge swdent. But I am coping with it. It is not possible wo wech the way I used ro in any case because we have too much material to cover. Students therefore have to be more independent of me." $(8,1 \mathrm{~A} 2)$

"The teachers in the third group are also open to others (B3). They are alert, obeervant, listen well, ard pay attention to others. They also ask others how things are doing "I am capable of doing more in my lessons now than just teaching. I listen to the shudents. I talk about the evening before. I ask then which concert they wen to. That is something I learned during the past year." (9, code 1B3, 1F2)

Our Alata (setedeher numbers 11 through 14 in the Appendix) also show teachers within the "eager to learn' group itself, who slightly differ from the other teachers in this group with regard to the effort put into the guidance of the cllass learning process (category A) and the helping of individual students (category B). For example, some teachers put exura time and effort into the preparation of their lessons and try to improve on what the textbook contains (A3). These teachers connect even more with students and other people (B4). They are alert, observant, listen well, and clearly see others. They are truly interested in what the student is doing and how he or she is doing. They test their assumptions regarding the student and adjust their view of the student as necessary. All in all, these teachers exert more fort to create more leaming opportunities than the other teachers within the third group. In other words, there are a few teachers with a real "yearning to learn" within the group of "eager to learn" teachers, and the following qootes illustrate this yearning. "Although I know my subject wery well, I still prepare my lessons every day. I look at who we are supposed to do; what steps we must vale; and where the students may rum into trouble. I also do every exercise that they have to so I tnow exactly what they experience." (7, LA3). "Stefan is a student who did not work wery hard during the last years. However, he is really working hard now to pass his exam and I think you have lo change your view of such a kid then..." $(13,2 \mathrm{~B} 4)$." I find one student hard to reach. Every studen has his own way of creating an, and hers... I don't know... I think I may hate to call her parents... I have to find a way to get her going." (14, 2B4).

\section{Conclusions}

The aim of the present study was to explore teachers will to learn. Greater insight was indead gained into what behaviors indicate the presence of a will to learn. In addition, we were able to distinguish a number of different ways in which a will to learn is manifested within the teaching workplace. "The combination of observations and a retrospective interview strongly contributed to our insights. Observation of the daily teaching process provided, for example, insight into the effort that the teacher puts into the process of managing the classroom and/or getting to know the individual student. The retrospective interview allowed us to question the teacher about a certain situation and our perspective on the situation as opposed to just his or her perspective. Given the limited scale of the study and the qualitative nature of the methodology, however, we do not intend to generalize to other teachers. It is also recommended that the lessons actually be videotaped in future research to provide the most objective view of the teaching situation possible. 
With regard to the first research question. six categories of belavious or statements that characterize teachers who are particularly willing or unwilling to learn were identified. As will be seem, each of the behaviors or statements within a eategory has the potential to provide a teacher with an opportumity to acquine new teaching knowledge.

The behaviors and statements constituting cattegory $A$ refleot a teacher who is "alert while guiding the learning process of a class". The actuities resemble the activities identified by Dumn and Shriner (1999) for those teachers who will not settle for less effeetive teaching. However, we also found the opposite to hold in a number of cases. That is, some of our teachers opted for a safe approach and thereby encountered relatively few potential leaming situations as a result. These teachers resemble the teachers described in the following manner by Desforges $\left(1995, \mathbf{p}_{n}, 390\right)$ : "they behave in such a way as to maximize predictability in the classroom and, when laeir routine operation does not appear to achieve the desired student behavior, they put in place actions that are intended to return classroom interation to normal". "This type of non-risk-taking behavior can possibly be explained in terms of the teachers" perceived self-efficacy, which was already mentioned as an influential factor in the Introduction to the present study. The greater the level of perceived self-efficacy, the higher the goals set by people, the risks that they are willing to take, and the commitment and perseverance shown in the pursuit of such (Bandura, 1997). The lower the level of selfefficacy, the greater the vulnerability to anxiety and the tendency to develop avoidance patterns designed to reduce fears. Huber (1995) similarly explains this difference between teachers in terms of tolerance of uncertainty.

The behavions and statements constituting category $\mathbf{B}$ reflect an 'openness to others" and reveal the importance of being open to other people, paying attention to them, and trying to connect with and understand them. In our view, this aspect of teacher leaming has not been described very often. When a teacher truly tries to comnect with students, the students may - in turn - constitute a potential source of teaching improvement. With increased information and familiarty, moreover, the teachers" inages of others may become highly differentiated and situation specific: About half of the teachers in the present study did not appear to really get to know their students. They also, then. showed a tendency to overgenernlize and relate student behavior to deep-seated personality dispositions rather than specific stimuli within the elassroom situation for example. Omce such attributions have been made, moreover, certain teachers have been shown to stubbornly stick to them even in the face of strong disconfirming evidence and to sometimes show a stronger belief in incorrect intuitions than objective data (Ross \& Nisbett, 1991).

The behaviors and statements constituting category $\mathrm{C}$ refer to the teacher being "critical of his or her own role or performance" and thus the process of cognitive attribution (Weiner, 1990). People may readily attribute failure to chance occurrences (i.e., external causes) and success to their own ability (i.e. internal causes) or, vice versa, failure to personal inability and success to chance occurrence. A small group of our teachers indeed appeared to produce mostly external atributions with regard to failure and thereby reduct their possibilities for learning from a particular situation. Other teachers clearly view themselves as the victims of the educational system, the classroom situation (see category $A$ as well), and/or 
unwilling behawion on the part of the students (see category $\mathbb{B}$ as well). As a resalt, they do not talke any action to improve the situation whille others teachers do (see category $\mathbf{E}$ as well). This pattern of behavior appears to reflect the phenomenon af learned helplessness as described by Seligman (1991). That is, when people believe that there is nothing that they can do to control negative or painful outcomes, they also come to believe that they are helpless.

The behavior and statements constituting category $D$ pertain to reflection in order toarn from experience. Korthagen and Kessels (1999) have emphasized reflection as an important step in teacher learning. And the behaviors and statements in this category are part of this reflection process. Some of our teachers reflected wia the posing of questions before, during, or after a particular experience. Some of our teachers sought feedback via the distribution of student questionnaires. And some of our teachers did nothing along these lines. In other words and in keeping with the earlier findinge reported in the Introduction, not all teachers appear to behave as reflective practitioners (Sehön, 1983, 1987).

The behaviors and statements constituting category E refer to the making of resolutions, on the ont hand, and patting these into action, on the other hand. According to Kolb's (1984) theory of experiential learning, making resolutions and putting these into action are necessary steps for learning from experience. And according to the sell-regulated perspective on learning (see Introduction), the planing and actual implementation of resolutions depend on the metlacognitive and affective learning strategies of the learner. One third of the teachers involved in the present stady did not oftem, put their resolutions in action, and a similar phenomenon was detected in previous study (van Eekelen, Boshuizen, \& Vermunt, in press). In other words, the will to learn appear to meet the ability to learn here. The relevant teachers said that they were willing to learn but did not know how, which could have arised from their conceptions of leaming. While the teachers are supposed to foster constructive situdent leaming, their conceptions of learning still lean towards knowledge transmission. These teachers look to others to provide them with a solution or the "right ${ }^{2}$ answer while others experiment, learn in a constructive manmer, and create their own solutions for problems. Studies of the learning of student teachers, monever, show those within the first group to also be more likely to mintain their misconceptions (Oosterheert \& Vermunt, 2001; Pintrich, 1999).

Finally, the behaviors and statements constituting category fir reflect the extent to which teachers can articulate their own learning experiences. (An overview of the specilic topiws that the teachers, in general, report learning about is presented in Table 1.) Nonaka and Takeuchi (1995) Have described the process of professional knowledge creation as the interaction between explicit knowledge and tacit knowledge: a cyclic process involving four steps: socialization, internalization. exteraalization, and combination. During the retrospective interview, the dialogue and reflection may have triggered "externalization" and thereby the articulation of tacit knowledge. However, quantitative differences were still detected between the teachers with regard to the number of learning results reported. Some of the participating teachers reported many learning results while others had difficulties reporting any.

With regard to our second research question, it was possible to identify three different patterns of behavior and statements or manifestations of the will to 
learn. A group of teachers who do 'wot see the need to leam' was detected and found to barely question their existing knowledge and behiefs. They do not, thus, seem 10 have a will to learn. A group of teachers who "wonder how to learm" was also detected. These teachers want to improve their performance - and are therefore clearly willing to learn - but do not know how. Finally, a group of "eager to loam" teachers was found to be very willing and able to learn.

\section{Discussion}

Taken together, the behaviors in the categories $A$ to $\mathrm{F}$ were found to be indicative of a teacher's will to learn. In the Introdmction, we mentioned that the notion of "a will to learn" is different tham such notions as "ability to learn" "self-regulated learning". "intention to learn", "motivation to learn", and so forth. Nevertheless, numerous examples of behavior strongly related to the aforementioned notions were encountered in our analyses. Fror example, the close relation between a teacher"s will to learn and ability to learn was observed on a number of occasions. We also saw goal-directed behavior and self-regulated behavior to occur whin categories $D$ and $\mathbf{E}_{\text {, respectively. }}$

By observing the daily prosess of teaching and undertaking both an initial and retrospective interview, we discovered the importance of considering not only how teachers approach situations but also how they actually handle them. Category A or "alert while guiding the learing process of a dass" and category B or "openness to others' can be seen to reflect the manner in which teachers approach various situations. Just what they do in these situations, however, is reflected by categories C through $\mathrm{F}$. In our view, teachers may encounter potential learning experiences, stemming from categories $A$ and $B$ but this does not mean that they necessarily learn from these. Prawatt (1992) has referred to this phenomenon as 'naive constructivism ' or the tendency to equate experience with learning. Learning cannot be simply equated with experience; nor can it be expected to readily flow from these (Desforges, 1995). A learner must approach and actively deal with an experience in order to learn from it, which is in keeping with otar constructive perspective on learning. So, for a complete portrayal of a teacher"s will to learn, wo now reognige that it is important to examine not only the starting point or basic will to learn but also the occurrence of such behaviors as those described in categorice $C$ through $F$.

\section{Directions for future research}

The results of the present study thave provided insight into which behaviors can be taken as indicators of a will to learm. However, the behaviors and paturns of behavior discerned here must be verified in larger seale research. Longitudinal research may provide insight into any transitions between the different manifestations of a will to learn during the career of a teacher. And a critical hierarchy or possible developmental sequence may then be revealed. An eager to learn" group of teachers is typically considered superior to a not seeing why there is a need to learn" group of teachers; is one categorization more characteristic at a particular point in the careers of teachers than another categorization? Or do such categorizations simply reflect individual differences across teachers? 
The spedfic ditracteristics of the thee groups of teathers identifed here should be wamined grim grex detail in future researeh. The present result reveated a subgroup of teachers wh a 'yearning to learn' within the 'eager to learn" group, and the question wh wher such a "yearning to learn" constitutes a separate manifestation of the will to learn? What drives this particular subgroup of teachers? For the "wot seeing the need to learn" and wondering how to learn" groups, examination of their eputemological perpectives mat be merited as these teachers may entertain an absolute or duallistic (Hofer \& Burr, 2001) perspective and thus see knowledge as something that is absolute or und anging and therefore be less likely to acept conflingting evidence than teachers who believe that knowledge is tentative and changing (Mason, 2000). According to Limon (2001), learners with less sophisticat tepistemological belief (i,e. knowledge is simple and certain) have been found to perfom relatwelly better in directive learning enviromment than in a constructivist one, which may also hold for teachers as well. That is, the teachers in the "wondering how to learn" group tended to soek only ready-to-implement suggestions while the teachers in the "not seeing why there's a need to learn" group were barely able to explicate any learning experiences at all.

One ean argue that our description of the will to learn implins a construct that we have not as yet mentioned: namely, the readiness or willingness of the individual to change. Such behaviors as agreeing or not agreeing with an educational imovation (category $A$ ), acting in accordance with an educational innovation or not (eategory $\mathrm{A}$ ), and feeling like a victim of the educational system or not (category C) point in this direction. And although we see a clear link between a particular will to learu and the readiness of the individual to change, further research is needed to verily such a relation.

Finally, when presented with the hehaviors described in Table 2 , the teachers studied here suggested that such an overview may promote further discussion of the willingness of teachers to learn. It was suggested that asking teachers to position themselves with respect to each category of behavior may prove worthwhile. It was also suggested that teachers may ask colleagues, coaches, or managers to avaluato then on the basis of such a list. And in such a manner, our findings may provide the starting point for the construction of various instuments to measure and evaluate the will to learn.

\section{References}

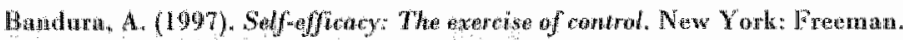

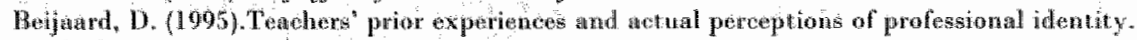
Terehers and Thohng. Theny and Praction, $1,281.294$.

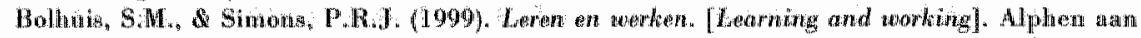
den Rinn: Sumsom.

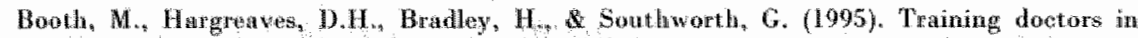

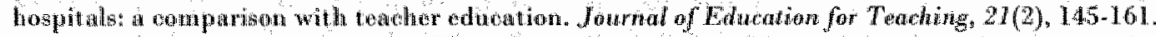

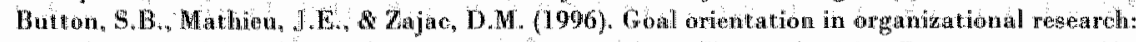

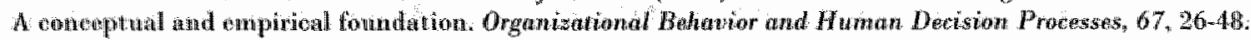

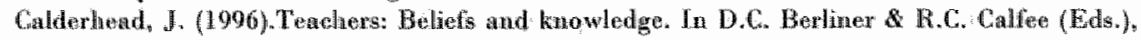

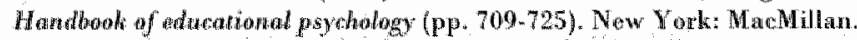

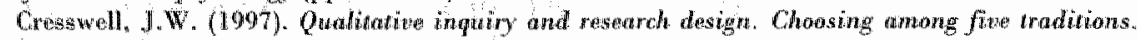
Thousand Oake, CA: SACE Publio tions. 


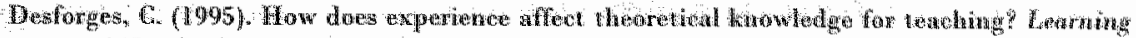

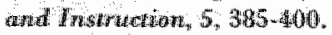

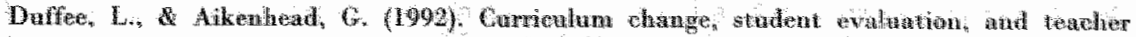

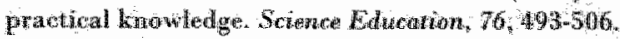

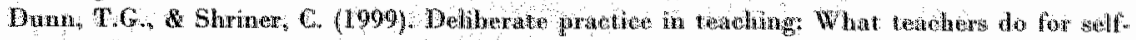

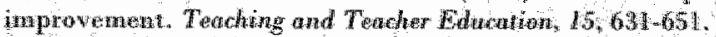

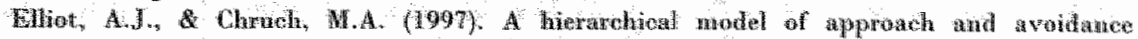

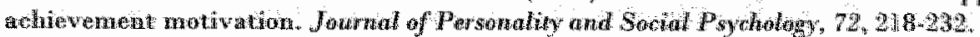

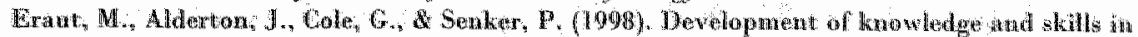

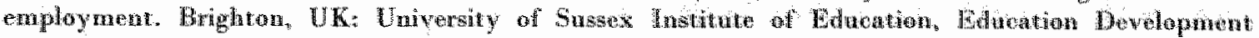
Building.

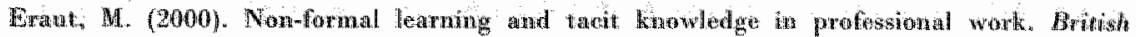
Tourmol of Educational Psycholog\%, 70, 113-136.

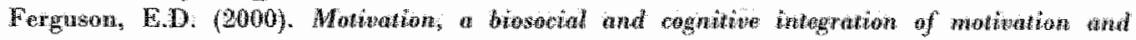
mwonin. New Vork: Onford Unversity Press.

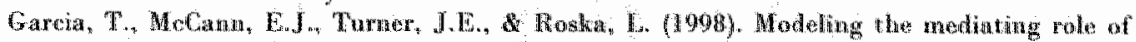

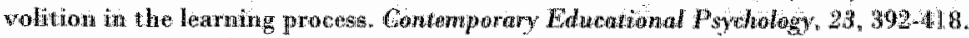

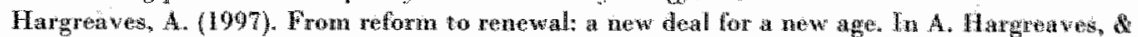

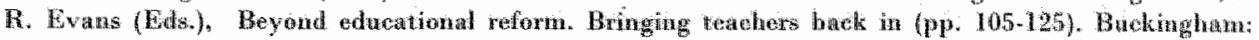
Opun Uniwersity Press.

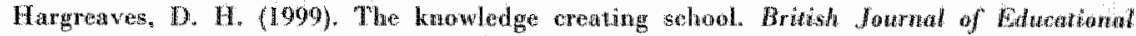
Studies, $47,145-161$

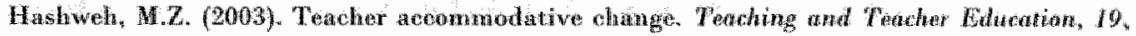
$421-434$

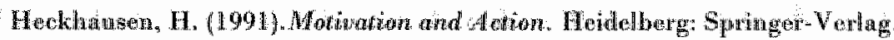

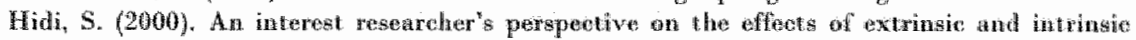

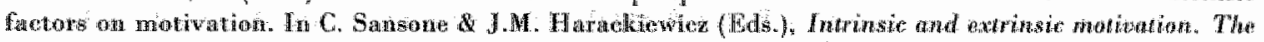

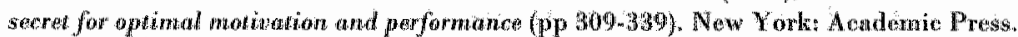

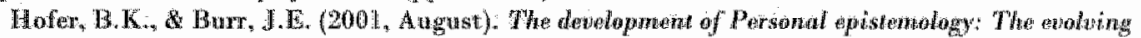

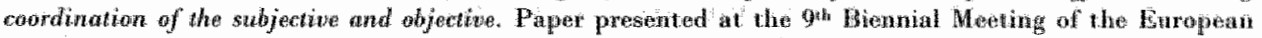
Associstion for Research on Learning and Instruction, Fribonts, switurland.

Haler, G.L. (1995). Assessing toleranes of unertaing. Paper presented at the Go Duropuan Conference for Besearch on Leaming and Instruction. The Netherlands; Namegen.

Kniglnt, P. (2002). A systematio approach to profossional development: Learning an practice. Teaching and Teacher Education, $28,229-241$.

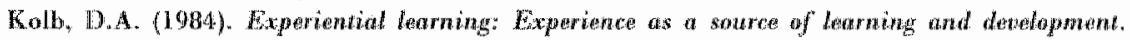
Guglewood Ciffs, NY: Prentice Hall.

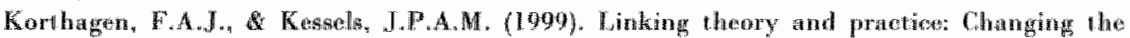

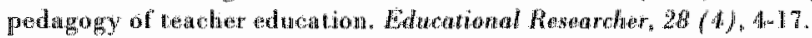

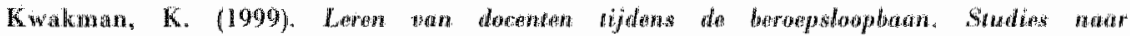

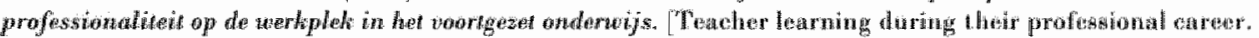

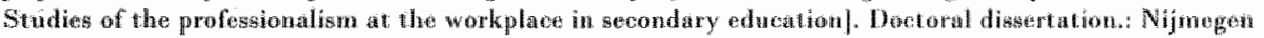
University, The Netherlands.

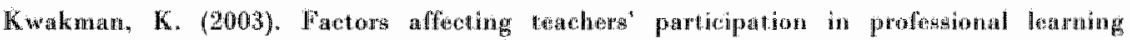

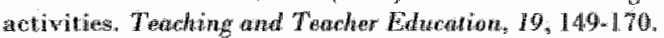

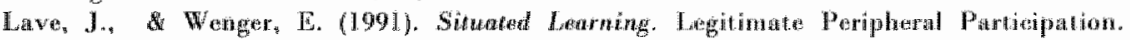

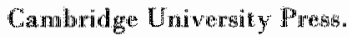

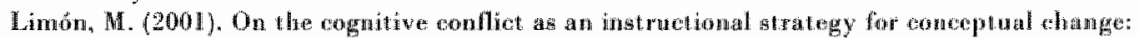
A toitinal appraisal. Leaming and Irstruterion, $11,357-360$.

Lohman, M.C. (2000\%. Fowirommental inhibitow to informall learung in the workplate: A wate

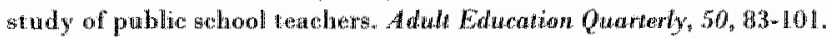

Marton, F. (1936). Phenometnography - A restarch approath to investigating different waderstandings of reality. Journal of Thought, 21, 28-4.9.

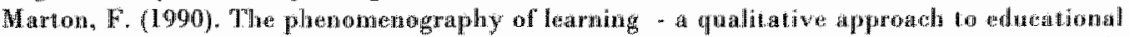

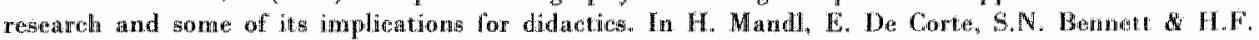

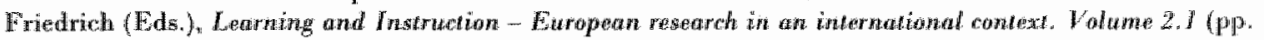
601-616) Ox ford: Pergamon Press.

Mason, L. (2000). Role of anomalous data and epistemological belicfs in middle sehool studenta" theory change about two controwersial topucs. European Journot of Psychology of Eaducation, $15,329-346$. 


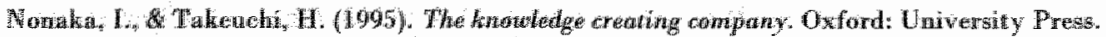

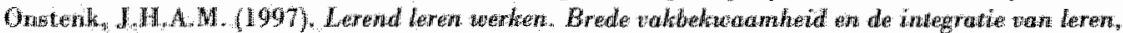

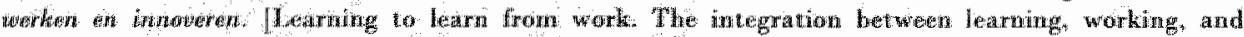

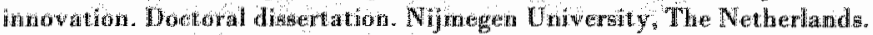

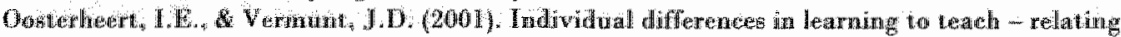

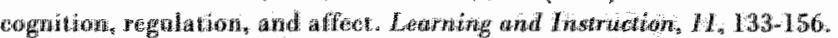

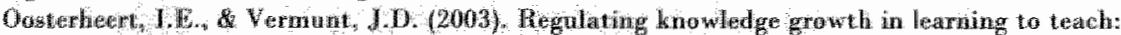

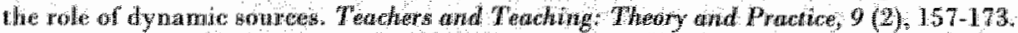

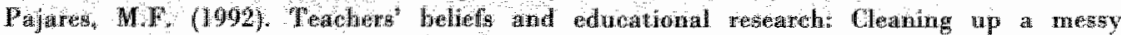

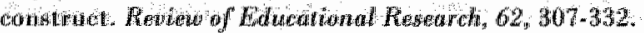

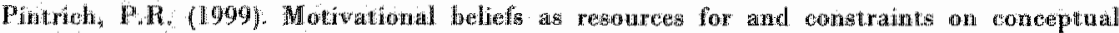

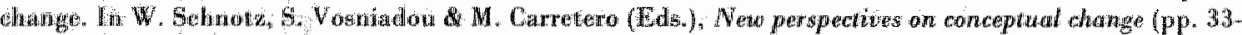

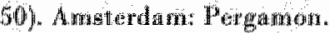

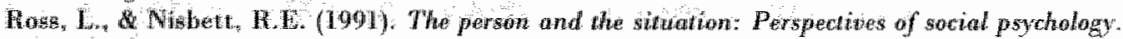
Now York: MoGraw-Mill.

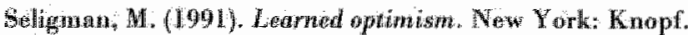

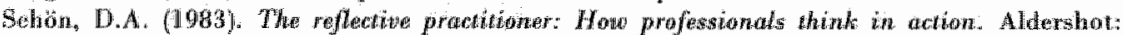

Arenta

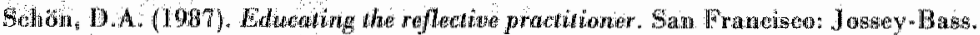

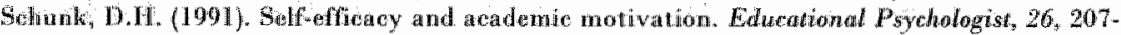

231.

Smylie, M.A. (1904y. Redesigning teadrers" work: Connections to the elasaroom. In L. Darling-

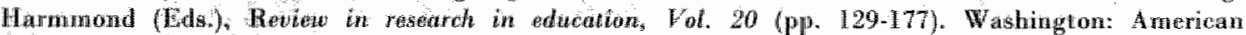
Diducaronal Tesereh Assomation.

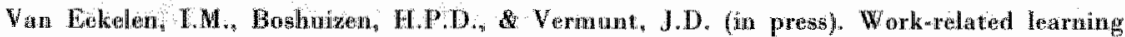

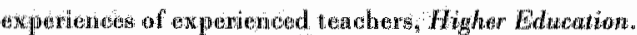

Verloop, N, Van Driel, M, Meyer, IP". (2001). Teacher knewledge and the knowledge base of wathing. Internatomal Jownal of Edweational Research, $35,441-461$

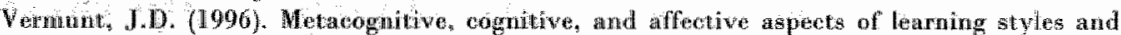

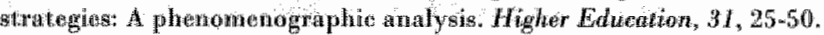

Vermant, J.D., Verloop, N. (1999). Congrnence and friction between learning and teaching Latenoung and Instraction, $9,257-280$.

Weiner, B. (1990). Actribution in personality: peychology. In 1 . A. Pervin (Eds, , Hondhook of personalig: Theory and reseanch (pp.465-484). New York: Gullford Press

Whitaker, P. (1993). Mnnaging Change in Sothools. Buekingham: Open Univensilty Press. 


\section{Appendix}

In the Table below, the percentage of the statements pertaining to each category of behavior for the 14 teachers interviewed in the present stady are reported The highlighted numbers indicate the subcategory of behawior with the highest percentage for a particular category of behavior. When there were two subcategorites with the same percentage, the highest number of behaviors was highlingled. flhere are two exceptions to this rule. Teacher 10 scored highest for the subcategory of A2 ("alert while guiding the learning process") when the interview data was coded. When observed, however, this teacher was seen to take many risks and to clearly experiment with the principals of the new program. Unlike most of the other teachers, he also showed such behaviors as organizing group work for students, giving students a voice in what to do during the lessons, and using on-line ICI in his lessons. We therefore categorized this teacher as A3 ("experiments with new approaches"). Teacher 11 scored high for the subcategories of B3 and B4 (the teacher is "open to others, pays attention to others" and "connects with others" respectively) when the interview data was coded. During the observation day, however, ho was involved in the coaching of individual students more often than the other teachers and we therefore decided to categorize this teacher as $\mathrm{B} 4$. 
Number of statements in interviews (percentages) for each category of behavior per teacher

\begin{tabular}{|c|c|c|c|c|c|c|c|c|c|c|c|c|c|c|c|}
\hline & Teweher number & $i$ & 2 & 3 & 4 & 5 & 6 & 7 & $a$ & 9 & 10 & 11 & 12 & 13 & 14 \\
\hline & $N=$ & & & & & & & & & & & & & & \\
\hline & & 62 & 60 & 61 & 106 & 76. & 85 & 55 & 74 & 72 & 83 & 73 & 91 & 55 & 88 \\
\hline$A$ & $\begin{array}{l}\text { A1. Wholds on to old } \\
\text { teatuing habits }\end{array}$ & 15 & 24 & 15 & 14 & 21 & 5 & 4 & 3 & 4 & 6 & औ & 1 & 2 & 2 \\
\hline 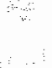 & $\begin{array}{l}\text { A ts allert to } \\
\text { Aassroom procesesh }\end{array}$ & 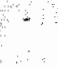 & 10 & 10 & 4 & 3 & 9 & 9 & 18 & 12 & 12 & 12 & 2 & 13 & 6 \\
\hline & $\begin{array}{l}\text { As expentimente with } \\
\text { new appootiches }\end{array}$ & $\therefore$ & 6 & 2 & 1 & 3 & 1 & 4 & 11 & 4 & 1 & 8 & 1 & 5 & 9 \\
\hline i & $\begin{array}{l}\text { Bl is not opent to } \\
\text { offere }\end{array}$ & 15 & 14 & 13 & 18 & 3 & 11 & 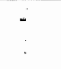 & - & 3 & - & - & 1 & - & - \\
\hline & $\begin{array}{l}\text { B2, bis mote opento } \\
\text { others }\end{array}$ & 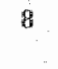 & . & 7 & 3 & 6 & 12 & 9 & 1 & 7 & . & 1 & 8 & $=$ & 3 \\
\hline 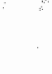 & $\begin{array}{l}\text { B3. Hop opt to pays } \\
\text { atertwon to onhers }\end{array}$ & 3 & . & - & 3 & 4 & 2 & 11 & 12 & 8 & 5 & 15 & - & $\tau$ & 8 \\
\hline 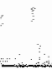 & $\begin{array}{l}\text { Bu, conneets witli } \\
\text { olhers }\end{array}$ & - & - & - & 3 & - & 1 & 2 & - & 3 & - & 11 & 14 & 7 & 8 \\
\hline C & $\begin{array}{l}\text { Q1. has not eritical of } \\
\text { own rols }\end{array}$ & 21 & 20 & 15 & 2 & 7 & 11 & 2 & i. & 1 & 6 & $\mathbb{1}$ & 5 & 2 & 3 \\
\hline & $\begin{array}{l}\text { C2. is aritical of own } \\
\text { role }\end{array}$ & 6 & 4 & 5 & 18 & 18 & 12 & 11 & 16 & 8 & 27 & 23 & 21 & 15 & 11 \\
\hline D & $\begin{array}{l}\text { D1. asks him/hergelf } \\
\text { no questions }\end{array}$ & 16 & 4 & 2 & 3 & 8 & 7 & 4 & - & 1 & - & 3 & - & $\therefore$ & - \\
\hline & $\begin{array}{l}\text { D2. refleets, asks } \\
\text { liminherself guestions }\end{array}$ & - & - & 3 & 2 & 3 & 4 & 2 & 18 & 8 & 12 & 5 & 12 & 18 & 13 \\
\hline 政 & $\begin{array}{l}\text { E1. does not know } \\
\text { what to do to } \\
\text { improve }\end{array}$ & 2 & 4 & 3 & 4 & 5 & 11 & 2 & 1 & * & 2 & . & 1 & - & 3 \\
\hline & $\begin{array}{l}\text { E2. resolwes fio take } \\
\text { action }\end{array}$ & - & 4 & 7 & 3 & 3 & 4 & 15 & $\|$ & 10 & 5 & 8 & 4 & 5 & 9 \\
\hline & $\begin{array}{l}\text { E3. undertakes atction } \\
\text { in order to learn }\end{array}$ & - & . & $\tau$ & 1 & - & 2 & 4 & 5 & 11 & 10 & 8 & 7 & 7 & 10 \\
\hline $\mathbf{F}$ & $\begin{array}{l}\text { Fl. is bardy able to } \\
\text { dostribe lestuming }\end{array}$ & 6 & 4 & 7 & 4 & 6 & 4 & - & 1 & 3 & - & - & - & - & 3 \\
\hline & 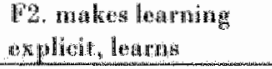 & 5 & is & 5 & 8 & 13 & 6 & 24 & 11 & 17 & 12 & 8 & 15 & 11.5 & 10 \\
\hline & & $\begin{array}{r}\text { P } \\
\text { do } \\
\text { net }\end{array}$ & $\begin{array}{l}\text { thern } \\
\text { of sed } \\
\text { trote }\end{array}$ & & $\begin{array}{r}\text { Pa } \\
\text { wond } \\
\text { in }\end{array}$ & & & $\begin{array}{l}\text { Patt } \\
\text { asatget }\end{array}$ & & & & & & & \\
\hline
\end{tabular}

In order to diseen different manifestations of the will to learn., the results in Table abowe were further analyed. By counting the number of ategories in which an individual scored mone than the lowest subcategory (e.g... in category A teacher 1 receved zero points, teacher 6 scored point and teachers 10 and 14 scored 3 points, and so on for all 6 categories), an intial ordering of the teachers from "not really willing to learn" to "willing to leam" was established. However, the final order (as presented in the Table) was reached by making the following qualitative decision. The initial positions of teachers 3 and 4 were switched because Teacher 4 scored quatitatively less than Teacher 3 but the profile of Teacher 4 for categories $C, D, E$, and $\mathrm{F}$ resembled the profiles of Teachers 5 and 6 more. 


\section{FIVE}

The fith chapter has been sulmitted to Teachers College Records as:

Van Bekelen, 1.M, Boshuixen, H.P.A, Vermunt, J.D. Fostering teachers' will to learn. 


\section{Fostering teachers' will to learn}

The topic of the present study is those teachers who do not appear to have a will to learn or willingness to change and may therefore delay sehool development. The primary goals of the study were a) to explore and describe the learning and change process for this specific group of teachers, b) to examine whether it is possible to stimulath these teachers to stant learning again using a tailor-made intervention, and $c$ ) to explore the relations benteen teachers" self-effcacy and will to learn. Inspired by the Trans Theorelical Model of Change, a muliple-case study involving seven high school teachers was anderkaken. The results provide a new perspective on the stage theory of leacher learning and educalional change processes and may assist principals, policy makers and change consultants in their daily business of facilitating teachers leaming and school development processes ${ }^{2}$

\section{Introduction}

Teacher leaming and professional development are integrally and inherently situated within the everyday workplace of teachers (McLAughlin, 1997; Putwam \& Borko, 2000). Despite the strong contribution of the workplace to such learning and development, however, the individual teacher"s participation and learing from workplace experiences are not completely determined by the workplace (Billett. $2002, p .38$ ). Just as students are currently assumed to learn best when allowed to actively construct and self-regulate thell own knowledge, a constructivist view of teacher learning and development appears to hold as well (McLAughlin, 1997; Putnam \& Borko, 2000).

Previous studies of theacher learning and development however, haves shown not all teachers to take such responsibility for their learning. For axample, Kwakman (2003) found powerful opportunites for teachers to learn within the workplace to often go unused. In a recent study of the regulation of teacher learning (Van Eekelen, Boshuizen, \& Vermunt, in press), moreover, three types of regulation could be distinguished with only the third type involving active self-regulation: spontaneous or externally regulated learning; non-linear or both extemally regulated and self- regulated learning; and planmed or self-regulated learning. Marks and Gersten (1996) also observed major differences in the levels of engagement for teachers involved in a voluntary staff development program. Fone categories of teachers could be identified and found to range from low engagement and low impact to high engagement and high impact. In other words, teachers working

\footnotetext{
"This research was funded by the "Task Force for the Tenewall of Initial High Sathool Yeare" from the Dutch Mishstry of Education and "Interstudie" , Educational Censultancy and Training. Arnhem, the Netherlands.
} 
whith one and the same context can differ markedly with regard to their attitude towards professional learning.

The topic of the present study is warkbility in the willingness of teachers to learn and particularly those teachers who do not appear to have a so-called will to learn reference. In a previous study, hachers" will to leam was defined as a "psychological state which the teacher has a desire to learn, to experiment, or to see or do something which has not been seen or done before (Van Eekelen, Vermunt, \& Boshwizen, submited). Teachers were indeed found to differ with regard to their perspetives on learning and professional development with the following distuctions clearly standing ovi: those teachers who do not see a need; those teachers who are wondering how to learn; and those teachers who are enger to learn (see next getion). In the current study teacher learning is viewed as constructive and situated, and more specifically defined as an experience in the workplace whereby a teacher' knowledge, skills, or attitudes are re-stablished or changed and recognized as such by the teacher him/herself.

While schools and educational innovation programs can clearly benefit from teachers who engage in professional development activities (Geijsel, Sleegers, Van den Berg, \& Kelchtermatu, 2001) principals, policy makers, and change consultants often encounter najor problems in the form of resistance from teachers who simply do not wish to undertake development activities. However, the persective of teachers who are anwilling to learn has yet to be sufficiently illuminated and the insights provided by the present study may greatly help those who work with teachers to better facilitate teacher learning and thereby school development and change.

The primary objectives of the present study are thus as follows: a) to explore and describe the learning and change process for teachers who do not appear to have a will to learn b) to determine whether it is possible to stimulate a group of teachers who do not have a will to learn to nevertheless learn; and c) to further explore the rellations between a will to learn and self-efficacy. And in order to pursue these objectives, the Trans Theoretical Model of Change (Prochaska, Diclemente, \& Norcross, 1992) has been borrowed from a different domain of stady - namely, the stages of change in molicalthy behawior (see below).

\section{Theoretizal bachground}

In order to provide a theoretical framework for the present study, a search was done for already existing theoretical models to help us describe, explore, and foster the learning of teachers who do not appear to have a will to learn. As the concepts of loarning and change clearly overlap (Simons \& Ruijters, 2003), the several typologies of how teachers react to change were lound to share many commonalities with the previonsly distimguished differences in teachers" willingness to learn (Van Eekelen et al., submitted). For instance, Lindblad (1990) identified six distinct manners of reacting on the part of teachers to a newly mandated curriculum in Sweden. The reactions of the teachers could range from "alienated" or "spectator' to "loyal officer." In other research, Sikes (1992) identified seven specific strategies for dealing with imposed change. The strategies could range from carrying on as before, leaving, general resistance and sabotage to grasping the opportunities. Evans (2000) identified three attitudinal responses to imposed change: resentment, resignation, or 
receptivity. And Rogers (1983) established a renowned typology of dhange on the basis of innovativeness when he distinguished Innovators, Early Adopters, Early Majority, Late Majority, and Laggards. In sum, the typology of diange for teachers can be seen to range from 'not willing to change' to "eager to change" and thereby parallel the manifestations of a willingness to llearn observed for teachers (see above).

Typologies of teacher change and willingness to change (i.w. learn) do not provide insight into how the individual change process actually occurs. However Hall and Louck (1977) examined the stages of teacher concern in relation to the levels of use for an innovation and found teacher concen to develop from "concerns about the self' to "concerus about the task" and finally "concerns about the students." In other research, Mevarech (1995) proposed a five-stage model to characterige the professional development of teachers when confromted with an innovation: survival, exploration, bridging, adaptation, and conceptual change. And hinally, Wood and Bemuet (2000) have recently proposed a three stage model of change based on Fenstermacher's 1994 theory of professional learming with the following stages: 1) reflective consideration, 2) problematizing practice, and 3) changing theories and practice.

It is most striking that all of the models of the individual change process just reviewed start from a phase in which the teacher is already willing to learn. Those phases in which teachers are not willing to change or learn are basically neglected Conversely, the willingmess to learn typologies reviewed above dearly distinguish those who are not willing to change (i.e., learn) but provide no insight: whatsoever into how the ehange process then occurs. Fortunately, a wheoretical framework that addresses both aspects of the change process was encountered in our search of the relevant research literature, namely the Trans Theoretical Model of Change.

\section{The Trans Theoretical Model of Change}

The Trans Theoretical Model of Change (TTMC) (Prochaska et al., 1992) was originally developed to explain the stages of change observed for smoking cessation but is now applied to many other areas of behavioral change (see Haggerty \& Goodman, 2003; Miller \& Hester, 1986). The more than 25 years of application for the TTMC has produced an extensive body of supportive empinional evidence from a variety of problem areas. The strength of the TTMC is that it takes the perspetives of people who do not appear to have a will to change into account and mattehes the stage of change with an appropriate intervention strategy (Purdie $\mathbb{B}$ MeCrindle, 2002). The TTMC was particularly attractive for ase within the context of the present stady, moreover, because the "readiness to change" phases incladed in the TTMC dosely resemble the manifestations of the willingress to learn identifed in previous research for teachers (Van Eekelen et al.., submitted).

The TTMC distinguishes five stages or phases of readiness-to-change. The first phase is precontemplation. The individuals in this phase are underaware or completely unaware of their problems. There is no intention to change in the foreseeable future - mostly defined as the coming six months. "Think of smokers who say" "Why shoald I quit? My granddad lived to be 80 and smoked his entire life." Failure to recognize and reststance to modification of a problem are hallmarks of this phase, and such defense mechanisms as the selective processing of 
information may be used to resist change in the face of increasing - often socialpressure to change (Prochaska \& Diclenente, 1982). In the second contemplonion phise, individuals become aware and recognize that a problem exists. At this point, they begin to reflect on the pros and cons of change. When the pros outweigh the cons, people may statt to think about overooming the problem. However, due to a lack of confidence in their ability to deal effectively with the outcomes associated with the changes (ie, a sense of self efficacy, see further), there is often little or no commitment to take action. Commitment making stands central in the third or preparation or decision phase of the TTMC. Most individuals in the preparation phase intend to take action in the next month and prepare themselves to do so by collecting relevant information. Once they feel sufficiently confident and have made the necessary prepatations, they move into the fourth or action phase of the TTMC. In mogt studies, individuals are classified as being in the action stage when they have successfully altered their behavior for anywhere from one day to six months: The fifth and final phase in the TTMC model is maintenance. The individuals have prevented relapse for at least six months and consolidate the changes already made. In both phases four and five, people modify their behavior, experiences, and/or environment in order to overcone their problems.

The similarities between the phases in the TTMC and the three yypes of willingness to learn identified in our previous research (see Van Eekelen et al.. submitted) are striking and suggest that teachers' willingness to leari can be conceptualized in terms of readiness to change. The phase one precontemplators within the TTMC resemble the "not seeing why there"s a need to learn" group of veachers who hold on to established habits and do not appear to have an open mind. Such teachers often blame the students or the educational system for things that go wrong and are seldom critical of their own performance on role. These same teachers do not ask about how to deal with difficult situations and often simply state that they do not need to learn any more about certain subjects and need not be visited by colleagues. The teachers in this group make no resolutions and therefore put no resolutions into action. They do not search for their own answers to problems; they simply seek, rather, ready-made solutions. And as a result of this sitwation, it is very hapd for such teachers to describe any learning results for themselves whatsoever.

Aspects of the contemplation and preparation phases clearly characterize the group of teachers who are "wondering how to leam". Unhke the first group of reachers, these teachers are a bit more open to others and critical of their own perfomance and role in the teaching process. The teachers in this group can also clearly state what they have learned at times. The essence of this group is that the tenchers want to improve their performance but simply do not know how. And as a result of this situation, these teachers do not make any learning resolutions let alone implemont them.

The action and maintenance phases of the TTMC clearly characterize the "eager to learn" group of teachers. Unlike the first and second groups of teachers, the "eager to learn" group of teachers undertakes concrete action in order to learn. The essence of this group is that the teachers want to improve their performances and undertake action in orden to accomplish this. The teachers reflect upon their own role and performance across situations and may be critical at times. These teachers 
have insight imto their good and bad gualities, and they can mention explicit learning opportunities and results:

Not only do the different phases of the TTMC clearly resemble the different manifestations of the will to learn among teachers, the TTMC also provides minght: into how the process of ehange and learning proceds from a position of loeng wnwlling to change or learn. The question that now arises is whether a healthoure model that describes the readiness to change and actual change process for such wnhealthy behaviors as smoking; overeating, or anorexia can also be used to describe teachers' readiness to change and the actual change process when this occurs. We think that this can be done for two reasons. First, the process of change and struggle for teachers bears the same characteristics as the process of - for instance - the overweight person who tries to follow a diet: denial can occur, the person may not know where to start, trial and error may occur, and so fortl. Second, the change processes of the overweight person and the teacher both result in improvement. The change process of the (sensible) overweight person results in improved eating habits. The change process of the teacher results in improved teaching behaviors. For instance, a teacher who learns to promote active, constructive, collaborative, and context-bound student learning is a better teacher than the teacher who only adheres to the traditionall transmission of knowledge. All in all, the TTMC appears to provide an excellent theoretical framework for the present exploration of the learning and change process mong particularly teachers who do not appear to initially show a will to learn.

\section{Cognitive intervention}

Prochaska, Velicer, Diclemente, and Fava (1988) developed two sets of psychotherapentic interventions in connection with the TTMC. The first set of interventions was largely experiential in nature. They focused on shifting the internal cognitive-affective responses of individuals mainly in the precontemplation, contemplation, and preparation phases of change. Such techniques as consciousness raising, dramatic relief, and environmental reevaluation were used. The second set of interventons was more behavioral in nature, that is, they aimed at the provision of the resources necessary for individuals to actually malke concrete changes un their lives. They were useful during mainly the action and mantenanee pliases of change but also - to a lesser extent - the earlier phases. Selfiberation, reinforcenent management, and stimulus control were among the techniques used.

Prochaska et al. (1988) found individuals in the precontemplation. contemplation, and preparation phases of change to benefit mostly from an experiential or cognitive intervention and this finding is of particular relevance for our investigation of teachers who do not appear to have a will to learn or change. Inspired by the originally interventions of Prochaska et al., we "translated" the interventions into more practical and acceptable interventions for teachers and further supplemented them with some insights on selfelficacy from the work of Bandura (1977). Bandura described self-effeacy as one"s "beliefs in one's capabilitics

3. With respect to the meatiog and measorement of the concept of teacher self-efficacy,

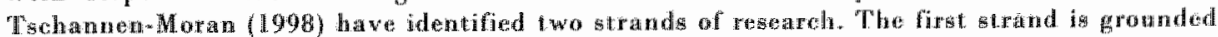
in Rotert's wort on Leens of Control (Rotter, 1966). The second sthand steme from somal 
to organise and execulte the courses of action required to produce given attainments" (p. 3). Teacher self-eficacy was relevant for the present study for two reasons. First, Dijlkstrid, Royackers, and De Vries (1998) have shown each of the readiness-to. change phases in the ${ }^{1} T M C$ to be aceompanied by a unique measure of perceived sulf-efficacy. Second, there is a growing body of data showing the selfefficacy judgments of teachers to be strongly related to their successful actuisition and use of new knowledge and skills (Ashton, 1984; Leithwood, Stembach, \& Jantzil, 2002; Steir \& Wang, 1988). More specifically, teachers with a strong sense of self-effeacy have been found to be more open to new ides and willing to experiment with new methods to better meet the needs of their students. Self-elficacy has also been found to affect the effort put into teaching, the goals that are set, and the resilience of teachers in the face of setbacks. On the basis of these findings, it is therefore assumed that those teachers who are 'eager to learn' or in the "action or maintenance phases" of the TTMC will typically have a strong sense of self-efficacy. Furthermore, those teachers in the equivallent of the "precontemplation, contemplation, or preparation phases" of the TTMC can be expected to benefit from interventions aimed at the modification of perceived self-efficacy as changes in their selfperceptions can be expected to lead more or less automatically to behavioral change.

In order to better understand how teachers and specifically those teachers who "do not see a need to learn" or "are wondering how to learn" can be nevertheless or further stimulated to learn, two different cognitive interventions will be applied. Within the eontext of the present study teachers were asked to experiment with cooperative learning in their classrooms. Cooperative learning fits the large-scale educational reform in which learning is conceived as an active, constructive, collaborative and context-bound activity. For the teachers who do "do not see a need to learn" the intervention aimed at modification of their thinking about cooperative learning, for the other group the intervention aimed at the strengthening of their self-efficacy by the provision of on-hands experience (see further). Both interventions meet the requirements of a new approach to in-service professional development. That is, traditional approaches focused on a top-down approach to disseminate knowledge in which teachers are provided with information and resources that they are expected to translate into action. In contrast, recent models omphasige the importance of teachers trying out new ideas, reflecting on outcomes, and co-constructing knowledge about teaching and learning in the context of authentic activities (for an elaboration, see Buthler, Lauscher, Jarvis-Selinger, \& Beckingham, 2004).

The following isswes with regard to teachers who are not willing to learn will When be considered: 1) the suitability of the TTMC to monitor these teachers' learming and change; 2 ) if and how the teachers' will to learn changed as a result of the two different cognitive interventions; and 3 ) the relations between teachers' will to learn and selfereflicacy.

\footnotetext{
loarning theory of Bandura (1997). The existence of these two separate but invertined

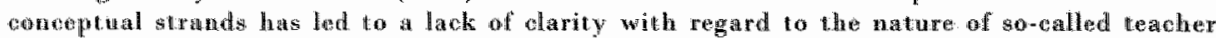

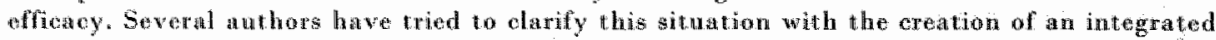
model (sea Tschannen-Moran at. al, 1990; Gbson Dembo, 1984j)). For the present study, the warte of Bumdura was drawn upon becanse we fomd his recommentations for how to strengthen

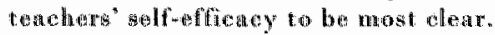




\section{Method}

The design of the present study was multiple case. A case study design was opted for" becanse we were interested in both of the types of proeesses deschbed by Reichardt and Cook (1979, p. 21): "The first meaning of process is monitoring: describing the context and population of the study, discovering the extent to which the treatnent or program has been implemented, providing immediate feedback of a formative type, and the like. The second meaning of process is causal explanation: discovering or confirming the process by which the treatment had the effect that it did". "The present study was intended to not only give a thick description' (Meniam, 1998) but also test several explanatory assumptions with regard to fostering teachers" will to learn. Given that we did not want to rely upon a single unit of analysis (i.e. one case) but replicate our results using multiple cases (Yin, 1993), it was decided to adopt a multiple-case design. Multiple cases can help specify the different conditions under which a theory may or may not hold and are, moreover, normally more powerful and convincing than single case designs (De Vaus, 2001).

\section{Research contert}

The present study was realized in three high schools located in the Netherlands. At the time of the study, the schools were implementing al new teaching curriculum requiring students to be more active, self-regulating, and cooperative in their learning. We chose managing cooperative forms of learning within the classroom as the central issue to be mastered by the participating teachers for two reasons. First, it can be easily be distinguished from other ways of learning. Second, teachers often find cooperative forms of learning difficult (some even nerve wrecking) and thus they might be not so willing to learn about them.

\section{Participants}

The methods of purposeful sampling (Patton, 1990) or criterion-based selection (Merriam, 1998) were used to select those cases that were "information rich." Information rich cases are those from which one can learn a great dual about issues of central importance to the purpose of one's research (Patton, 1990, p. 169). The selection of cases (i.e. participants) took place in two steps. First, those teachers judged by their prineipals as meeting the criteria for "do not see a need to learn" or "wondering how to learn" within the participaning schook were selected for indusion. Second, whether the teachers recommended for inclusion actually met the selection criteria was confinned in a verification interview with each of the teachers (see below).

The number of cases to include in a multiplecase stidy in largely a matter of judgment (Yin, 1989, p.57). Within the context of the present study, selection of the most informative cases for the testing of our propositions was considered more important than selection of a large number of cases. Of course, constraints of time, money, and access to relevant cases also played a rolle (De Vaus, 2001). Although we would have liked to sample until a point of saturation or redundancy was reached (Lincoln \& Guba, 1985), this was not possible within the time frame of the present study. "The sample size was initially set at eight teachers: four "who do not see the need to learn" and four "who were wondering how to learn." As might be expected in 
light of the types of teachers we were looking for aceral of the teachers invited to participate in the study "that deals with the best ways to help teachers master cooperative methods of teaching" declined to participate. Workload and a range of personglprofessional issues were typically cited as the reasons for declining. The first eight teachers recommended and willing to participate were invited for a werification interwiew. The interview results showed three of the leachers to indeed fit the ategror of "do not see a need while four teachers represented the category of wondkring how and one keacher proved eager to leam" as she was already Implementing cooperative forms of learning in her classroom. The latter teacher was therefore excluded from the participant group, which thus consisted of seven teachers in the end (see Table 1 ).

"ilallo 12: Summary of background characteristics for seven participating teachars

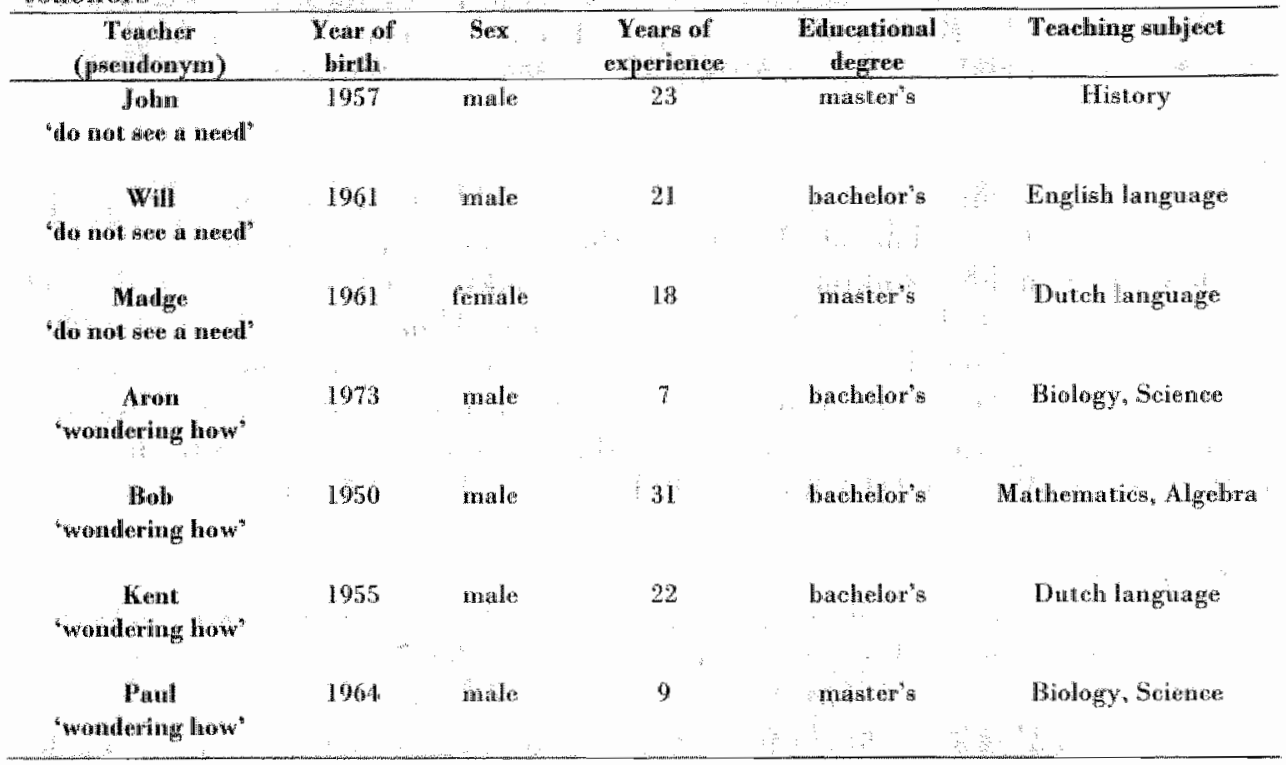

\section{Interventions}

Two tailot-made interventions were developed for purposes of the present study. One intervention was specifically designed to fit the characteristics of the "do not see the need to learn" teachers, the other to suit the "wondering how to learn" teachers. Bandura"s (1997) four sources of selfefficacy information were ased to design the two interventions developed for purposes of the present study. The four sources are: 1) enactive (mastery) experiences that serve as direct indicators of capabilities; 2) vicarious axperiences that alter efficacy beliefs by observing other people performing similar tasks; 3 ) verbal persuasion in which others can guide individuals to believe in their own capdibilities; and 4) psychological arousal that indicates one's valnerability to dyshonction. Research findings have further shown information gained via enactive mastery experienes to be most significant determimants of perceived selfefficacy (Bandura Adams, \& Beyer, 1977). 
The first intervention (designed for the "do not see a need to lean" teachers) intended to stimulate their perceptions and interpreations of cooperative learning. The teachers were placed in various situations to allow them to discower what cooperative learning might mean for them. Starting from several viourious experiences, the intervention carefulty progressed towards enactive experiences. Al three of the 'do not see a need to learn' teachers were individually involved in the interventiont in fact, two of them were participating as the sole participants in the present study from their sehool.

The first intervention was initiated with the watching of a wideotiped cooperative learning lessom. The teacher was asked to comment on what he or she saw, share lis or her thoughts, and discuss lis or her perceptions and interpretations of the videotape. Next, the teacher was asked to observe a cooperative lesson conducted by a colleague and to complete an observation form. Omee agan, a discussion of the participant's perceptions of the observed lesson ensued. Thereather, the participating teacher was asked to simply prepare a cooperative lesson. He or she chose the class and the manner. And if necessary, assistance was provided with the preparation. Finally, the teacher was asked to experiment with the prepared cooperative lesson in wo to three lessoms. "This was again followed by a discussion of the teacher's perceptions and interpretation of the lessens that were taught:

The second intervention (designed for the "wondering how to learn" group) differed from the intervention designed for the "do not see a need to learn' group on three fronts. First, the second intervention did not foeus on the teachers" perceptions and interpretations as much as the first intervention. The focus of the second intervention was more on practical questions regarding "how should I do this or that:" Just as for the first intervention, however, the second intervention also involved the teachers being placed in various situations in order to alllow them to discover the answers to theix cooperative learning questions more on less on their own. Second, this intervention involved a clear and immediate focus on the experience of cooperative learning itself (i.e., enactive mastery experiences). "The teachers were asked to undertake the preparation and conduct of cooperative lessons. Third this intervention had the participating teachers - who all worked at the same school wim. work in a group, which conld vary from two to four teachers. That is, the teachers were asked to learn cooperatively and thus experionce cooperative learning themselves in addition to teaching and helping their students leam cooperatively.

The second intervention was initiated with a preparatory meting. During the first half of this meeting, a videotaped cooperative learning lesson was watched and followed by extensive discussion and questions. When appropriate, so-called just-in-time brief definitions and examples of cooperative leaming were provided by the researchers. During the second half of the preparatory meeting, two teacher pairs were formed. Each pair of teachers was then asked to prepare two cooperative lessons to be presented by teacher $A$ in the first week and teacher $B$ in the second week. Thereafter, all lour teachers came rogether for reflection and a second preparatory meting, and the teaching and reflection cycle was then repeated in the following three weeks. 


\section{Data collection}

following Yin (1989), a multiple methods approach to data collection was adopted. Five instrmiments were used. I) a verification interview, 2) a self-efficacy questionnaire (one at the beginning and two at the end of the study), 3) observation followed by retrospective interview, 4) collection of emails sent by the participants and field notes made by the researchers during intervention period, and 5) a closing interview. Data collection occurred parallel to the intervention and spanned a tenweek period, as indicated in Table 13.

Table 13: Summary of data collection and interwention

\begin{tabular}{|c|c|c|c|}
\hline $\begin{array}{l}\text { Weets } \\
\text { manduri: }\end{array}$ & 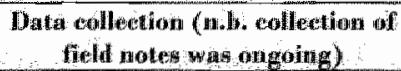 & $\begin{array}{l}\text { Motervention "do mot see the } \\
\text { necdl wo learn" }\end{array}$ & $\begin{array}{l}\text { Intervention "wondering } \\
\text { how to learn? }\end{array}$ \\
\hline L. (TI) & 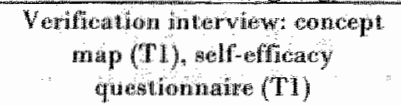 & & \\
\hline 2 & . & Wew videotaped lesson & Preparation mesting \\
\hline Fi & $\begin{array}{l}\text { Ciststroory obgervation and } \\
\text { rettospective interview }\end{array}$ & Observe colleague & $\begin{array}{l}\text { Exprominemall lesson, } \\
\text { partmer observes }\end{array}$ \\
\hline$\vdots$ & $x^{2}=$ & & \\
\hline 4 & $\begin{array}{l}\text { Classroom observathon and } \\
\text { retrospective thiterview }\end{array}$ & Reflection on observed lesson & $\begin{array}{c}\text { Obserwation of partner" } \\
\text { experimental lesson }\end{array}$ \\
\hline 5 & $\begin{array}{l}\text { Classroom wbservation and } \\
\text { retrospective interviex. }\end{array}$ & Preparation of a losen & $\begin{array}{c}\text { Reflection and preparation } \\
\text { medting }\end{array}$ \\
\hline 6 & $\therefore$ & Experimental lesen & $\begin{array}{l}\text { Experimental lesson, } \\
\text { partner observes }\end{array}$ \\
\hline 7 & $\vdots$ & $\begin{array}{l}\text { Reflection on experimental } \\
\qquad \| \text { wsison }\end{array}$ & $\begin{array}{l}\text { Observation of partner's } \\
\text { expertimental lesson }\end{array}$ \\
\hline 8 & $\therefore$ & $\therefore$ & $\begin{array}{c}\text { Reflection and prepatuation } \\
\text { meteting }\end{array}$ \\
\hline$(12)$ & 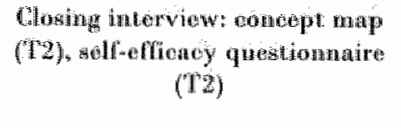 & $\therefore:$ & औ \\
\hline an (ns) & 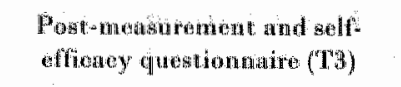 & & \\
\hline
\end{tabular}

The verification interviaw was conducted with all of the teachers prior to any other data collection (TI). At the beginning of the interview, the participant was asked to create a concept map or graphic representation of his or her understanding of cooperative learning in the classroom. The merits of using concepts maps to explore teacher leaming have been demonstrated in several studies (Meijer, Zanting o Verloop, 2002, Winitzy \& Kavchak, 1995; Zanting, Verloop, \& Vermunt, 2003). The remainder of the interview was devoted to explanation of the concept map. It focused on teachers" knowledge of cooperative learning as deseribed in the concept map and their willingness as such to put it into practice. 
At the end of the interview, the participants completed the Self-efocncy questionnain developed by Evers, Bromwers, and Tomic (2002). Given that selfefficacy beliefs are always linked to a particular domain of activity, two particularly impontant domains for the new teaching paradign were examined. The first domain was cooperative working' ( 7 items); the second domain was 'working independently' (3 items). The self-efficacy items were rated along a six-point Likert scale ranging from 'totally disagree' to 'completely agree". Reliability analyses as performed by Ivers et al. indicated Cronbach's alphas of .80 for selfefficacy beliefs related to cooperative working and 68 for self-efficacy beliefs related to working independently.

During the intervention period, thee to four sucessive hours of observation. at a time were logged for each teacher. These observations included per teacher both experimental and "regular' lessons. Detailed field notes on the teachers" actions and dialogues were collected during the observations. At the end of each observation period, a retrospective interview was undertaken. The teacher and researcher reviewed the events that ocenred during the observation to determine whether the teacher had learned from them or not.

During the intervention period, the teachers were also asked to respond to several emails sent to them by the researchers in order to monitor their learning process. Such questions as the following were posed in the emails: "Did you work in groups this week?" "If not, why not?" "Do you need assistance?" "What might be hellpful for you?" "If you did work in groups, can you describe the process?" "What was the result?" "Did you make any resolutions for the next time?" Additional field nofes were made during the meetings with the teachers, and teachers" experimental lesson plans and completed observation forms were collected.

During a semi-structured closing interview (T2), the teacher and researeher reflected upon the intervention pexiod. At the beginning of the closing interview, the teacher was asked to again create a concept map of his or her understanding of cooperative learning in the dassroom. The teacher was then shown his ot her first concept map, and any differences between the first and second concept maps were discussed. Thereafter, the treachers were again asked to complete the self-efficacy questionnaire. If there were any noteworthy differences in the scores produced by the wacher upon furst versus second administration of the self-efficacy questionnaire, these were discussed. Finally, the TTMC was explained to the teacher and he or she was asked to describe his of her change process during the period of intervention in terms of the phases of the TIMC. The teachers were asked about who or what contributed to the change process (or not) and also their future plans with regard to cooperative learning in the classroom.

Two months after the closure of the intervention period, which was just before the end of the school year, post-medsurement was undertaken via email (T3). Each teacher was asked about any cooperative activities after the intervention period and his or her cooperative learming plans for the coming school year. In addition, the teachers were asked to complete the self-effecacy questionnaire for a third time.

In sum, all of the interviews werte audiotaped and transcribed verbatim. Two concept maps - before and after intervention - were available for each participant. Self-efficacy ratings before interwention, immediately after intervention, and two months later were available for all the teachers. Descriptive field notes from 
atascoon olsservatwing of the texchers, additional notes regarding the interactions during the interwention meetings, and the emalled answers to guestions posed by the researchers during intervention were also all a vailable.

\section{Data analysis}

Following Miles and Huberman (1994), data analysis was conduced in three discrete steps. For the frst two steps, the indwidual participant constituted the wnit of analysis. For mensure within-axe analysis, the transcripts of the interviews were frist divided into text framents and coded with regard to a number of concepts of particalar relewance for the present study ( $e . g$. different aspects of teacher's will to learn, teacher's beliefs about cooperative working, teacher's beliefs about pupil learning in general, teacher's self-effcacy, etc.). The coded fragments of text were then transfered herally to a case outline" for each teacher. That is, fragments of text refering to similar concepts were positioned next to each other to create a case ontline for each teacher.

In the second analytic step, the case outlines for the seven teachers were summarized within a large conceptually-chustered matrix (Miles \& Huberman, 1994, p.127). The descriptive validity of the conceptually-clustered matrix was ensured via actual discassion of the different concept maps during the clesing interviews with the teachers (i.c., member checks; aee Merriam, 1998). That is, each teacher was asked to analyze the differences between the two concept maps created by him or her and invited to discuss whether they had developed along the phases of the TTMC or not. This information was transeribed and later entered into the ease outlines and, thereafter" the conceptually-clustered matrix. The descriptive validity of the conceptually-clustered matrix was further established by having a committee of experts from the field check whether the seven case outlines were correctly summarized and represented within the matrix or not.

The third step in the analyses involved cross-case comparison. That is, the conceptually-chstered matrix was corrected, if necessary, and then taken as the starting point for a constant comparative analysis (Glaser \& Strauss, 1967). Common palterns or processes that recur across the different cases are sought. Preliminary descriptions of the observed patterns or processes are then developed. iteratively diecked against all the data, and nodified as necessary.

\section{Results}

In Table 14, the change process for the different teachers is outlined from the beginning of the intervention (TI), to the end of the intervention ( $\mathrm{T} 2$ ), and finally two monthe after completion of the intervention (T3). The data show all of the teachers with the exeption of John to move at least one phase forward with regard to their willinghess to learn by the end of the intervention period. Two months after the intervention period, however, three of the weachers were found to have regressed somewhat. 
Table 14: Summary of change progress dwing and after the intervention period

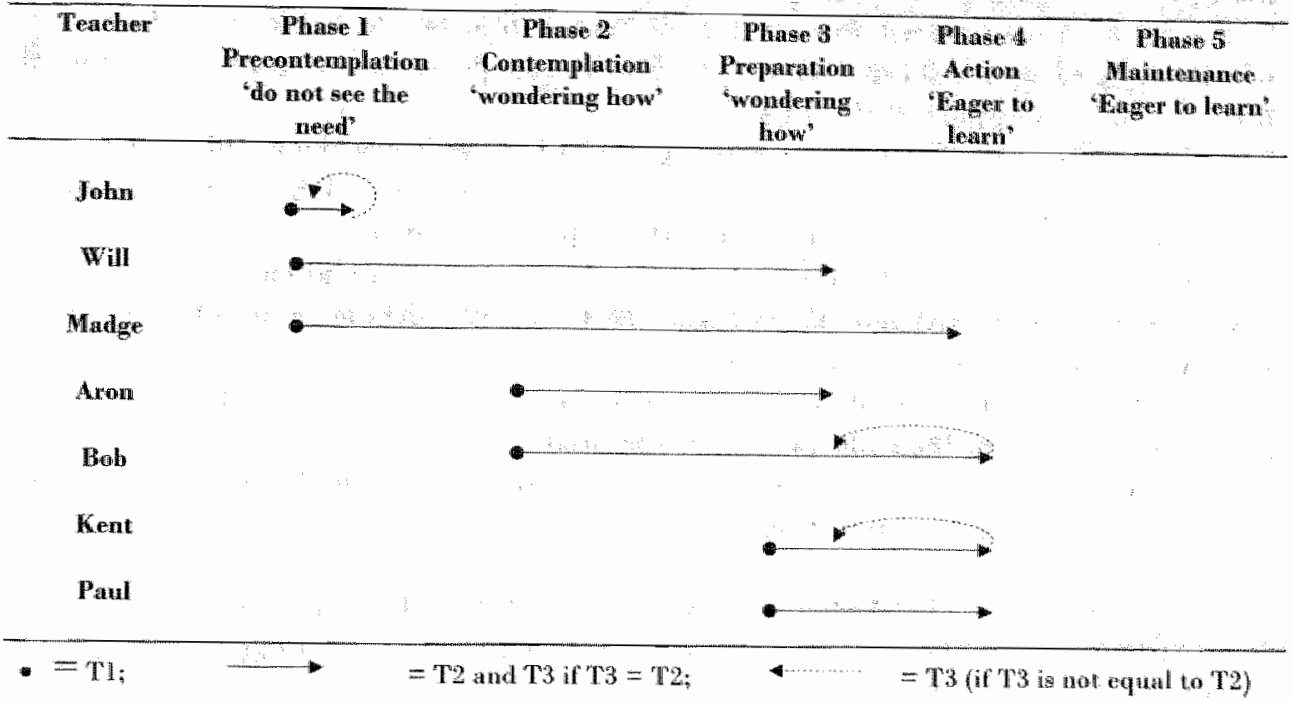

In the following, the change process for each of the teachers individually will be briefly described. Thereafter, the smilarities and differences in the observed patterns of change will be considered along with a discussion of the observed similarities and differences.

\section{Brief description of change process for each teacher}

John. Right from the beginning (TI), John's views on the new manner of learning were very clear: "It just does not work that way. I have watehed twenty years of educational change already and cooperative learning is just another change. Let other teachers do it in their lessons. It makes me redundant, and the students don"t like it". "John did not feel a need to change as he considered himself to be doing a good job of teaching and dealing with students. John made it very clear that his (vocational education) students were not sufficiently talented to work cooperanively. In addition, he considered working cooperatively too time consuming.

At T2, Joln clearly stated that he had started in TTMC phase one [precontemplation]" and was "still in phase one". He nevertheless found that he had progressed slightly within this phase: "I realize now that I ased to work more in pairs and that I could do this more often now."

Two months after completion of the intervention ( $T$ ), John reported not having put this into practice. He wrote: "My students score fairly well on their final exams and I think I'm doing a fine job. so why should I change something that works?"

Will. At the start of the project (T1), Will found it diffichlt to visualize just what cooperative learning could mean for his classroom practices. "unitially. my view on cooperative learning was vague and not very positive. I wondered about the results it could produce. I did not want to work in sach a manuer and would only do 
so if If really had to "During the intervention period, Will found it difficult to manage the regular classtoom process: especially changing from one part of the lesson to another created unrest. He pereerved himself as being only hall way towards a good rolationship witll his classes. And he positioned himself in the initial precontemplation phase of the TTMC.

At the end of the intervention period (T2), Will positioned himself at the end of the (third) preparation phase. He had a clear picture of what he wanted to work on: "Now, I have experimented with cooperative learning and talked about it with ny colleagues. I think that both the teacher and the student can benefit from a changing role for the teacher. There are several ways of working cooperatively that I want to test and evaluate in the future."

At T3, Will reported not working cooperatively during the past two months. Nevertheless, he and his colleagues had prepared several cooperative lessons for the coming year. Will was thus planning to work cooperatively in the near future and therefore in the (third) preparation phase at follow-up as well.

Madge. At T1, Madge mostly mentioned the disadvantages of working cooperatively. Har biggest concern was the benefits that working cooperatively would yield in light of the extra time costs.

During the intervention, Madge noticed that she and the students unexpectedly liked cooperative leaining. She also saw the test results for her class to be better than those for other classes that did not work in a cooperative manner very frequently. At T2, Madge thas positioned herself in the (fourth) action phase of the TTMC. She knew for sure that she was going to continue to work with cooperative learning. This is quite remarkable as she was still convinced that the traditional transmission of knowledge was the most efficient manner of working (time-wise). She thus construed cooperative manners of learning as something extra - something one can do when the regular program has been completed.

At T3, Madge reported that she had continued to work with cooperative manners of teaching and clearly planned to continue doing so. She wrote: "I plan to continue with it twice a week. I have seen that it works and that I like working this way".

Aron. At Pil, Aron had mixed feethigs about cooperative learning and positioned himself in the (second) contemplation phase of the TTMC. As a science teacher, he frequently had his students work in pairs on lab projects. Working in groups of nore than two was "missing the obvious' in his opinion. Aron thought that: lower-level wocational students might benefit from cooperative manners of learning but not ligher-level students. With regard to the first group, he was also interested in learning more about several manners of cooperative learning. With regard to the second group, he said he had so much material to impart that cooperative learning methods would simply cost too much time; knowledge transmission was quicker.

During the intervention period, Aron experimented with different mamners of cooperative learning, noticed that he liked having the students work cooperatively, and also found the cooperative methods to offer several advantages. He intended to continue working cooperatively after the intervention period. When initially placed in the (fourth) action phase of the TTMC at T2, however, Aron 
disagreed with the researchers. In his view, preparation phase three nore accurately reflected his will to learn. Aecording to Aron, he was working with cooperative mamers of teaching bot only because of his involvement in the present study. And although he had experienced and noted several of the henefits of cooperative learming, he really wondered whether he would continue working cooperativelly after completion of the intervention. "I know, now, that lim able to do it. But not doing it is easier".

Aron's forecast came true. Two months after the intervention period, he reported rarely working with cooperative learning due to a lack of time. He mevertheless planned to conduet at least $10 \%$ of his lessons in cooperative mamer during the coming schoolyear. At T3, thus, Aron remained in the (third) preparation phase of the TTMC.

Bob. Bob did not have many opinions about cooperative learning prior to the intervention (T1). He reported "doing nothing about it although he probably

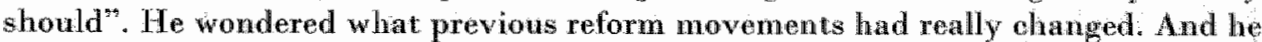
wondered whether the current reforms would work for vocational-education students. Bob was thas placed in the (second) contemplation phase of the TTMC.

By the end of the intervention (12), Bob was very enthusiastic about cooperative learning. The method clearly suited his mannes of working, with students learning according to the principles of self-discovery. "I can observe the students doing their work better mow." And instead of the small experimental lesson required as part of the intervention. Bob cooperatively worked through an entire math chapter during the intervention period. He noticed that the methods worked very well and even with classes that are known to be difficult to teach in general. Bob concluded that cooperative manners of working were not only good for students - and especially students in vocation education - but also for teachers as well. Bob was thus placed in the (fourth) action phase of the TYTMC at T2.

At $T 3$, Bob reported "other things having greater priority" and no continued cooperative learning as a result: He did however, planned to continue with it in the following school year. At T3, thus, Bob regressed slightly from the (fourth) action phase of the TTMC to the (third) preparation phase.

Kent. At $\mathrm{T} 1$, Kent was already convineed of the ad wantages of cooperative learning. He considered himsell too "traditional" as a teacher and wanted to become more of a "coaching' teacher. And he figured that cooperative learning could help him do that. Kent had not attempted to put his plans into practice prior to involvement in the present study because he "did not know how", had to be sure that "the students would not be harmed", had "too many students in al class" or "didn't want things to get out of hand in the classroom'. Kent was thus classified as in the (third) preparation phase of the TTMC at TI.

During the intervention period, Kent appeared to find it difficult to create and design cooperative manners of working. Positive experiences during the intervention and the fact that Kent planined to continue working with cooperative learning methods in the futare led him to place himself in the (fourth) action phase of the TTMC at T2. 
At T3. however, Kent reported having only worked coopieratively on one occasion after completion of the jinteryention. He still planmed to work cooperatively at least once month during the commg school year or when the textbook would allow this and therefore classiffed himself as being back in the (third) preparation phase of the TrMMC at T\%.

Paul. At M1. Paul reported already having concrete plans for cooperative leaning. In His wew, cooperatwe leaming methods could yeld bigger "eognitive" effects than tradional teaching nethods. When asked about the types of roles he planned to use in his gromp work, his imnediate response based on curiosity and at clear will to learn was: "Roles? What do you mean? What kinds of roles exist?". Paul was thus categorized as in the (third) preparation phase of the TTMC at TI.

At 12, Paul noticed that cooperative methods of working did not immediately bring the effects initully aned for. Not only did his students need time to get aceustomed to working cooperatively, he did too. During the intervention period, Pawl appeared to have dilficulties relating positively to his students. The ase of cooperatwe learning methods appeared to help sonewhat but not enough to solve the problem. Paul reported having even more questions at the end of the intervention that at the start but remaned eager to search for suitable answers and dearly planned to continue working cooperatively in at least one of his classes. Paol is thus classified as being in the (fourth) action phase of the TTMC at T2.

At T3, Paul reported that he has indeed continued to work cooperatively for the remained of the school year. "The class was keeping up well with it, next year $I$ will continue:" Panl thus remained classified as being in the (fourth) action phase of the TTMC at T3.

\section{Similarines and differences in observed patterns of change}

Inspection of the different patterns of change for the seven teachers involved in the present study produced a number of different insights. To start with the study provided greater insight into particularly the position of those teachers who "do not see a need to learn." John was the only teacher who did not ehange either during or wfror the intervention. Allhongh John is an exception when compared to the other toachers, he nevertheless represents a broader group of teachers and, allong these lines, so-called "immotives" are often distinguished from "precontemplators" in the smoking cessation literature. Immotives are smokers who are planning newer to puit or not to quit within the next five years (Dijkstra et al., 1998) and thus thought to be "stuck". "Precontemplators," in contrast, are thought to be "well on their way" to the actual contemplation of whinge. And although John was categronzed as a "precontemplator" at the beginming this study, we would now consider him an "inmotive."

With regard to the first objective underlying the present study, the TTMC expanded with the immotive phase of change (or non-change) - appears to be quite useful for the description and analysis of teacher learming and change. For instance, both the teachers. Will and Arom placed themselves in the preparation phase at T2 and reported not being sure that they would continue to work cooperatively in the future. At T3, both teachers were still in the same phase, which shows the participating teachers to be quite accurate and straightforward in their prediction of 
future change and behavior (with the teachers Kent and Bob constituting exeeptions to this pattern). This finding is in keeping with a pervasive finding within the smoking cessation literature, namely that self-reported readiness to change is a strong predictor of actual quitting behavior (Dijkstra et al., 1998).

With regard to the second objective of the present study, the results presented in Table 14 show the willingness of all the teachers with the exeeption of John to increase from T1 to T2. The results for those teachers who were already "wondering how to leam" show collaborative initiatives (e.g. the second intervention) to be suitable to promote the professional development of teachers who are "wondering how to leam". Two of the three teachers who initially "do not see the a need to learn" demonstrated major changes in their willingness to learn as a result of the first individualized intervention.

A number of factors appear to explain the progression of those teachers who were initially not very eager to learn into the next phase of the TTMC during the intervention period. As in previous studies (Van Eekelen et al, in press; Kwakman. 2003), the participating teachers provided a variety of explanations. In general, however, the following aspects of the interventions were mentioned as being particularly helpful: 1) help with the translation of such vague and abstract terms as "active" and "cooperative" into concrete and practical lessons; 2) stimulation of selfexperimentation and thereby seeng that something actually works, how it works, and thus self-discovery; and 3) stimulation of the observation of each other's lessons.

The results in Table 3 also show the growth in the willingness of the teachers to learn during the intervention period to not always be sustained. Three teachers actually regressed, and two teachers (i.e., Will and Aron) did not continue to wse the cooperative methods employed during the intervention period and thus remained in the preparation phase of change. According to the teacher Aron, some teachers may depend too much on the individuals (e.g. researehers, trainers or consultants) providing the intervention and therefore fail to self-regulate their learning. This phenomenon was also reported by Butler et al (2004) in their study on teacher developments. And although most of the participating teachers onlarged their willingness to teach in a more cooperative manner, this does not necessarily mean that they changed their practices or their beliefs (Pajares, 1993). Fon instance, Madge and Aron were both found to entertain contradictory beliefs at the end of the intervention period (T2). It is certainly possible that these teachers are in a state of cognitive conflict and indeed need to reorganize some existing ideas to fit with new data (Piaget, 1975). Such cognitive conflict may constitute the first step in a learning process but not be sufficiently powerful to produce a major conceptual change (Limón. 2001). The disequilbrium may be too frightening: there may be insufficient verbal interaction or social support; and the existing social structure may simply permit passive as opposed to more active compliance (Palinscar, 1998). Nevertheless, the teacher experiencing cognitive conflict has come a long way allong the willingness-to-learn continumm, and the same can be said about those teachers who regressed after completion of the intervention as they, too, have at least experienced what cooperative learning is all about.

With regard to the third objective of the present study, it was assumed that any growth in the teachers" willingness to learn could be explained at least in part by changes in their self-efficacy. The results in Table 4 show small but generally 
consistent girow in the teachers" self-eficacy from both TI to T2 and T1 wo T3. The numbers andicating the differences in scores between two different points in time on a six-point scale.

For six of the seven teachers, self-efficacy in the domain of 'cooperative working" (CO W) consilstently increased from T1 to "T2 and Tl to T3. That the selfefficsty of he seventh teacher (i.e., John) remained the same is in keping with his "immotive" state. Six of the seven teachers also progressed at least one phase further in terns of the TTMC and thus showed clear increases in their willingness to change (see Table 3). And five of the teachers showed sustained increases in their selfeffictw and at least one phase of progress in their willingness to change between "T1 and T3. Thus pattern of growth in both self-efficacy and willingness to learn suggests a relation between self-efficacy and willingness to learn. However, after the interwention period (i.e., between $\mathrm{T} 2$ and $\mathrm{T} 3$ ), the changes in selfefficacy and willingness to learn show a very diffuse pattern. The self-efficacy scores for one of the aforementioned six teachers can be seen to remain the same while his willingmess to change declines (see Bob). The self-efficacy scores for two other teachers can be seen to dechne while only one of them regresses with regard to willingness to change (see Will and Kent). And the selfefficacy for the three remaining teachers inereases shghtly while they remain in the same TTMC phase of willingness to change (see Madge, Aron, and Paul). In other words, the expected relation between self-efficacy and will to learn is detected on some but not all occasions within the present study.

The data with regard to "working independently" (WI) also show the selfefficacy of most of the teachers in this domain to increase from T1 and T3. This finding surprised us as our intervention was not specifically aimed at this domain of functioning and self-efficacy is generally assumed to be domain specific. When we asked the teachers about an explanation, however, Kent mentioned the following: "An explanation could be that I feel more secure in general now. I feell better in general and that is noticeable for al aspects of teaching." 
Table 15: Growth in teachers self-efficaty wh respeet to "cooperative working" (COW) and "working independently" (Wi)

\begin{tabular}{ccccccc}
\hline Teachers & T1 & T2 & T3 & T-T2 & T2-T3 & T-TI \\
\hline John (Co W) & 2.9 & 2.9 & 2.9 & 0.0 & 0.0 & 0.0 \\
(WI) & 3.7 & 3.7 & 4.0 & 0.0 & 0.3 & 0.3 \\
Will (Co W) & 2.3 & 3.6 & 3.3 & 1.3 & .3 & 1.0 \\
(WI) & 3.7 & 4.3 & 4.0 & 0.7 & -0.3 & 0.3 \\
Madge (Co W) & 4.1 & 4.3 & 4.7 & 0.1 & 0.4 & 0.6 \\
(WI) & 4.0 & 5.0 & 4.8 & 1.0 & -0.2 & 0.8 \\
Aron (Co W) & 4.3 & 4.4 & 4.6 & 0.1 & 0.1 & 0.3 \\
(WI) & 5.3 & 6.0 & 5.3 & 0.7 & -0.7 & 0.0 \\
Bob (Co W) & 4.0 & 5.0 & 5.1 & 1.0 & 0.0 & 0.7 \\
(WI) & 4.7 & 5.3 & 5.3 & 0.7 & 0.1 & 1.1 \\
Kent (Co W) & 3.3 & 4.3 & 4.0 & 1.0 & -0.3 & 0.7 \\
(WI) & 4.0 & 5.3 & 5.3 & 1.3 & 0.0 & 1.3 \\
Pand (Co W) & 3.3 & 3.6 & 3.7 & 0.3 & 0.1 & 0.4 \\
(WI) & 4.7 & 5.0 & 5.3 & 0.3 & -0.7 & -0.3 \\
\hline
\end{tabular}

\section{Conclusion}

The focas of the present study was on teachers who are not very willing to learn and whether they can be stmulated to learn or not. On the basis of the results of the multiple cases studied here, we argue that the teiacher learning and change process encompasses more stages than the change models reviewed in the Introduction where the TTMC (Prochaska et al., 1992) was also examined in considerable detail. A new Teacher Willingness to Learn Model is proposed to account for the first objective of this study (see next section).

With regard to the second objective to this study, two interventions were used to stimulate teachers" will to learn within the present study: an indidual approach and a collaborative approach. The individual approach involving sinaply thinking about a change to start with was found to be effective for two of the three teachers who initially "did not se a need to learn. The collaborative approach was found to be affective for those teaclvers who were initially "wondering how to learn." The relapse observed within the present study demonstrates the need for cominuous and high quality guidance of the professional development of teachers. 
And finally, the oppeted relations between solf-effeacy and teachers" will to leam (sudy objective three) were detected but not on all oecasions. Partially, the results indicate arclation betwen growth in selfeffrcacy and an increase in the willingness to learn (indicated by a progression in phases in terms of the TTMC).

\section{Tieacher Wullingness to Learn Model}

The new Teacher Willingess to Learn Model includes a zero or immotive stage of willingness to leam in addition to the five stages of change from the TTMC.

Thale 16. The new Teacher Willingness to Learn Model

\begin{tabular}{|c|c|c|c|c|c|}
\hline Phase 0 & Phase 1 & Phase 2 & Phase 3 & Phase 4 & Pliase 5 \\
\hline Inmotion & Precontemplation & Contemplation & Preparation & Action & Maintenance \\
\hline
\end{tabular}

A 'zoro' or so-called immotive stage is needed to characterize such teachers as John who is simply not willing to modify his teaching practices within the next few years. Such teachers are convinced that their manmer of teaching is best and often appear to be "stuck" in old habits. A zero stage of change is thus called for by not only the present data but also data from the field of addiction research showing an immotive or zero stage of change to clearly exist (Dijkstra et al., 1998).

After the zero stage in the Teacher Willingness to Learn Model comes the stage of precontemplation. The teachers in this stage are not really interested in learning about change or acquiring new information on a specific topic. It is not that they cannot see the solution, they cannot see the problem (Prochaska et al., 1992). Failare to recognize the problem and resistance to the modification of problems are also hallmarks of this precontemplation stage. Although the statements of these teachers resemble those of immotive teachers in phase zero, precontemplative teachers differ in that they are on their way to change (instead of being stuck). When challenged or coached appropriately these teachers will move to a next stage, the immotive teachers will not. Selective perception and an external locus of control can maintain such denial or resistance for an extended period of time, and such wachers may therefore benelit from the use of such consciomsness raising techniques as observation, confrontation with information that counters existing beliefs, and insight into the negative consequences of current behavior for themselves and/or others.

The second stage in the Teacher Willingness to Learn Model is that of contemplation. In this stage, teachers recognize that their classroom activities are in nexd of improvement or change, but they do not yet commit themselves to such hange. In lact, the perception of one's practices as problematic and/or recognition of the existence of new challenges may constitute a necessary but not sufficient prerequisite for change (Wood \& Bennet, 2000). We say "necessary but not sufficient." because the teacher may simply fail to adapt despite current cognitive conflict (Piaget, 1975): the teacher may lack sufficient selfefficacy to initiate the change process; or the teacher may simply not know how to change his or her current practices. The plans of the teacher in this contemplation stage can thus remain rather vague for a rather extended period of time, and such teachers may 
therefore benefit from the demonstration of new behaviors and experimentation with new behaviors.

The third and next stage in the Teacher Willinginess to Learn Model is the stage of preparation or decision. Teachers in this stage realize that they really should change and plan to do this in the nearby future (i.e. within a month). Sone may search for new information and ask for tips or advice. Others may rellect nore systematically on their own classroom practices. And some may spontaneousb? experiment with new behaviors on a small scale. In the end, the decision to ohange one"s classroom practices may be made. However, this decision does not imply actual initiation of the change process as external circumstances may lead teachers to wait for the "right" moment. Teachers in the preparation stage may therefore benefit from the receipt of specific answers to their questions and the making of specitic agreements with principals or advisons with respect to how and when to start.

The fourth stage in the Teacher Willingness to Learn Model is the action stage. In this stage, the teacher becomes involved in a continuous learning process with experimentation, reflection, and further action. Such action need not lead to definite changes in teacher attitudes, beliefs, or practices (i.e, actual teacher learning) because beliefs tend to be self-perpetuating and to persist despite the presence of contradictory information (Pajares, 1993). Teachers in the action stage of willingmess to learn may thus benefit from environmental encouragement of their plans in the form ofl sufficient time to prepare, classrooms sizes that fit their plans and continuous coaching.

Finally, when a teacher is able to maintain a new behavior for at least six months, he or she has reached the fitth stage of the Teacher Willingmess to Learm Model: the maintenance stage. The teacher has actually changed his attitudes, behavior, and beliefs and is actively working to consolidate and further explore the changes that have been made. The teacher is also able to self-regulate his or her own leaming process.

The new Teacher Willingness to Learn model outlined above may be incorrectly taken to imply three things. First, it may be incorrectly taken to suggest that teachers only start to learn or change in the fourth or action stage. In our view, every transition to a new stage implies some change of atituds, beliefs, and/or behavior - no matter how slight - and thus learning (see delinition of 'learning" in the Introduction).

Second, the Teacher Willingness to Learn model nay also be incorrectly taken to suggest that teacher learning and change is a one-watinear process. $A$ s the literature on smoking cessation indicates (Prochaska ot al., 1992). however, most people relapse at some point during a change process (see, for instance, the teachers Jolnn, Bob, and Kent from the present research). Several rounds of progression and regression - to perhaps a previous stage - are needed to reach the final stage, and some people may never reach this stage. The new Teacher Willingness to Learn model should be viewed as a spiral. Individuals do not move endlessly in circles. And relapse does not mean regression back to the beginning. Relapse, rather, allows one to leam from one's mistakes and to try something different (Diclemente et al., 1991).

Finally, the Teacher Willingness to Learn model may be incorrectly taken to suggest that the will to learn is general as opposed to domain specific. Just anself- 
efficacy, a teacher will to learn is domain specific. And the focas of the present study was on teachers" will to learn within the domain of cooperative working. Madge was considered only a precontemplator within the domain of cooperative learning but an eager learner with the domain of philosophy as she was working on her Master" in this field. Aron was considered a contemplator within the domain of cooperative learning, but performed in the maintenamce phase with regard to the use of Information Technology during the lessons. That is, a teacher"s will to learn can be very domain speafic:

\section{Discussion}

In closing, we would tike to call for more research to verify the proposed Teacher Willingness to Learn nodel. An issue of some concern within the present study but possibly of major concern in futurestudies is the identification of reliable criteria to determine when a teacher has truly learned. In the smoking cessation literature, this is easy: A smoker who has totally quit snoking has clearly reached the action stage of change. But when, exacty, has a teacher confronted with a need to change reached tho action stage of change and thus learned? Another issue of concern is that the Teachers Willingness to Jearn model is not a typical deterministic (and thus rigid) model in which one factor may be altered to add another stage or phase in the teachers development, instead it resembles a more liexible approach in which a number of factors affect either the movement from one stage to another or the acquisition of another phase. These factors include for instance experience, (selfefficacy) beliefs and abilities. Future research should nevertheless provide more clarity in the boundaries that distinguish one phase from another. For instance, the boundaries between the group of immotive teachers and precontemplators need a refinement in order to distinguish these groups more easily. Future research is also necessary to investigate the observed relations between self-efficacy and teachers' will to learn on a larger scale. It should take the recent discussion of alternative paradigms for research into teacher efficacy into consideration (see Labone, 2004). The research into the construct of teacher efficacy has been dominated by corrolational studies, altemative research paradigms are suggested to redress this imbalance. Finally, future research should take into account the challenges formulated by Butler al. (2004). In their study to teachers" development they also observed the phenomenon that the participating teachers became too dependent on researchers for maintaining instructional changes. They recommended ( $p .453$ ): a) avoiding dependence on "outsiders" for sustaining an innovation; b) fostering developmont of self-sustaining communities of practices within schools, rather than a tenporary" program.

To conclude, the proposed Teacher Willingness to Learn model distinguishes itself from most other teacher development models with the inchsion of "readimess to learn" and particularly "not so willing to learn" stages. And in such a manner, the model provides not only a more realistic view of the teacher change and development process but also a more nuance perspective on teacher learning and change as teachers are no longer classified as "resistant," but in terms of their willingness-to-learn stage. From a theoretical perspective this study has therefore 
provide a new perspective on phase theory in teacher learning and change processes. These phases may be viewed as benchmarks in assessing learning, change or sohool development processes and thereby provide researchers and reformers with valuable information about the progress in these processes. From a practical perspective, the different stages in the Teacher Willingness to Learn model can be used by principals to discuss teachers' intentions with regard to various developments within the field of teaching. In keeping with Barnett and McCromick (2004), we recommend the principals to recognize the needs and concerns of the individual teacher with regard to these developments and start from there.

\section{References}

Ashton, P. (1984). Teacher -efficacy: A motivational paradigin for effective teacher education. Journal of Tecocher Education, 35(5), 28-32,

Bandura, A. (1997). Self-efficacy: The exercise of control. New York: Fremati.

Bandura, A. Adams, N. E., Beyer, J. (1977). Cognitive processes mediating bohavionral change. Jourmal of Personality and Social Psychology, $35,125-139$.

Barnet, K.. \& McConnick, J. (2004). Leadership and mdividual principal-teacher wationships in schools. Educational Administration Ouarterly, 40(3), 406.434.

Billett, S. (2002). Toward a workplace pedagogy: guid ance participation and angagenout. Adult Edacation, Qharterly, 53(1), 27.43.

Buthler, D. L.., Lauscher, H. N., Jarvis-Selinger, $5_{* 4}$ \& Beckingham, B. (2004), Cwllaborations and self-regulation in teachers' professional development. Teaching and Teacher Education, $20,435 \times 455$.

De Vaus, D. A. (2001). Research Design in Socind Researdh. London: Sage.

DiClemente, C. C., Prochaska, J. O, Fairharst, S. K., Velicer, W. F Velasque, M. M.,

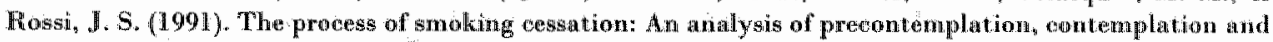
preparation stages of change. Joumal of Chinical Psychology, 59, 295-304.

Dijkstra, A., Royackers, J., \& De Wries, H. (1998). Smokers in four stages of readimess to change. Adictive Bahatiors, $23,339-350$.

Evarns, $L_{2}$ (2000). The effect of educational change on morale, job satisfaction and motruation. Moumat of Educational Change, $1,173-192$.

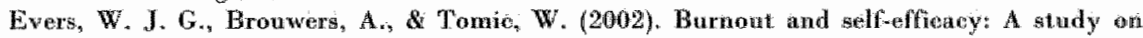
heachers' beliefs whem impllementing an innovative ducational system in the Netherlands. Brifish Jourwal of Educational Psychology, 72(227-243).

Fenetormacher, 6. D. (1994). The knower and the knowm: The nature of knowledge and

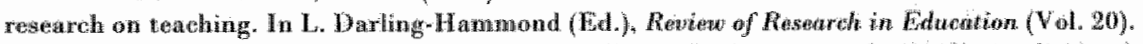

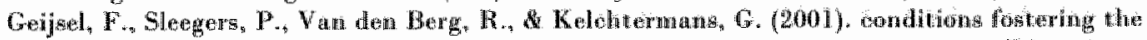

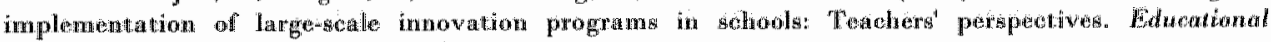
Administration Quarterty, 37(1), 130-166:

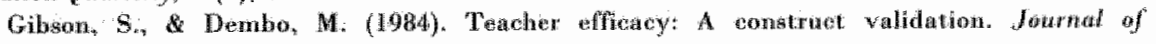
Educational Psyeliology, 76(4), 569-548.

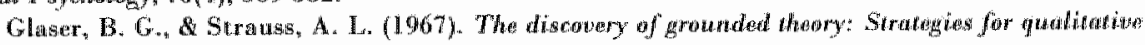
research. Chicaig Allithe.

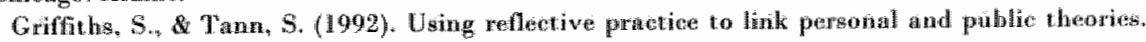
Journal of Education for Teaching, IO(1), 69-84.

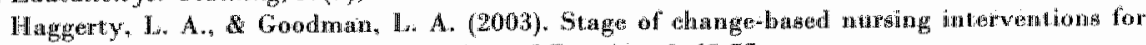
victimg of interpersonal wiolences Jognn, Principles and Practices, $1,68-75$.

Hall, G. E, \& lownks, S. (1977). A developmental model for deterniming whether the

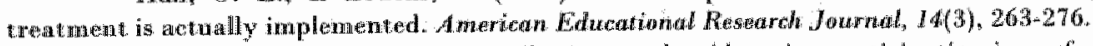

Kwaknam, $K$, (2003). Factors affecting teachers learning perticipation in profeswional loarming activities. Tedching and Tequer Educatian, 19, 149-170.

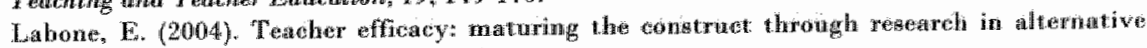
paradigms. Teaching and Teacher Eidication, $20,341.359$.

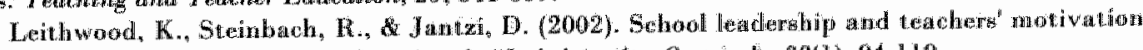
to implement accoumitability pulicies. Fducational Administration Quarierly, 38(1), 94-119. 


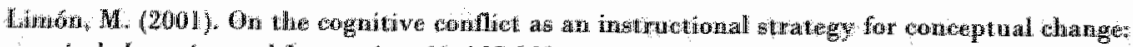

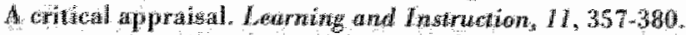

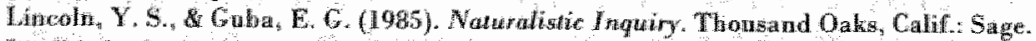

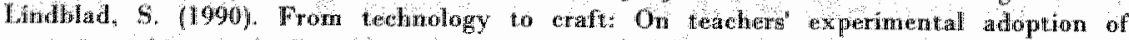

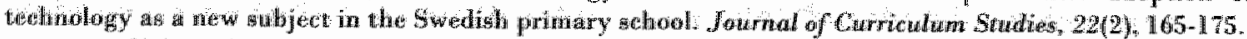

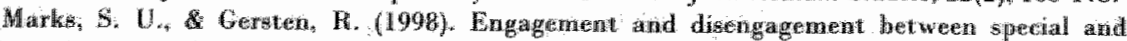

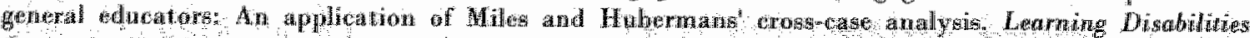
Ounterly, $21,34-56$

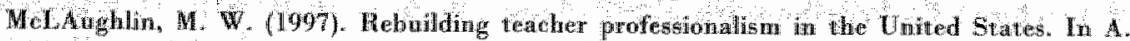

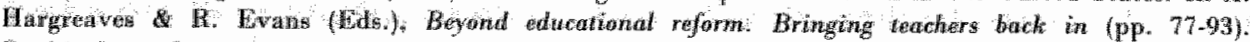
Buckingham: Openti Univerity Press.

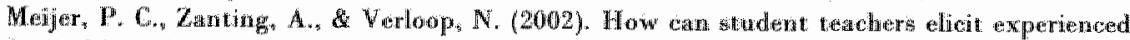

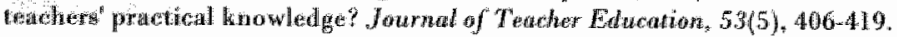

Mariam, S. D. (1998). Qualitative research atnd case sudy applications in eduation. San

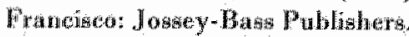

Mevalueh, $Z,(1995)$. Tequers" pethe on the way to and from the profesional develoment

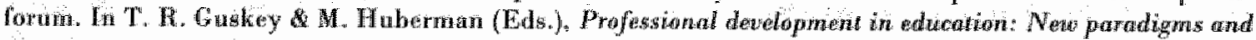

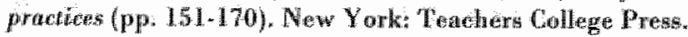

Miles, M. B. Huberman, A. M. (1994). Qualihane data analysis. Thonsand Oaks: Sage Publications.

Miller, W. R, H Hester, R. R. (1996). The affeotivness of alcoholism treatment. In W. R. Miller \& R. R. Hester (Eds.). Treating addictive behowwws: Processes of change (pp. pp. 121.174). New York: Plenum Press:

Pajares, M. W' (1993). Teachers" beliefs and educational researeh Oleaning up a messy

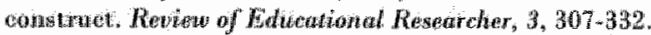

Palingerar; A. S. (1998). Soctal constructivis perspectives on teahing and learning. Anmual Review of Psychology, $19,34,5-375$.

Patton, M. (1990). Qual hative Evaluation Methods (2nd. Ed.). Thousand Oaks, Calif: Sage:

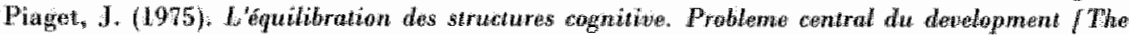
development of thaght: equilibration of cognivive struatures). Pars: PUF (eng. wans. Now York: Viking Wrosis.

Prochaska, J. O., Didemente, C. C. (1982). Trans theoretieall therapy: Towards a mone

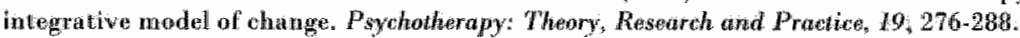

Prochaska, J. O., Didemonte, C. C., Noreros, J. C. (1992). In seareh of how people change: Applicalions to addictive beha wors. Ameriean Psychologiat, 9, 1102-1114.

Prochaska, J. O., Vellies, W. F., Diclemente, C. C., \& Fara, J. (1988). Measuring processes of chenge: Applications to the cesation of smoking. Journal of Consuling and Clinical Psychology, 56(4), 520.528.

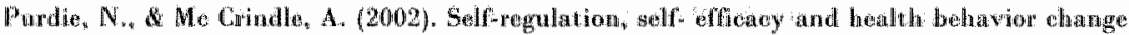

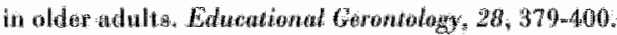

Putnam, R. T., Borko, A. (2000). What do new wiews on knowledge and thinkiug have to

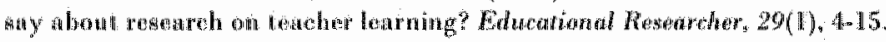

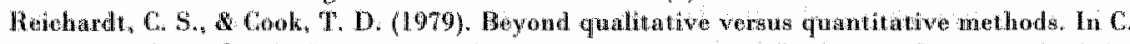

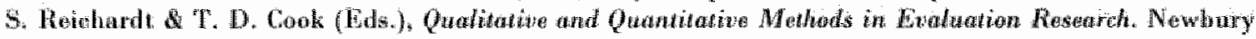
Pallit, Galit, sogen

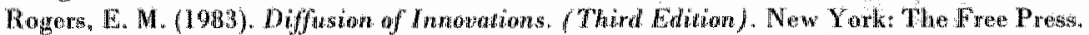

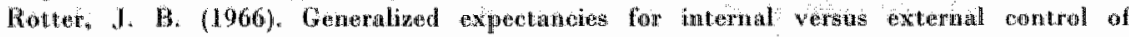

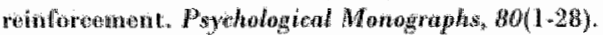

Sikes, P. (1992). Imposed dhange and the wperienced texcher. In M. Fullam A. Hargreaves

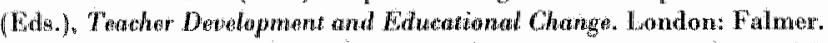

Simons, P. R., A Ruhinters, M. P. C. (2003). Professionals' conceptions of learning, dotelopmem, thonge and innowation. Paper presented st the European Association for Learning and Instruction, Padova, Italy.

Stein, M. K. W Wang, M. C. (1983). Teacher development and school improvement: The

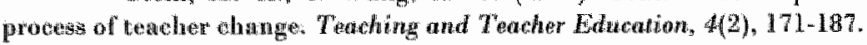

Tschamen-Moran, M., Woolfolk-Hoy, A., \& Hoy. W. K. (1998). Teacheir-fficacy: Its moaning and its thes sure. Revan of Eduentional Resench; $68(2), 202-248$.

Van Eekelen, 1. M., Boshuizen, H. D. A., \& Vermunt, J. D. (in press). Work-related leamüg processes of experienced teathers. Higher Edudation. 


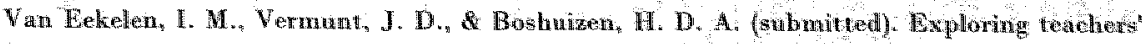
will to learn.

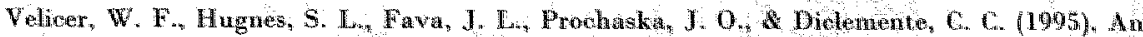
empirical typology of subjects withm stage of change. Ald herte Behaviors, 20,2992320 .

Wuitzy, N., Kancllak. D. (1995). Learnitg to teach. Knowledge develophent in elassmom management. Thaching and Teacher Fducation, $11(3), 215.227$

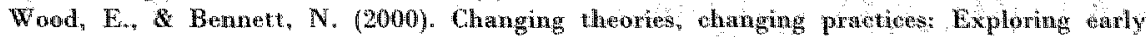
childhood teachers professional learming. Teaching and Teacher Edvation, $16(16), 635-647$.

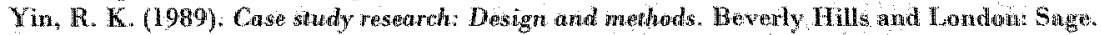

Yin. R. K. (1993). Applications of onse study research. Newbary I ark, Gallformia: Sage.

Zawting. A. Verloop. N. Nermunt, J. D. (2003). Using interviews and concepti maps fo asses mentor teachers' practical knowledge. Highur Education, 46, 195-214. 



\section{General conclusions and discussions}

The four empirical studies presented in this thesis were undertaken with the goal of contributing to a better understanding of how experienced teachers learn at the workplace. In this final chapter the results of these studies are summarized and discussed within the context of the six general questions that are presented in the Introduction. These questions are:

- what learning activities are carmed out by teachers during their daily work schedule?

- what is the role of reflection in teacher learning?

- how do teachers regulate their learning?

- how can a teacher"s will to learn be described?

- what situational factors influence teacher learning?

- how should learning be fostered for those teachers who do not have a will to learn?

Also inchided in this chapter is our proposal of a new model of teacher learning based on the results of these studies. Finally, we present the practical implications of our results and suggest possible directions for future research in the area of teacher learning.

\section{A summary and discussion of the findings within the context of the six general questions}

What learning activities are carried out by teachers during their daily work sehedule? Within the constructivist view of leaning, learring activities are viewed as important determinants of the quality of learning. In the first three studies of this thesis, three types of learning activities were successively inwestigatied, namely, general, interactive, and motivational.

The first study provides general overview of the four most important activities resulting in teacher learning: (1) learning from interactions; (2) learning by doing: (3) learning by reading; and (4) learning by reflection. Learning derived from interactions with students, colleagues and other people was reported the most frequently, followed by learning by doing (performing a task such as preparing a class, writing a paper, or correcting hornework on one's own). Learning by reading and taking time to reflect were the least frequent learning actiwities reported.

The second study takes the outcome of the first study - that learning by interaction is the learning activity most adopted by teachers- one step further. The goal of the second study was to investigate precisely what types of interactive learning actiwities actually generate workplace learning by exploring what employees and their interaction partmers actually do during the interactive work situations that lead to learning. The interaction behaviors of teachers and their interaction partners were compared to those of two very different oecupational 
groups - namely, professionals working in the financial sector and police officers. Based on the results of these comparisons, two overwiews of the types of activities generally corried out by adul learners and their interaction partners are presented. Five general types of interactive activities were identified: (1) performance of normal work. (2) application of something new, (3) information seeking, (4) exchange of Information, and (5) thinking about work experiences. The results showed that veachers, more offen than people working in the other two professional sectors, "himk about work experientes". That is, the teachers interviewed during this study often reported that either during or as a result of an interaction they observed or were conscious of their own behavior, the behavior of others, or "normall behavior in the organization, without necessarily doing something with those observations. Note that this is something different than reflection (see next general question). Relative to the other two occupational groups, moreover, the teachers reported more often a twow way exchange between interaction partners, mostly by the learning activities "discussion" and "brainstorming". "The teachers also differed from financial service professionals and police officers in the sense that they hardly ever reported the interactive learning activity "performing occupational job" (i.e., performing interactive routine tasks) and newer reported "preparing for work-related activities" and "checking information" as interaetive learning activities.

As the first study had also shown that some of the teachers did not feel motivated to learn from their work activities or in their workplace, study three explores the concept of a teacher's willingness to learn. The results of this study provide information on what may be called motivational or affective learning activities as carried out by teachers. "These behavioral activities could be separated into six categories: (1) having the ambition to discover new practices; (2) being open to new experiences and other people; (3) being pro-active: attributing successes and mistakes to internal causes; (4) question-asking after performance; (5) undertaking an action to learn; (6) recognizing leaming processes and the results thereof. Categories one and two reflect the manner in which teachers approach various (working) situations (a teacher's initial willingness to learn). Iust what they do in and with these situations in terms of learming; is reflected by categories three through six (a toacher's willingness to learn after or during a potential learning experience). All of the teachers interviewed showed varying behaviors in the context of the six categonies and, consequently, showed different results with respect to their learning outcome.

To answer the question of just what learning activities are carried out by teachers during their daily work, this thesis examines the several types of learning activities that were observed. These learning activities are intrinsically different. Whereas the first study indicated general types of activities, and the second study explored in more detail one of these general activities (learning by interaction), the third study focused on motivational activities that overlap the general (and thus also the interactive) activities, that is, the motivational activities influence whether and if a teacher will learn while interacting, either while doing, reading or thinking.

An exploration of these learning activities adds to the empirical basis of this thesis in its goal of determining how teacher learning proceeds in the workplace. In a previous study on teacher learning activities, Kwakman (2003) reported on the frequency of teacher participation in (routine) professional learming activities stach as 
reading, experimenting, retlecting, and collaborating. The present hesis broadened and examined the sub-activities of this collaboration activity in more depth by focusing on the learning experiences that evolved during classroom work and it took into account motivational learning activities. Nonetheless, continued research is still necessary. One future lime of investigation is to examine on a larger scale whether teachers indeed do not perform certain of the interactive behaviors that we performed by other workers in other occupations (as indicated in study two) or whether teachers just do not learn from these activities (while other workers do) and, if not, what factors may account for this.

\section{What is the rolle of reflection in teacher learning?}

Reflection during and after "doing" is considered to be an important mental process that is required to transform experience into knowledge (Kolb, 1984; Schöm, 1983, 1987). Several models describe how reflection in teacher learning should take place (Ferry \& Ross-Gordon, 1998; Korthagen, 1993; Korthagen \& Kessels; 1999 McAlphine, Weston, Beauchamp, Wiseman, \& Beauchamp, 1999).

The importance of reflection as an experience in teacher learning ean not be found in our empirical data. All of the teachers we interwiewed 'looked back' on their experiences; thus, in one sense they all "reflected". However, very few of those who participated in the first study reported a planned or structured form of reflection. Only a small percentage of teacher interaction in the second study was ased for Evaluating a situation in the past or present in order to see if improvements are necessary for the future". In the third study, it was apparent that not all teachers showed the behavior of reflective practitioners' (Schön, 1983, 1987), for some were perfectly satisfied with their practices and were anlikely to question provaling educational processes in the nearby future.

Based on our studies we question whether all teachers reflect on their experiences to learn as prescribed in the several reflection models. Althotgh reflection might be important in theory for teacher learning, our studies showed that: in practice (at the workplace) teachers often do not act according to these expectations. "This does not mearn that the reflection models are wrong, only that they prescribe a way of learning that might be too idealistic for most teachers to cairy out by themselves under most circumistances.

Similar findings have been reported by others. Kwakman (2003) concladed that reflection only seems to appear in coaching situritions, wher it is more or less explicity organized. She suggests that teachers, like students, need guided and sustained opportunities to reflect and that without this guidane reflection might not be a sufficient condition for learning. Other studies in the firld of teacher (student) education have demonstrated that student teachers differ in the way they reflect and that their level of reflection (for example, deep versus surface) determines for a large part the quality of the learning outcomes (Mansvelder-Longayloux. Beijaard, \& Verloop, 2002). For instance, when the (student) teacher is looking back on an experience, he/she often does so in terms of self-evaluation: "what did I do well", "why did it happen", and what shall I do differently the next time". In this superficial manner of "refleetion", new and deep insights are rarely developed becaluse the teacher is "reflecting' within his or her existing framework of reference ingtead of discussing, questioning, or expanding this framework. Thus, even iff teachers do look 
back on an experience(s) (reflect), this does not guarantee (as indicated in the aforementioned reflective models) that this necessarily leads to changes in what they do the mext time they approach similar situation (Tucker, Stronge, Gareis, \& Beers, 2003).

\section{How do leachers regulate their learming?}

According to the constructivist perspective on learming, all learners must approach and actively deal with an experience in order to learn from it. In the same tradition, most theorics on self-regulated learning piotwe a learner who is personally setting his/her goals, personally selecting the leaming resources, and personally monitoring and evaluating the leaning process. The conclusions that can be drawn from the second study of this thesis (on the interactive activities of workplace learning) can be related to these theories, in that optimal teacher learning may require an extra effort on both the parts of the teacher and his or her interaction partners in order to evoke a recipirocall learning process.

However, it is questionable whether all teachers are actually capable of making this extra ffort. On the basis of the other three studies, we can conclude that not all of the teachers participating in the studies were able - or willingly - to self-regulate their own learning. For instance, the conclusion drawn in the first study was that the participating teachers differed in their ability to self-regulate their learning. Three types of regulation were determined: (1) external regulation; (2) both external and self-regulation; (3) self-regulation. Most of the participating teachers reported spontaneous or non-linear learning experiences (mostly unplanned and extemally regulated). However, both the first and the third study showed that following a learning experience not all of the teachers made resolutions for improvement or to undergo new learning experiments, let alone implement them a next time (which is assumed to be part of the experiential learning cycle; Kolb, 1984). Some of these teachers did not see the need to learn, while others did not know how to learn. Consequently, it was less likely that they searched for challenging learning situations, let alone deal with those situations on a selfregulatimg manner. Finally, the fourth study showed that not all of the participating terchers continued their learning within the context of co-operatwe learning after the intervention period. When the period of external regulation had stopped, these weakers were found to still be very dependent on the external regulation of the rescarchers and they did not self-regulate their learning activities.

Thus, questions concerning the willingness and ability of all teachers to selfregulate their learming arose during the course of the research project. We found this to be a striking development since a general expectation of society today is that teachers are able to coach their students into becoming self-regulated learners. The condusion that may be drawn is that self-regulation as an ideal of (adult) learning might not be reached by all teachers and might not be reached in all situations. There is mounting evidence that teachers (and probably other individuals as well) differ in the manner they regulate their learning. For instance, studies reported in the field of student learning show a similar pattern as they demonstrate that students regulate thein learning in different ways (Oosterheert, 2001; Vermeten, 1999; Vermunt, 1996). Fenwick (2001) discussed the focus on rational control and mastery within self-regulative experiential learning models as she felt it ignores the 
role of desire m learning and sidesteps ambivalences and resistances in the learning process. "It depersonalises the learner as automomous, rational kmowledge-making self, disenbodied, nising albove the dynamies and contingency of experience" ( $\mathrm{p} .6)$.

It can also be concluded that teachers do not always hove to regulate their learning in an active and deliberate manner in order to learn new teaching behavior. Teachers are learning, even although most of their learning processes are spontaneous and non-linear and thus not (entirely) self-regulated. A similar conchusion was made by Oosterheert et al. (2002) with regard to student teachers' learning processes. They found three types of regulation: (1) external regulation; (2) active, intentional self-regulation; (3) dynamic self-regulation. According to Oosterheert et al. dynamic self-regulation evokes spontameous insights that play an important role in learning. The use of this dynamic self-regulation depends on the emotional response of the learner to the (consequences of the) outcomes of learning. It was argued that in the course of information processing, learners can assess, pre. attentively, whether the outcomes of learning, or the consequences of it, are desirable or frightening (and thus whether the information should or should not be taken into account). Consequently, in order to evolke spontaneous and non-linear teacher learning (in addition to the planmed ways of learning), teachers should be open to new experiences and their emotional consequences. Whether all teachers are open for these new experiences - for example, whether they all have a will to learn is answered in the next section.

\section{How can a teacher's will to learn be described?}

The willingness to leam has been defined as "a psychological state that involves a desire to learn, experiment, and see or do something that has not been seen or done before". It is considered to be domain-specific as opposed to a generic characteristic, thus a teacher can be willing to learn in one area while not be willing to llearn in another.

The first study showed that not all of the participating teachers were motivaled to learn from their work experiences or during their work. This finding was further investigated in study three by exploring the concept of teachers" will to learn (study two did not deal with his topic). Based on the results of study three, we were able to identify three groups of teachers with respect to behavior manifesting their willingness (or lack thereof) to learn: those who did not see any need to learn; those who were wondering how to learn; and those who were eager to learn. It was concluded that these teachers not only differed in the manner in which they approached various (working) situations (their initial will to learn), they also differed in what they did in and with these situations in terms of learning (willingress to learn after or doring a potential learning experience). Thus, the results of the thind study demonstrated that not all of the participating teachers were willing to learn, let alone able to learn from their experiences at the workplace.

In the fourth study, the three manifestations of a teacher"s willingness to learn were placed within the framework of the Trans Theoretical Model of Change (TTMC, Prochaska, Diclemente, Noreross, 1992). The TTMC perspective provides a developmental perspective (insight into the process of change) and a basis for how to deal with teachers that are not so willing to learn. Consequently, the "not seeing why there's a need to learn' group of teachers were placed within the TTMC phase of 
Precontemplation, the wondering how to learn" teachers were considered to be comparable to people who are in the Contemplation andor Preparation phase, and the "eager to learn" teachers were percenved to be in an Action andor Maintenance phate.

This fourth study provided a greater insight into the position of those teachers in particular who do not see a need to learn. An additional zero" or socalled imolive stage was proposed characterize those teachers who are not willing to modily their teachng practices at all. Such teachers are convinced that their mamon of teaching is the best one and often appeas to be stuck" in old habits. In contrast, Precontemplators" are thought to be "well on their way" to actually contemplating (the implementation of) change. We conchded that the original "do not see need to leam group comprises both immotives and precontemplators and needs further refinement to provide more darity in the boundaries that distinguish these two phases.

The resulte of the fourth study also clearly confimed the existence of a growp of teachers who are "wondering how to learn". These teachers showed behavior similar to that found in the Contemplation and/or Preparation phases, which can be characterized as: (1) an awareness and recognition that a problem exists; (2) refection on the pros and cons of change; (3) a lack of confidence in the ability to doal effectively with the outcomes associated with the changes (ien a sense of self effuacy). Consequently, these characteristics result in a hesitant commitment to take action.

We concluded that teachers" will to leari shonk not be taken for granted. Our studies indicate that some teachers "do not see the need to lean' or "wonder how to learn". Similar manifestations of teacher behavion (teachers unwilling to change) are reported in the literature on teacher ehange (e.g. Lindblad, 1990, Rogers, 1983; Sikes, 1992). In order to provide a complete description of teachers" will to learn. the Teachers Willingness to Learn Model was developed (an expansion and adaptation of the Trans Theoretical Model of Change). New in this model, as compared to other teteher learning models, is its acknowledgement that teacher learming processes may start with one or mone phases of an unwilinghess to learn. As such, this model may Berve a theoretical framework for the exploration of the leaning and ehange proceses among, in particular, those teachers who do not appeat to initially show a will to learn.

\section{What sitwational factors influence teacher learing in general?}

Tacher learning and not-learning are not only influenced by a teacher"s willingness lo leam, but both processes take place within the classroom, the school and, partally, within the professional learning enviromment outside of the school (Hargreaves, 1997; Lave \& Wenger, 1991). Several authors have described context factors that influence teacher learning (Eraut, Alderton, Cole, \& Senker, 1998 ; Kwakman, 2003; Smylie, 1994), and the results of studies one and two of this thesis supplement this knowledge basis. Study three did not address this question of influencing situational factors, while study four focused solely on how to influence the learning of a specific sub-group of teachers - those teachers who do seen to have a will to learn. This latter question is addressed in the following section. 
Study one did not reveal a clear picture of the factors that molwence tomoher leaming: there were very many, sone of which contradieted each other (semed to be both stimalating and inhibiting) For example, some teachers memtioned no time or the fact that they had to share an office wh a colleague as in hibiting factors, while others mentioned that it was a matter of 'making thme and that they benefited from the knowledge of the officemate. We therefore concur with Kwakman (2003) that teachers perceive both the task and the work envinoment very subjectively with respect to what promotes their individual learning processes. Thus, there is no one dimensional answer to the question of which situationat factors infuence teacher learning as this latter process is dependent on how the individual perceives his/her situation.

Nevertheless, there is a mple evidence of the influence al interaction on teacher/adult learning. Study two explicitly focused on the role of the mteraction partner of the teacher in his/her learning. All sorts of people can directly fultill this role (for example, colleagues, managers, students, family members, and friends). Direct interaction ean take place in a one-lo-one conversation or in groups, Indirectly, the role of interaction partner ean be fulfilled via written material or artifacts (books, websites, newspapers, occupational magazines, otc.). The results of the second study showed that the interaction partmers of teachers contribute to the learning of the latter mostly by providing specifie information and that while the behavior of the interaction partne within a work situation is not always experienced as being positive or encouraging, it is nevertheless viewed as educative. Apparently. teachers (and other adult learners) not only benefit from enconragenent and positive reactions from their interaction partner but also from the negative reactions of others - on occasion. Furthermore, teachers were found to differ from professionals working in the financial service sector and police officers in that they did not report learning from interaction partners occupying a higher (their bosses) on lower hierarchical position. Conversely, teachers reported relatively nore learning interactions with their peers and students. This finding can be explained by the relatively flat orgamizational characteristics and the relatively antonomous position of teachers. The conclusion that can be drawn from study wo is that the different interaction partners within an organizational hierarehy all play their own, unique role in the workplace learning of adult learners. Thus, in ordar to promote optmal teacher learning, the working enviromment of teachers showld encourage frequent (informal) interaction with their colleagues and (ream) managers.

Thus, although stady one pot the importance of sitoational favtors in perspective, study two showed what interactive lesming activitios and which
interaction partners may influence teacher learning. To our knowledge such a detailed examination of the role of interaction in leacher learning has not been carried out by others. This is remarkable in itself as provious studies have shown interaction to be an important source for an ongoing development of workers (Billett, 2002; Daley, 2001; Eraut et al., 1998).

How should learning be fostered for those teachers who do not seem to have a will to learn? While schools and educational innovation programs can clearly benefit from teachers who engage in professional development activities, principals, policy makers, and change consultants often encounter major problems in the form of 
resistance from teatiers who simply do not wish (or have the ability) tho undertake development activities. The guestion of how to foster learning for those teachers who do not geem to have will to learn was the main concern of study four.

In this fourth study, two interventions were used to stimulate teachers" willingnesis to leart: an individual approach for those teachers who do not see the need to learn and a collaborative approach for those teachers that "are wondering how te learn". Both interventrons are based on the findings of Prothaska, Velieer, Diclemente and Fava (1988) and were developed while working with the TTMC model. Theserestearchers found individuals in the Precontemplation, Contemplation, and Preparation phases of change to benefit mostly from an experiential or cognitive intervention. For those teachers who "do not see a need to learn", the intervention aims at modifying their thinking on cooperative leaming; for the other group, the intervention aims at strengthening their self-efficacy by providing on-hands experiences. Thus, both interventions are tailor-made for each of the two groups. Both approaches were fotnd to be effective in the sense that after the intervention period the willingness of all of the participating teachers (except one) increased; that ilis all of the participating teachers (except one) reached at least the next phase of the TIMC. However, the relapse of some teachers after three months following the end of the intervention period demonstrated the need for continuous and high-quality coaching to ensure the professional development of teachers.

A number of factors appeared to explain the progression of those teachers who were initially not very eager to learn into the next phase of the TTMC during the intervention period. As noted alteady in study one, the participating teachers had their own idiosyncratic set of explanations that were based on their subjective pereeption of the sitution. In general, however, the following aspects of the interventions were mentioned as being particularly helpful: (1) help with the translation of such vague and abstract pedagogical terms as "active" and "cooperative" into concrete and practical lessons; (2) stimulation of selfexperimentation and thereby the actual experiencing that something actually works, how it works, and thus, self-discovery: (3) stimulation of the observation of each other's lessons, These llast two aspects of the interventions confirm the use of enactive (mastery) experiences and vicarious experiences as sources to enlarge a teacher's selfofficacy (Bandura, 1997) and, conseguently, a teacher's willingness to learn to be affective.

All in all, the results of the fourth study demonstrated that even teachers who do not seem to have a will to learn can be stimulated to learn through the application of tallor-made guidance methods. This also implies that a teacher's unwilingness to learn is not necessarily only determined by individual characteristics; it ean be influenced as well by the environment in which a teacher works. Those teachers lacking the will to learn may re-commence learning once their environment provides tailor-made guidance.

\section{Discussion: the individual constructivist perspective reconsidered}

Teacher development and learning is often considered from the individual constructivist viewpoint on learning, in which many aspects of self-regulation, experimental, and reflective learing theories are incorporated. These ideas are 
summarized in the left column of the table betow (see also chapter one). The results of the studies reported in this thesis provide nuanes and oriticisms of this perspective as they clearly show that not all of the teachers participating in the studies were willing to leam, let alone able to actively plan on self-remglatio their learning, or even to reflect on their experiences in a structured manner (right side of Table 17).

Table 17: Teacher learning based on the results of the studies presented in this thesis (right) compared to the constructivist view on learning (left)

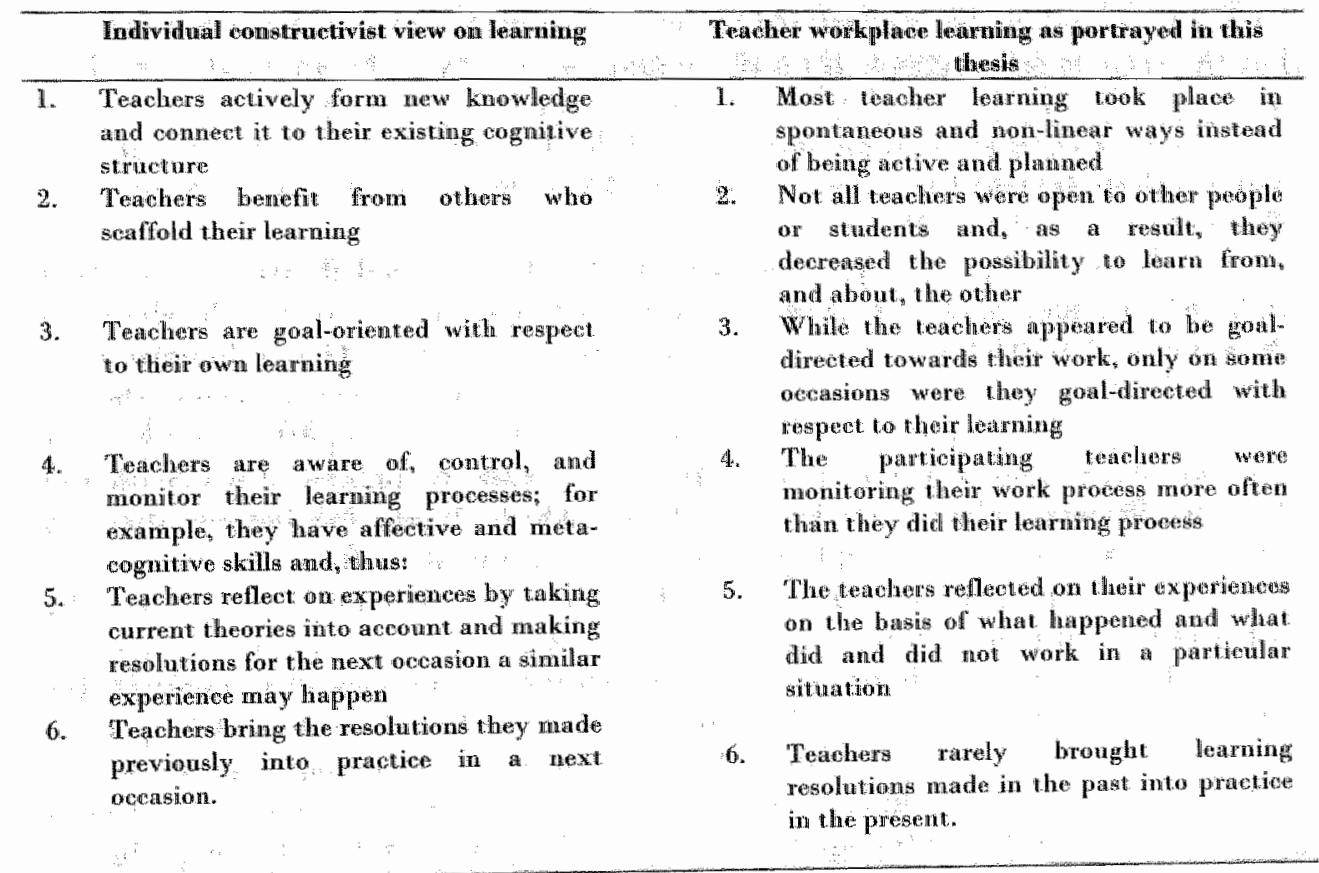

The results obtained from our four studies indicate that not all teachers are able to self-regulate their learning, as shown on the left side of the table. Furthermore, for learning to occur, teachers do not always have to regulate, plan, or monitor their learning, as it can also take place through external regulation in a spontaneous and/or non-linear manner of learning. However, for spontaneous or non-linear learning to develop, we assumed that teachers should have a will to llearm ('be open') in a specific situation, and we found that this was not always the case: the will to learn of the teachers participating in these studies varied from person to person, from situation to situation (wher, where, with whom), and from domain 1.9 domain (what). And, although all teachers may encounter potential learning experiences, this does not necessarily mean that they learn new teaching behaviors from these. Prawat (1992) has referred to this phenomenon as "naive constructivism". 
All in all, we lawe severe reservations about the individual constructivist. view. It consusts of prescriptive theories and models about learning (for example, experiential, reflective, and self-directed learning nodels) that describe how learning in its most perfect form, should or could take place. As such, it is not a represtutative perspective of how teachers aetually leam new teaching behavior at the workplace (descriptive theory). The individual constructivist view has not only been brought into question on the basis of our results, but at least three other perspectives lave been proposed that concur with our conclusion.

Ome of these, the cross-eultural perspective, brings to mund that the individual constructivist view of learning primarily describes the assumptions, inchinations, and preferences related to "natural" adult learning in a Western society. For the Hmong tribes people from the mountains of Laos, who are used to working. cooperatively and to look to their teachers for direction and guidance, our ways of working that emphasize autonony and which place the focus of control with the individual student will be experienced, initially at least, as dissonant and anxietyproducing (Podeschi, 1990).

Fomhermore, it is questionable whether the rational decision model that underlies the individualistic view (techriques of reflection, personal dewelopment planning, and portfolios) is truly accurate (Harrison, 2000). The techmiques offer teehmical rational solutions which fail to address the challenges of managing the self in the here-and-now moment. Moreover, the techniques are most effective when the information avalable is complete and future trends are predictable. Since neither of these conditions applies to modern society (in which change has become the only constant) and given that people may not be so rational in their choices but are influenced by emotions and anxiety, individual regulation may become a risky rather than a rational enterprise.

Finally, on the basis of a neuro-scientific perspective it is questionable whether all human beings are able to (or wish) to be such an autonomous person. According to Slob (2004) the human brain is constantly changing and developing under the barrage of new information and experiences. Human beings are not born as autonomous entities, although the brain may develop as such under the influence of upbringing and education. Thus, in order for the brain to develop, individuals need in social and information-rich environment. However, social and structural bartiers still determine unequal patterns of access and participation in learning and career progression. Individuals who are not yet autonomous persons and who find themselves in an information and socially poor environment will not easily be able to learn these solf-regulating skills nor bo able to place themselves into a situation that can provide these resources. It is therefore questionable whether individuals who are not brought up with this autonomous attitude will ever be able to regulate, or to start regulating, their own life. Likewise, by extrapolation, we doubt whether experieneed teachers who are not antonomous learners and who mainly work in the isolation of their own olassrooms will ever develop into antonomous learners.

In the light of all these comments and eriticisms, why is it then that this individual constructivist perspective on learning from experience is so persistent? We explain this by the fact that this perspective closely relates to the view held by contemporary society that every individual should be able to, and even wishes to, live his or her life by making individual choices (for example, autonomous citizen 
and a whidrawing government). The essence of this individualistic new can be derived from (liberal) humanistic valaes, beliefs, and goals that enaphasize selfimprovement, empowerment, and personil development the desirable" Westemized wiew of the self is represented as a ratonal, self-aware, whall. informed decision maker, freely choosing between learning opportanities and career destinations" (Harrison, 2000, p. 316). As such, this view on learning is not a politically innocent and value-neutral pedagogy. Mortover disguised by the apparent neutrality of academic knowledge grounded in the discipline of cognitive psychology, this individial constructivist perspeetive on learning from experience also serves contemporary political agendas.

\section{Towards a sututed constructivist view on teacher leaming: a new nodel}

Even though the situated view has also come under criticism (sed chapten one. section on workplace learning), on the basis of the results from our studies and the aforementioned perspectives, we believe that a situated constructivist view on teacher learning is more accurate in describing how teachers learn than the individual constructivist view. Many situated cognitivists (we nse the shorthand term 'situated cognitivis" to represent social constructivism, situated loaming, situativity, and sociocultural theory; see, for example, liave $\mathbb{Q}$ Wenger, 1991 ; Bereiter \& Scardamalia, 1993) have their origins in the sociohistorical school of psychology developed by Vygotsky (1978). Vygostky argued that a complete examination of learning requires an examination of the individual as well as social and institutional concerns (Vygotsky, 1978; Wertsch, 1998). This multi-dinensional approach has laid the groundwork for a dialectical model of learning in which bodh the individual and the context interact in critical ways. As such, the situated perspective emphasizes that learning is rooted in the situation in which a person participates and not only in the head of that person performing the learning activities. As a result of this "situatedness", a learning process may or may not progress and may or may not evolve in a certain direction. Thus, this situated perspective is in accordance with our definition of teachers" will to learn in that it recognizes that leaning may vary from situation to situation. from person to person. and from domain to domain.

As most of the models within this perspective focus on the interaction with the stuation in which the learning takes place - and do not describe how that process actually takes place (Illeris, 2003) - we propose a descriptive model of teacher learning that does describe the various manners of teacher learning at the workplace. 
Rigure 6. 1: Teacher learning model

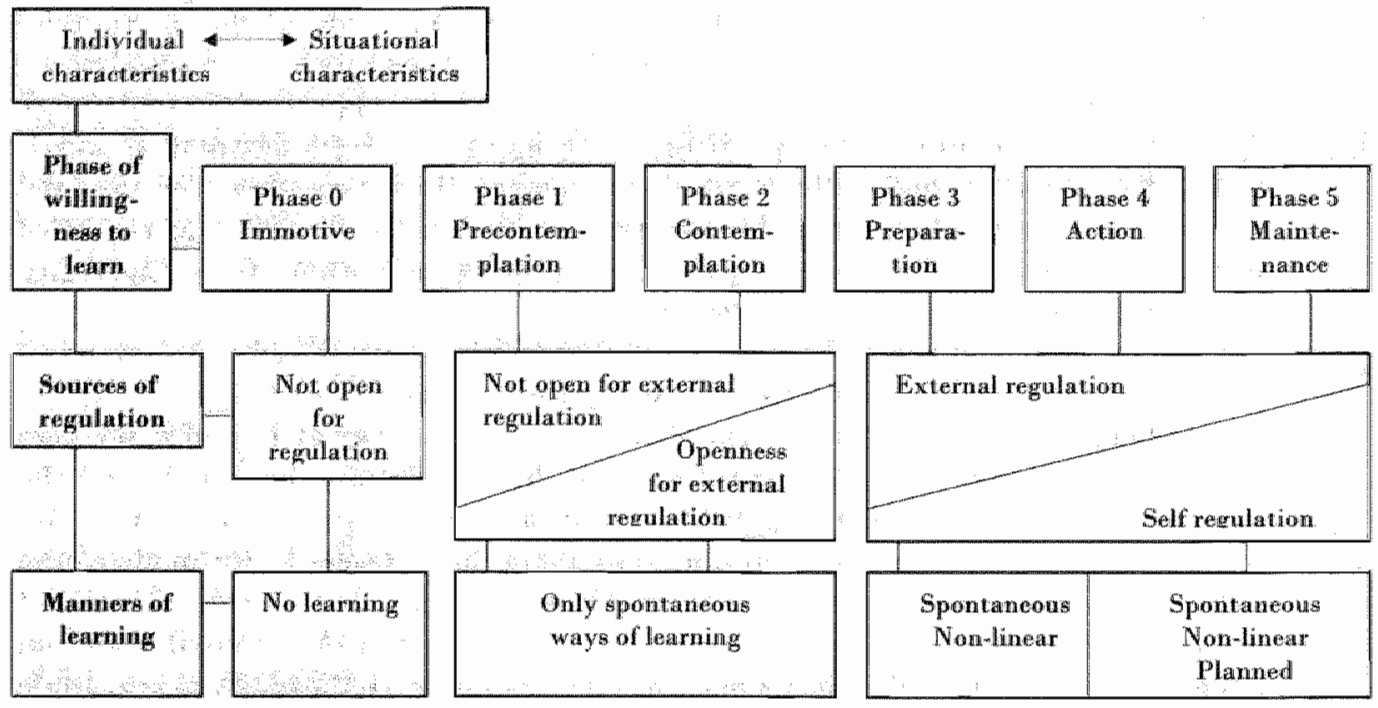

The model combines the various aspects of teacher learning that were examined in the four empirical sudies:

A. the dialectical relationship between the individual and the situation ("situatedness" of learning);

B. the phase of willingness or readiness to learm:

C. the regulation of learning;

D. the manners of learning.

Taken from top to bottom the model reads as follows. The combination of an individual, with his or her unique characteristics (biography, personality traits, gender, etc.), if a particular working situation (with whom, when, where, about what, ete.) may construct a possible opportunity for learning. However, whother and how that leaming actually takes place is contingent on the dialectal relationship between the individual and stuation. Depending on this dialectical relationship (A), the individual will have a certain willingness or readiness to learn that can be designated by phases of the new Teacher Willingness to Learn Model (B, see study four). The phase of "willingness to learn' affects the regulation by which the learning can take place (C). An immotive teacher will not be open to any type of regulation at all (no openness), whille a precontemplator (phase 1) or contemplator (phase 2) will gradually develop towards a more openness for external regulation. A teacher in the Preparation phase (3) is open for external influences and will commence selfregulating his own learning. Teachers in the Action and Maintenance phase are able to loam by extermal regulation, self-regulation, and/or a eombination of both. The diagonal lines in the model do not start precisely in the corners because regulation in learning is never completely self-or externally regulated. When a learner decides to learn something (self-regulation), this is usually because some stimulus im the environment has triggered the desire to learn or has opened the way to learning (see 
also Candy, 1991). Notwithstanding, when this something tin the environment has triggered the learning (external regulation), it is because the learner is paying attention to that something (and thas self-regulation). Finally, the teacher way of regulation relates directly to whether the teacher nay benefit or choose from more or fewer ways of learning (D). The inmotive teacher who is not open to any external regulation at all will not learn - on at best will only re-llearn what he or she already knew or thought he or she knew. A teacher who is more or less open to external regulation may experience spontaneous learning processes. A combination of external and self-regulation may foster a non-linear learning process, while selfregulation may lead to a planned learning process.

We use two examples to illustrate the model. A teacher with a history of many classroom management problems and low self-efficacy on cooperative learning (A) might act as an immotive (B) when asked to experiment with cooperative learning. He or she might even disregard every piece of information that deals whith the positive sides of cooperative learning due to a process af selective attention, thereby decreasing his/her chance of benefiting from an external manner of regulation. An internal regulation towand cooperative learning is not likely at this stage of this teacher's willingness to learn (C). As long as the teacher is not open to accepting any (positive) information, there will be no learming of this topic in this situation (D). A second teacher is, a result of a certain dialectical relationship between his or her individual characteristics and the particular situation (A). situated in the Preparation phase with regard to cooperative learning (B). Contrary to the first teacher, he or she might have observed a colleague who is already working with cooperative ways of learning. And since this teacher is in the Preparation phase, he or she might ask this colleague what is going on and, as result of this displayed interest, he or she might even be invited to visit a cooperative lesson of the colleague (both internal and external regulation) (C), Since the teacher is open to new experiences, spontaneous and non-linear ways of learning will occur (D).

In conclusion, our model of teacher lewming is a descriptive model of the varions ways in which teachers may on may not learn new teaching behaviou from an experience at the workplace. This proposed nodel incorporates and oxtends the Teachers" Willingness to Learn model that was introduced in sudy four. It shows that teachers" willingness to learn depends on the dialectical relationship betweon individual and situation and that this willingness influences the way reachers regulate their learning and, consequently, how and what they learn. Accordingly, it demonstrates that teacher learning and self-regulation in learning is not a given fact but depends on teachers" willingness to learn in a certain situation. Furthermore, the model indicates that the (by most constructivists prescribed) progression towards becoming a more self-regulated learner (less dependent on external regulation) may be preceded by a period of progression towards more openness to external regulation. Without this openness to external regulation, coaching towards self-regulation in learning seems to be "a bridge too far". 


\section{Practical Implications}

The preceding discussion contins several implications for teacher workplace leaming within the frameworl of the premise that the best learning enwironment for teachere does not exist. In general. we recommend recognizing the needs and concerns of a spectic teacher as an individual, and to start from there. Teachers difter in the way they percedwe and interact with their surroundings, thus what work for one teacher does not neessarily work for another. An individual approach is necessary in order to organime or facilhate teachers learning and to ehange processes (Barnett McCorkmick, 2004, Kwakman, 2003). In this section, we set forth number of suggestions that may be used as guidelines by teachers, educational managers and change consultants to organize teacher learning.

\section{Implications for teachers}

The general attitude held by contemporary society is that learning is supposed to be "fun", challengring" and "obvious". Within this context, there is a definite" "taboo" for individuals/ teathers who are not (so) willing to learn. That learning may also encompass lear, anger and confusion is often ignored. As a result, a teachers (an)willingness to learn is not a topic that is casily discussed between a teacher and his or her director. In a contunation of the same, people functioning in contemporary society are supposed to behave as autonomons individuals. Consequently, there is also a tabow for those individuals/teachers who may not be able or willing to self regulate their life and learning. Wo plead for breaking with these two taboos:

Moreover, our desire is to encourage teachers to accept responsibility for breaking with these two taboos. As the results of the studies reported in this thesis indicate that teachers regulate their learning and learn in different ways, we would like to encourage individual teachers to ask for and to focus their educational manager's attention towards how they learn best, what they don't like to learn and why, and what they need from their schools (direction and support stafl) in order to foster specific aspects of their learning. In order to stimulate teacher learning, today"s school managers demand of their teachers that they participate in workshops, collegial consultation, team teaching, ete, and/or create their own persomal development plans and initiatives. These initiatives do not always take the individual teacher"s learning concerns into account. As many schools value and want to do juatice to individual differences in student learning, teachers should be able to daim equal inghts with respect to teacher learning (teach what you preach) in that teacher learning may require individually oriented learning strategies (which is something different thain learning on one's own). To summarize, it may be helpful for each teacher to ask that his/her manager pay attention to the following:

whether and in which situations the teacher is (not) willing to learn, and why, how capable the teacher is in regulating his or her learning.

and, since we live in a Westerm society, how the particular teacher can be supported (if necessary) to learn (to self-regulate) his or her learning.

"The proposed Teacher Learning Model provides the ingredients for just such a conversation. We therefore suggest that, if necessary, a teacher should ask for coaching to gain more insight into hisher individuallearning process. The coaches 
showld be ahle to discuss this teacher's learning proeess by rethting if to existing leaming theories (the comtent) while at the same time explicating how they are coaching the teacher in the here and now situation (the process). By exploring the content and demonstrating the process the teacher gains more insight binto (a) his/her own learning and (b) the process by which he/she conld conch students to become self-regulated learners (see also Munro, 1999).

\section{Implicanions for educatonal managers}

For educational managers and change consultants we recommend a oustom-made approach when organizing or facillitating the learning of an indwidual teacher. Similar to what has been proposed in the section on Implications for teachers, we also encourage eduational managers and change consultants to take their own responsibility in discussing with each teacher just how he or she is willing and able to regulate his or ther leaming. Once it is "in the open", in which phase of the Teacher Willingriess to Learn Model the teacher places himself or can be placed with respect to a certain topic, a tailor-made learning environment can bo developed for each individual (group of) teacher(s). Creating a tailormade learing enviromment (such as the two interventions in the fourth study) is something diferent than asking oach teacher to ereate his/her own personal development plan (PDP). The creation of a PDP may work for those teachers who are eager to learn, oven though they may not like the bureaneratic manner of writing down these plans, but for those teachers who are in phase zero, one or two of the Teachers Willingness to Learn Model, the creation of a PDP will simply not work, for these teachers are not able - and will not be able - to self-regulate their learning with regard to these topics. In our view, PDPs do not represent a tailor-made approach to teacher learning tor they compel each teacher to learn in the same (planmed) manmer without any consideration being given to whether the teacher is willingly and able to learn that way. The next logical question, therefore, is just "what is a balor-made approach?" To address this question, we discuss in detail the specific suggestions that have evolved from our studies with respect to immotive teachers and teachers who "do not see the need to letun, "womdering how to learn", "eager to leam".

Fon all teachers, but especially for those teachers "who do not see the neod to leam" with respect to a certain topic (phase I, precontemplation), it might be helpful for coaches and managers to keep in mind the self determination theory of Deci and Ryan (1985; 2000). Deci and Ryan argued that human personality growth and well being are affected primarily by three basic needs - the need for anonomy. competence, and relatedness. With respect to antonomy, humans have a basio noed to be the origins of action and experience their behavior as volitional or scrmming from the self. It is this autonomy in particular that accounts for those teachers "who do not see the need to learn". For these teachers, the collective school-based programs that are obligatory for all teachers in the school workplace seem to he in contradietion with the autonomy and the will to learn. For teichors who are not really willing to learn, such collective programs are a waste of time. As an alternatiwe, these teachers may benefit from a discussion of the negative effects of not learning, either for the teacher hin- or herself and/or for his or her onvironment. An possible helpful alternative is the observation of the leacher's lessone by a third party and a subsequent stimulating reflection on the latter"s own teaching practice 
as and of providing fredback, whereas providing suggestions for change is most often not useful in this teacher (non)willingness phase, for they are not yet open to these. Instead, focos should be directed lowards the first small sep: that the teacher ins willing and able to take in a particular situation (the second basic need as described by Deci and Ryan is the need for competence). Assistance should be offered in taking this step, if necessary, and progress hould be closely monitored. Finally, as the need for relatediess or belonging is the third basic need, it is necessary to truly connect whth these teachers for a long period of time. For the "not seeing the need to learn' group especially, frequent contact ('you are seen") and a lot of patrence is an absolute necessity.

For llose teachers who "wonder how to llearn" (phases 2 and 3), it may be worthwhile to help them formulate what the pros and cons are of that learning. The third study showed that some of the participating teachers did not feel competent in relation to educational change (low efficacy). Verbalization and the modeling of appropriate strategies by the coach or other teachers may be beneficial for these teachers" efficacy and learning. In addition, it may be helpful for teachers to observe a "coping" model (a colleague), someone who inivially has difficulty with a task and then eventually masters it. This can increase a teacher's efficacy and learning more than only observing a "mastery" model. Clearly, it is necessary for these teachers as well to take that first small step wheh falls within their field of competence. If toathers" willingness to learndevelops towards the direction of the third stage of the Teachers" Willingness to Ifearn Model, teachers could be assisted (if necessary) by providing concrete examples and by coaching in preparing their learning experience. The making of specifie agreements on when and what the teacher is going to do and the monitoring of these agreements, enlarges the ehances that the action is actually going to take place.

Teachers belonging: to the "eager to learn" group (phases 4 and 5 ) need a stimulating environment that is supportive of their (self-regulated) initiatives; bureaucracy is often counter-productive with these teachers. Providing challenges and assistance when asked may foster their learning. These teachers may also benefit from discussions on the areas of education that motivate them or on new areas or developments that interest them. If possible, "eager to learn' teachers should be placed in an inter-ative ratationship with (external) people interested in the same subject: Show perspectives, new possibilities and new developments in the profession that they might wish to explone; ofler these teachers a new role in the organization or a teacher intern that may assist in their learning. Finally, offer assistance by creating the physioal environment necessary for their educational experiments (for example, larger dassrooms different furniture, personal computers, etc.).

Teachers who seem to be immotive (phase 0), and thus not (willing to) learn one or more specific topics, became our greatest concern during the course of our studies. In our search for "unwilling teachers" some principals admitted that they mote of less had lost contact with these "unwilling" and "resisting" teachers ("I don"t want to spend more energy in him/her; ] just leave him/her"), that these teachers" behavior was grudgingly acepted without further discussion. Although, we agree with these principals that a (re-)opening of the discussion takes a lot of energy with often no or sometimes few results, we nevertheless suggest making the attempt. for toleration will surely not change these teachers. Moreover, we suggest making strict 
agrements with these teachers. In general, there are two types of agrements. In the first type, the mital step is the acceptance by the primcipal that the teacher is not willing to heam certain aspects of his work. Subsequently, the teacher and sohool principal agree on the topics the teacher is and is not expected to learn. The topics on which the teacher is supposed to learn are specifed, and these leaming processes are closely monitored by the manager. In the second type of agreenent linere is no aceeptance that the teacher is not willing to learn on certain topics. In this type of agreement the teacher is forced into a dewelopment process. Criteria that indicate the results to be met at the end of the development process and the consuquence of not meeting them are specified (as is the assessment procedure). Teachers who do not meet the criteria after the development process, are told to leave (lad off). This last agreement may seem harsh, but from the perspective of the large group of willing teachers, it is a fair option.

\section{Implications for change managers and educational consultants}

Change in schools is often initiated under the following motto: "start wh those who want to change, the rest will follow". In study four we were able to denomstrate that a "reversed change approach" can also be successful. Five teachers of the same school participated in this intervention study. These "not so willing to learn" teachers were presented as "the pilot group of cooperative learning" by their managens. As a result of the intervention and this manner of communication by the management, other teachers began to ask the intervention group teachers questions about how and what to do with cooperative learming. Very quickly "whe not so willing to leam" teachers were seen as experts on cooperative learning, which consequently stmalated their own efforts. Teachers who were already in the process of cooperative learning asked why they weren't invited to participate in the pilot group, and so on! llherefore, we suggest a new rmotto: start with those who do not want to change, for those who wish to change, will do it themselves!

In addition, educational consultants and trainers often respond to the question of "But what shall I do with those teachers that do not want to change?" with the quick answer of: "Don"t invest too much energy on those $5 \%$ who do not want to change". We consider this a very dangerous position to take. Some educational managers follow this advice hterally by completely stopping to interfere with these teachers and ultimately by simply tolerating their behavior. As a result there are no constrainks holding these teachers back from doing "their own thing", neither are there stimblations to start working towards the changed direction. We therefore suggest the following motto: "Stop tolerating their bellawior and start discussing it with them".

\section{A critical reflection and suggestions for future research}

This purpose of this thesis was to question whether and how experienced teachers are currenty learning from experiences at the workplace, a workplace that is subject to change itself. We took for granted that teachers should learn and change within the framework of the current views on learning held in their schools and in line with contemporary society"s demands. In the educational community, which is witimately what a school is, teachers are educational professionals who have to bridge the gap 
between the school's (or the national) educational phillosophy, the possibilities and regurentents of their teaching: domain and, last but not least, their own preferred way of working. The combination of these factors can produce tensions, as we have seen in this thesis. This thesis did not perceive the nolividual teacher's perspective on these dewelopments and his or her prefterred methods to be of overriding importance and, instead, gave prionity to the shool and society"s interests. However, contemporary standards and views on what comprises good learning and teaching may be replaced within a few decades. We never discussed with teachers whether these contemporary views are "right' and whether teachers should (and can) llown or change atwording to these views on learming and teaching (see Van Veen, 2003). This question of "right" was often posed by those teachers not (so) willing to Hearn, for it is formost these teachers that consider the current views on education to be contrary to therr ow $\mathrm{n}$ ideas and interests.

An issue that concerned ns when carrying out the present studies, but one that should posibly concen future studies as well, is the identification of reliable criteria for determining when a teacher/worker has truly learned. In the present thesis we used the criterion that if a teacher said that he/she had learned something, this was accepted as a leaming result. A question that then may anse is how to deal with the quality of these learning results. For example, what criteria determine whether teacher has accutately learmed/mastered cooperative ways of learning. With this in mind, we recommend addressing the important research question of how (implicit) learning at the workplace should be measured. Such research should also take spontaneous and nom-linear ways of learning into account. An improved anderstanding of spontaneous learning is important in order to counteract the dominating theories of planned ways of learning, while a better understanding of the process of non-linear learning is necessary because this type of learning connects so well with the complex and chatic environment of workplace learning as well as to the world of modern multimedia learning. Such questions should be addressed not only in an educational setting but also in different contexts (for example, industry, service sector, healthorre).

An intrinsio methodological comeern of the studies presented in this thesis is what they are based on a small-seale qualitative research design. As such, we report on behaviors and patterns of behavior that must be verified in larger scale research projects. Foremost, wo would like to eall for future nesearch to verify the "Teacher Learning Modal proposed in this chapter. This inherenty implies nore research into (a) The Teachers Willingness to Learu Model and (b) teachers" self-regulating leaning processes. As with the Teachers Willingness to Learn Model, futare research should provide more olaty in the boundaries that distinguish one phase from another. For instance, the boundarics between the group of immotive teachers and precontemplators need to be refined in order to be able to distinguish between these groups more easily. More research should also provide mone examples of phasespecifio interventions that are effective in coaching someone into the next phase. With respet to self-regulation in teacher learning, we suggest that future research be directed towards examining how eontempotary teachers are learning to learn. A large proportion of the current teacher population has been educated in the cognitivist era, when the dominant view on learning was on how to transmit knowledge. Nowadays, the focus is on creating knowledge. Not all teachers have 
adapted to this thanged vew on learning, and the assumptions and bellefs about learning are still in the cognitivist mode. Therefore, future rosearoh should take into account the different pistemological beliels held by different tachers. Some may have an absolute or dualistie (Hofer $\&$ Bur, 2001 ) epistemological perspective on knowledge, which may obstmot their leaming. Future research shonld not only investigate how teachers themselves leam to lean, but also investigate fow this relates to the manner they teach the process to their students. Finally, and in a more general context, future studies may wish to examine to what degree selfregullated learning if, should, and can be learmed by students of different ages, teachers and/or other working people. The three perspectives given in the Discossion section of this chapter - the cross-cultural view the criticism on the rational-decision model, and the neuro-scientific perspective - may each serve as an starting point for this type of research.

\section{References}

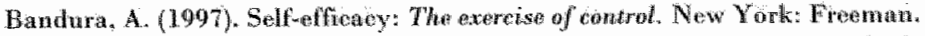

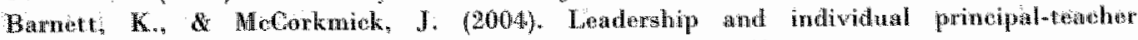

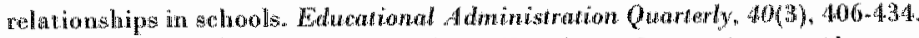

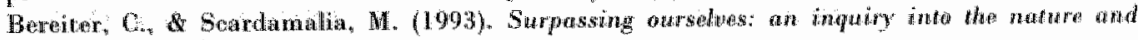
amplications of expertise. Ohotago: Open Court.

Billett, S. (2002). "Towird. workphate podagogy" guidance participation and engugement: dult Education Quarterly, $53(1), 27-43$

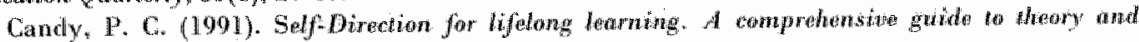
practice. San Francisco Iosisey-Bass.

Daley, B. J. (2001). Learning and professional practice a study of fon probssions. Aduh Education Quarterly; $52(1), 39-54$.

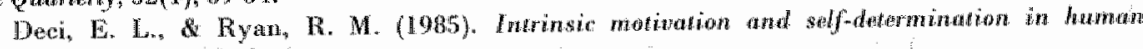
behavar New Yonk: Plenum Press.

Deci, E. Ju, Ry an, R. M. (2000). The what and why of goal punsuits: Human needs and the self-determination of behavior. Psyohological Inquiry, 1/4).227-268.

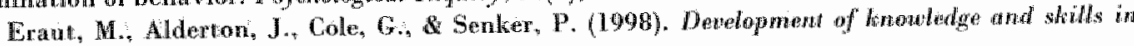
emplomment. Brighton: Univensity of Sussex.

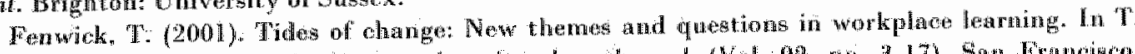

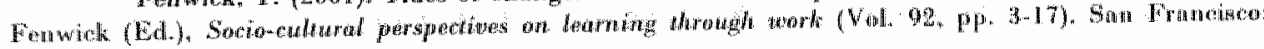
Joxgey Bassis.

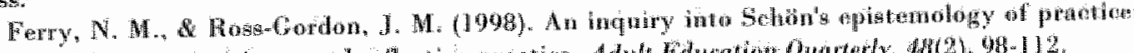

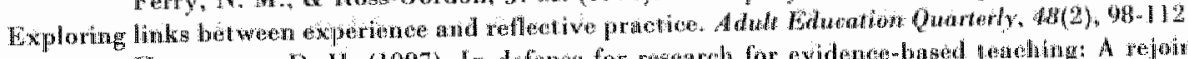

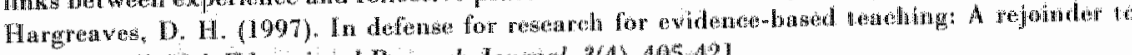

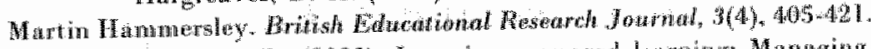

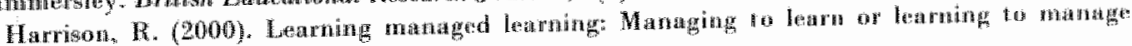

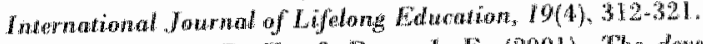

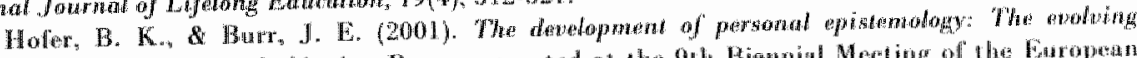

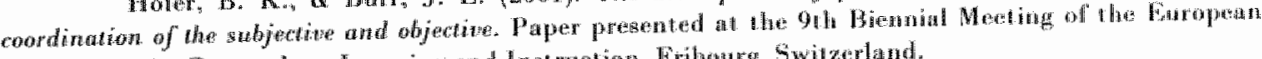

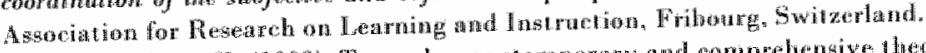

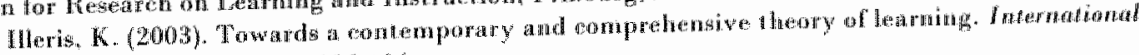
Journal of Lifulong Edacation, $22(4), 396$ (3) 106 .

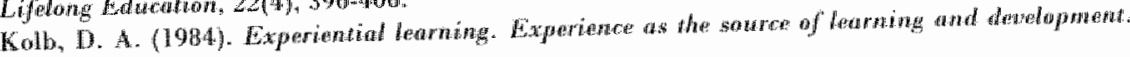
Einglewaod Clifte Prentice Malli. Ino.

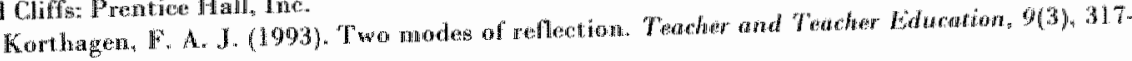

326

Konthagen, F. A. J., Kessels, J. P. A. M. (1999). Linking theory and pratide Changing the

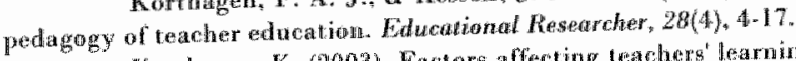

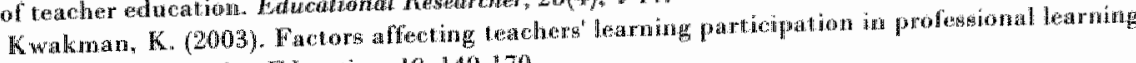
activitues. Teaching and Teacher Educhan, 19, 149-170. 


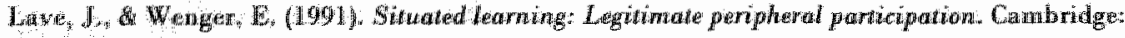
Cambidge Onverity Press.

Lindhlad, 8. (1990). From teohnology to eraft: On teachers" experimental atoption of technology as a niew sulty eet in the Swedish primary school. Journal of Curriculam Studies, 22(2), $165-175$.

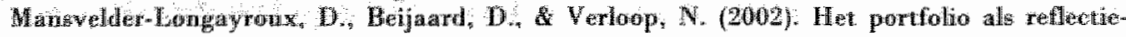
instrument vor doesnien in opleiding [Portfolic as reflection instrument for student veachers]. Pedougragleche Siudien, $79,269-206$

MeAlphine, $L_{\text {n }}$ Weston, C, Beauchamp, J., Wiseman, C., Beanchamp, C. (1999). Building a meta-eognintive model of reflectron. Higher Education, $37,105-131$.

Mano, J. (1999). Leaning nore abount learaing ümproves teacher effeetiveness. Sctrow

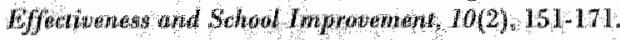

Dositerhert I. (2001). How studen teachers learn: A psychalogical perspective an hnowledge construction in learning to seach Maastricht: Shakex Publishing.

Oosslerhert, 1 , Wermunt, J. D, Denesen, E. (2002). Assessing orientations to learning to Weach Brilish Journal of Edweational Psychology, 72, 41-6j4.

Podeschi, F. (1900) Teaching their owin: Minorities challenges to mainstream institntions. In J. M. RosstGordon a II. G. Martin \& D. Briacoe (Fds.), Serving eulturally diverse populations. Sam Francise: Jotsey-Bass.

Proehaska, J. 0., Diclemente, C. C., Norcross, J. C. (1992). In search of how people change. Applicestiones to addictive hehavions. American Psychologist, $9,1102-1114$.

Prothaska, J. 0., Volicer, W, F., Diclemente, C. C., \& Faya, J. (1988). Measuring processes of oliange: Applicationg to the cessation of smoking. Journal of Consulting and Clinical Psychology, 56(4), $520-52 \%$.

Rogers, E. M. (1983). Diffusion of Innowations. (Third Edition). New York: The free Press.

Schön, D. A. (1983). The reflective pracititinuer. New York: Basis Books.

Schön, D. A (1967). Educating the reftective practitioner. San Francisca: Jossey-Bass.

Sikes, P. (1992). Imposed change and the experienced teacher. In M. Fullan \& A. Hargreaves (Eds.), Teacher Development and Edlucational Chinge London: Falmer.

Slob, M. (2004). Het poreuze ik. [The porono me]. De Wollskirant, Septenber $4^{\text {th }}, 14$.

Smylie, M. A. (1994), Redesigning teachers work: Connections to the classroom. In L. DarlingHammond (Ed.), Rewdow in research in eduction (Vol. 20). Washington: Anerican Educational Research Assiogiation.

Tucker, P. D., Stronge, J. H., Gareis, C. IR., \& Beers, C. S. (2003) The efficacy of portfolios for teacher evaluation and professional development: Do they inake a difference? Educational Administration Quarderly, $39457,572-602$.

Van Ven, K. (2003). Teachers" enotions in a context of reforms. Katholieke Universiteit Nijmagen, Nijmegen, The Netherlands.

Vermetren, $Y_{*}$ L. (1999), Consistency and variability of studen learning in higher education. Uapublished Doetoral disartation. Universty of Brabant, The Nethertwends.

Vermont, J. D. (1996). Mota-cognitive sognitive and affective aspects of learring styles and stratregies: A phenomenographic analysist. Higher Bducation, $21,25-50$.

Vygotaky, L. S. (1970). Mind in soctely: The dewelopment of higher psychological proedsses. Cen nobidge. MA: Harvard University Press.

Wortsel. J. V. (1998), Mind as achion. New York: Oxford Univeraity Press. 


\section{Summary (in Dutch)}

\section{Doel wan hes onderzoek}

In dose dissertatie wordt verslag gedaan van onderzoek naar hoe docenten leren van ervaringen die ze opidown tijdens hun werk. Meer specifiek wordt er gekeken naar:

a. hoe docenten leren op het werk en hoe dit leren verschilt van het leren van de praktijk bij andere beroepsgroepten, en

b. hos de wil om te leren (de leerbereidheid) van docenten kan worden beschreven en worden beinvloed.

De kewze van het thema is onder meer ingegeven door twee maatschappelijke ontwikkelingen. De exre: van leerlingen en studenten wordt verwacht dat ze un toenemende mate actief hun eigen leren sturen. Dit roept de vaag op hoe docenten zelf hun leren sturen. De tweede: in het kader van onder meer het competentiebeleid wordt stilzwijgend van docenten verwach, dat ze zich willen ontwikken. Deze dissertatie stellt dit uitgangspunt ler diseussie.

Een extra reden voor deze themakeuze is het feit dat er wetenschappelijk gezien erg weinig bekend is ovew hoe docenten leren van ervaringen op thun werkplek. Veel wetenschappelijke hiteratuur richt zich op het leren van leerlingen en studenten en nict zozeer op het leren van docenten (en nog minder op het leren van ervaren docenten in de dagelijkse praktijk). Als het leren van docenten al onderzocht is, gebeurte dit wanit een individueel constructivistische invalshoek. Centraal in die zienswijze stat de manier warop het individu het eigen leren (an)stuurt. Uit deze zienswijze zijn tal van preseriptieve modellen voortgekomen. Zij beschrijven op welke wijze docenten idealiter zouden noeten leren. In de wetenschappelijke literatuur treedt momented echter een verschuiving op van een constructivistische naar een meer situationele visie op leren. In de situationele visie ligt de nadruk meer op de relatie tussen het individu en de situatie die anknopingspunten biedt voor leren. Deze relatie bepalt op welke wijze leerprocessen ontstan. In deze dissertatie zijn vanuit deze lastst genoende visie een viertal sudies nitgevoerd om te komen tot cen descriptief model, dat in katrt brengt niet op welke wijze docenten moèten leren, matr op welke wije docenten in feite lexen van ervaringen op han werkplek.

\section{Onderatehsuragen.}

De dissertatic bestaat uit zes hooldstukken. Hoofdstuk éen omschrijt de doelstellingen en de onderzoeksvragen, geeft een overzicht van de voor de dissertatie relevante literatuur en gat in op de gehanteerde methoden bij het onderhave onderwoek. Het tweede tot en met het vijfde hoofdstuk beschrijven vier $k$ walitatieve studies naar loren van docenten en hon bereidheid daartoe. De studies staan op zichzelf, maar zijn gerelateord aan zes algemene onderzoeksvragen, te weten:

1. welke leeractiviteiten ondermemen docenten on te leren van ervaringen op hun werk?

2. wat is de rol van welfrellectie op het leren van docenten?

3. hoe sturen docenten hun leren? 
4. hoe kan de wil om te leren wan docenten worden omselireven?

5. welke situationele factoren beinvloeden het leren van docemen?

6. hoe kan het leren van docenten die niet ro leethereid nijn, wouden gestimuleerd? In hoofdstuk zes staan de conchases beschreven on worden ze bediseussiewd. for worden anbevelingen gedaan voor verolgonderwow ovor hoe het leren wan docenten op de werkplek gestimuleerd kan worden.

\section{De eerste studie}

Het aerste onderzoek richte zich op de vaty op welle wijze docenten in hed hoger onderwije leren en hoe ze het eigen leren sturen. Vijfien ervaren docenten van drie verschillende hbo-instellingen in Nederland hebben an bet onderzoek doelgewonen. De data zijn verzameld door middel van open interviews en en dekt ronisoh dagbolk dat de docenten gedurende een maand bijhistden. Fot onderwok stoelt op drie theoretische invalshoeken binnen het construetivisme: zelf regulentend loren, evwaringsleren en leren met behulp van reflectiecycli. Uitgande van deat invalshoeken aijn vijl hypotheses over (zelfsturend) leven bij docenten onderwocht, te wetem:

1. het leren van docenten is gelfgestuurd;

2. het leren is gepland;

3. het leren is cyclisch;

4. het leren is reflectief en

5. het leren leidt tot een gedragsverandering.

Het doel van deze deelstudie was om te onderzoeken of deze vijf hypotheses het leren van docenten op hun werk juist weergeven. De nitkomsten van het onderzodk wijzen ait dat niet alle deelnemende docenten hun eigen leren sturen. Fr xijn drio versohillende sturingsprincipes gevonden die duiden op drie verschillendo leerprocessen.

Bij spontane leeprocessen is ar iets in de omgeving dat het leren veroorzalst; de doeent is er zelf niet actief op uit om iets te heren. Het hikt alsof het leren "opeens" ontstaat. Naar a anleiding van bijwoorbeeld een gesprek of een situatie in de les, realisert de docent zich opeens hoe hij iets (in het vervolg) noet aanpakken. Bij

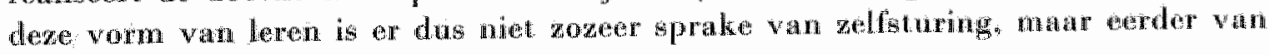
externe sturing.

Bij de tweede vorm van leren, het net-linewir lerw, wordt hot leren in gang gezet doordat de docent probeert een probleem op te lossen. Hoewel het probleem van buitemaf komt (externe sturing), beshil de doent zelf actiof op woek le gata nar en oplossing (zellsturing). Door deze actiove opstelling van de docent (hij moet er echt iets voor doen) onderscheid deze vorm zich van de hiervoot genoenda vorm. Het leeproces bij deze vorm van leren is dus probleem gesturd. Het verwarrende is echter dat de doeent zich niet zoteer een leerdoel stelt, maar een werkdoel (oplossen van een probleem). Hij plant dus niet wàt hij gat leren en ook niet hòe hij dir gaat doen (gie hieronders).

Bij de derde vorm wan leren, gepland teren, weet de docent van te vorea wat hij gat leren en hoe hij dat gaat doen. Hij heef een lesdoel en richt daar de situatic op in. Deze vorm van leren is zelfgestuurd. De docent rumt bijvoorbeeld tijd in om vakliteratuur te lezen; hij gaat op lesbezoek bij een collega of oefent bewust met een andere didactische aanpalk. In tegenstelling tot het niet-lineaire leren is de docent 
bewust berig met leren. en pas in de weede plats met het oplossen van cen problectu.

De weeste leersituaties die door de doenten werden gerapporteerd zijn niet zelfgestuard (hypothese 1 ), ze zinn als zodanig ongepland (hypothese 2) en zijn dus "spontan" enfol" "nict-lineair", en maken geen deel wit wan een oyclisch proces, zelfs nist als ze zelfgestuurd plaatsvinden (hypothese 3). De rol wan reflectie in het leren (hypothese 4 ) kwam in het onderzock niet duidelijk naar voren. Hoewel de docenten wel terugkeken op hun ervaningen en woornemens formuleerden, gebeurde dit niet op een gestructureerde, planmatige manier. Ex werden weinig gedragsmatige veranderingen gerapporterd (hypothese 5). Opwallend was ook dat meer dan de helft van de deehemende docenten rapporteerde dat ze niet teveden was met de eigun levresultaten. Fnkelen gaven aain dat ze niet meer gemotiweerd waren om zich als docent verder te ontwikkelen.

De uitkomsten van dit onderzoek leilden tot de conclusie dat docenten die met name sponkane of niet lineare leersituaties rapporteren, wich ontwikkelen door kleine verbeteringen in hun werk door te voeren. Deze docenten leren dus niet door bewust hun leren te sturen en te planmen.

\section{De weede studie}

Aangezion het eersto onderzoek tevens had uitgewezen dat veel leerprocessen wam docenten ontstan tijdens een interactie met bijvoorbeeld collega's of studenten, richtte het tweede onderzoek zich op de vragg wat (en meer specifiek welk gedrag wan beide interactiepartners) een dergelijke interactie tijdens het werk leerzaam makkt.

In deze studie ziju de leeractiviteiten van docenten wit het hoger onderwijs vergoleken met de leeractiviteiten van politieagenten en medewerkers van een veryekeringsmatschappij. Het doel van het onderzoek was on meer zicht te krijgen op de specificiteit van de situatie warin leden van de drie verschillende beroepsgroepen zich bevinden en op de gevolgen die dat heeft voor hun leeractiviteiten. In deze studie is gebruik gemakt van data nit de eerste studie, angevold met onderzoksgegevens wit de politie-en verzekeringswereld.

Hot onderzoek heeft geleid tot twee werschillende overzichten warm emimijds het gedrag wordt gespecificeerd van de lerende (docent, politieagent en veryekeringomedewerker) en anderzijds van zijn of haar interactiepartner(s). Opvallend was dat lerenden wiet alleen leren van en interactiepartner die zich bemoedigend opstelt, maar juist ook wan een interactiepartner die zich "negatief of "niet volgens de verwachting" opstelt. Wanneer te drie beroepsgroepen met elkaar vergeleken worden, vallen driw zaken op. Ten eerste: docenten rapporteerden relatief whing situaties warin en interactiepartmer zijn leren expliciet stimulexde. Ten tweede: docenten gaven vaker an dat ze gedurende een interaetie, of als gevolg daurvan, zich bewust werden van hum eigen gedrag, van het gedrag van anderen of van zaken binnen de organisatie in het algemeen, echter zonder expliciet iets met deze bewustwording to doen. Tenslotte: de docenten gaven vaker dan de politieagenten en de verzekeringswerknemers an dat hun interactie een tweezijdig (in plaats van een énzijdig) karakter had, bijvoorbeeld doordat ze aan het 'brainstormen' of 'discussiëren' waren. Daarentegen rapporteerden de dortenten een 
beperkter antal "routine interacties" en helenaal geen intenacties wawn wo wid voorbereidden op hun werk of waarin ze verkregen nformatie controleerden.

Opvallend bij de vraag wie de belangrijkste internetiepartners wrem, was het feit dat de docenten wauwelijks voodbeelden gaven wanteractins net hun leidinggevenden. Dit in tegenstelling tot polliteagenten en vergekeringswerknewers. Deze vitkomst kan worden verklatard door de relatief platte organisatiestructum op veel scholen warin de leidinggevenden een groot antal nensen moeten ansturen.

Gecondudeerd kan worden dat en deel van de gevonden versehillen tussen

de drie onderzochte beroepsgroepen kan worden verklaard wit de contexten, de werkzaamheden en the verschillende organisatiestructuren vam de genomde bedrijven. Daarnast kan worden gecondudeerd dat de interactie tussen verschillende niveaus in een organisatie een positieve invlod heeft op het leren in de praktijk. Voor docenten blijkt de frequentie van de interactie net hum leidinggevenden ten opzichte van de andere wee beroepsgroepen erg beperkt Tot slot Inidt de conclusie uit dit onderzock dat een goede interantie de expliciete aandacht van beide interactiepartners vaagt, bijvoorbeeld in de vorm van het expliciet gebruiken van de leeractiviteiten zoals geformulerd in dege studie. Beide interactiepartners, hebben namelijk verantwoordelijheid te nemen in het leren met en van elkar om, wederzijds, leren van de praktijk mogelijk te maken.

\section{De derde studie}

Het derde onderzoek richte wich op de leerbereidheid vary docenten. Dit onderzoek had tot doel om in kaart te brengen:

a. door welk gedrag een leerbereide docent wich onderscheidt van en niet zo leerbereide docenten.

b. welke verschillende vormen wan leerbereidheid docenten in het voorgezet onderwijs laten zien.

Een docent wordt als leerbereid beschouwd als hij zich actief opstelt on te leren van ervaringen in het werk. Dit reikt dus verder dan alleen gepland, intentioneel of zelf-gestwurd leren; de docent staat ook open voor spontane of nonhineaure vomen van leren. Veertien docentem nit de bovenbouw van bet voortgeret onderwijs (tweode fase) namen deot an dit kwalitatiof opgezette onderzock. Door middel van halfgestructureerde interviews en retrospecticve interviows nas aamieiding van lesobservaties zijn data veramold. Op basis hiervat werden drie verschillende vormen van llecrbereidheid gew onden.

De eerste vorm is te vinden onder docenten "dis niet inzien warom ze zouden moeten leren". De groep kenmerkt zich door:

1. miet open te stan voor mogelijk lewsituaties die zich voordoen widen lhot: werk, het vermijden van risico's in de las an het vasthouden aam eigen geplande werkwijzen:

2. niet open te staan voor hun leerlingen en de leerlingen niet goed the kninen;

3. en weinig kritische houding te hebben ten anzien van hum eigen functionem en anderen (bijwoorbeeld leerlingen, directie, het ministerie) de schuld te geven van hun situatie;

4. zichzelf geen uragen te stellen over hun eigen functioneren;

5. zelf nauwelijks actief te zijn om hun functioneren to vorbeteren:

6. het moeilijk te vinden om aan te geven wat ze leren van han werk. 
De wede categore van leerbereidheid is te winden in de groep docenten idie wich afvraagt how ze (iets) moeten leren:. Deze groep docenten is als wolgt te Kenschetsen:

1. ze gtat miet erg open woor mogelijke leersituaties die tich voordoen tijdens het werk, te vernijdt roto's in de klas en houdt vast an de eigen geplande werkwjoe,

2. ze staat engszing open voor hun leerlingen, mar spreekt zich ook wel ongenuanceard an over de leerlingen;

3. ze is hritisch op het eigen fonctioneren en neigt er soms naar on anderen de schold te geven van een situatie:

4. ze stelt zichzelf retorische vragen over het eigen fanctioneren:

5. ze weet net op welke wigte ze zelf liet functioneren kan verbeteren, ze wil het wel, mat creetert geen eigen oplossingen en ze is op zoek naar pasklare oplosingen wan anderen:

6. Le kain wel angeven wat ze leert van het eigen werk.

De derde groep docenten kan als "leerbereid" gekenmerkt worden. Deze docenten hebben de volgende kenmerken:

1. ze staan open voor diverse mogelijke leersituaties die zich voordoen tijdens het werk, ze zijn alert op wat ind de klas gebeurt en passen hun handelwijze daarop anas

2. ze zijn alert op de individuele leerling en spreken een genuanceerd oorded over hen wit:

3. ze zijn kritisch op hun eigen funotioneren;

4. ze stellen zichzelf vragen over hun eigen functioneren en reflecteren daarop;

5. ze maken voomemens en ondernemen actie om hun functioneren te verbeteren;

6. ze kunnen aangeven wat ge leren vain hun werk.

Geconclideerd kan worden dat. het derde onderzoek geleild heeft tot een nadere verduidelijking van het begrip leerbereidheid. Ten eerste zijn er verschillende vormen van leerbereidheid in kaart grebracht; ten tweede is duidelijk geworden dat een leerbereide doeent situaties op het werk niet alleen anders benadert (met een

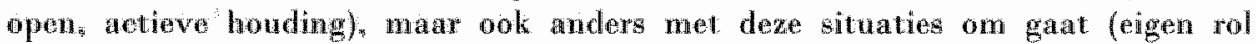
bekijken, richzil vragen stellen, voomemens maken en witvoeren).

\section{De vierde studie}

Het vierde en laatste onderzock richtte wich op de vraag hoe de leerbereidheid van "niet a leebbeide docenten" gestimuleerd kan worden. De belangrijkste doelen van dit onderzoek waren:

跑: het in kaart brengen van ho lear- en veranderingsprocessen verlopen bij deze specifieke groep doeentea;

b. het onderzoken of het mogelijk is om hum leerw, c.q. veranderingsbereidheid te stimuleren met behulp van op mat gemaak te begeleiding en

c. te onderzoken of er een verband bestaat tussen de mate van self-efficacy (vertrouwen in en doelgerielutheid van eigen kumen) en leerbereidheid.

In het onderzoek is gebruik gemalkt van een bestaand model dat verandering van ongezond gedrag besehrijt in wijf fasen (het Trans Theoretical Model of Change, het TTMC, Prochaska, Diclemente Norcross, 1992). De drie vormen van leerbereidheid (zie studie drie) bleken goed in dit model te passen. 
Het model is niet alleen gebrukt on het leer-en veranderingsproces wan deze docenten te beschrijven, ook werden op basis hienan twee versehillende unterventies uitgewerkt. Aan het onderzod hebben zeven niet zo loerbereude docenten" op het gebied van samenwerkend leren in de las neegedaan. Drie daarvan zagen niet in warom ze zouden moeten leren (eerste fase van lexbereidheid volgens het TIMC, zie sohema 1) en de overige wier wisten niet hoe we het zouden moeten doen (tweede enfof derde fase van leerberedheid volgens het TTMC). De eerste groep docenten is gedurende drie maanden individueel begeleid, de weade groep onderging de zogenoende groepsinterventie.

Een belangrijk uitgangspunt in het individuele traject wormde de andacht voor de docent voor wat betreft zijn aceptatie van en de torgen rondom samenwerkend leren. En werd voor de drie docentem in dit traject een traject op mat gemaakt, dat niettemin bestond uit een antal vaste onderdelen. Deze waren: het becommentariëren wan een video, het observeren bij een collega, en het voorbereiden, uitproberen en evalueren van en wgen samemwerkend-leren-les. De individuele docent bepaalde het tempo warin en het antal keven dat hij en onderdeel wilde doen. De vier overige docenten, die an de groepsinterventie meededen, werden willekeurig ingedeeld in dwo's. Het duotraject besloeg twee cyoli, watrin een docent samen met zijn duopartner een eigen les voorboreidde en vervolgens uitvoerde, terwijl zijn partner daarbij toekeek. Vervolgens observeerde hij zijn partner, terwijl die zijn les witvoerde. Tenslotte keken zij beiden terug op de lessen en bereidden zij weer een volgende voor.

Uit de witkonsten van bet onderzoek blijkt dat een angepaste versie van het Trans Theoretisehe Model of Change en bruikbaat middel is om het leer-en veranderingsproces van docenten te beschrijven. Op basis van het onderzok en het Trans Theoretische Model of Change hebben wij en nieuw model on wikkeld dat de ontwikkelingsfasen nar leerbereidheid bij docenten beschrijt. Het model bestaat uit vijf fasen en een extra "nul" fase.

Schema 1: Vijf fasen die de leer-en veranderbereidheid van docenten beschrijuen

\begin{tabular}{|c|c|c|c|c|c|}
\hline Tase 1 & Irom 1 & Fase 2 & It asta & Figer d & frotes 5 \\
\hline $\begin{array}{l}\text { Net } \\
\text { Heedlonetid }\end{array}$ & $\begin{array}{l}\text { Problenta } \\
\text { orthenning }\end{array}$ & 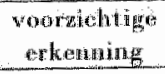 & wourberefollin gir & mewiony & 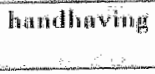 \\
\hline
\end{tabular}

De docent in fase 0 is niet van plan om nu of in de coekomst to veranderen. In die zin is hij vergelijkbaar met de verstokte roker: "Ik ga niet stoppen met roken: mijn opa rookte altijd ware shag en is lachtig geworden". Dit docent behoort tot de kleine groep ran docenten die warschijnljk ook niot neer zal veranderen. Deze docent is niet geinteresseerd in bij- of nascholing rondom (activerende) didactick, want hij wil zijn lesen helemanl niet veranderen. De docent neent informalite selectief war: met name die dingen die zijn eigen opvattingen bewestigen.

De docent in fase 1, de fase van problemonthenning, is herkenbar an uitspraken als: "Waarom zou ik mijn lessen moeten veranderen, mijn leerlingen halen toch altijd goede cijfers?". In tegenstelling tot de docent in fase nul realisecti hij zich wel dat het misschien ook anders kan, mar hij betrekt dit voorlopig nog niet op zich 
zelf of whin figen lessen (Laten ze bij godsdienst matr gamenwerkend leren doen"; "Bij mijn wak kan het niet). Hij woelt zich valk het slachtoffer van de politiek en de schoolleiding die "almaar" veranderingen ankondigen. Deze docent is echter niet zo sterk overtuigd wan zajn gelijk als de docent in fase null en zal met de juiste begeleiding wich kunen ontwiklen naar de volgende fase.

De doeent in fase 2 , de fase wn wow tohtige erkenning, ziet in dall er sprake. zou kunnen whin van een probleem. Voor sommige leerlingen zou cen meer actwerende worm van leren missehien wel beter zijn. Hij denkt dat hij daar binnen nu en een half jaar ook wel mee aan de slag zal gaan. Deze docent is vergelijkbaar met de roker die zegt: 'Op termijn gat ilk stoppen met roken'. Eigenlijk, als de docent. (en de wergellikbare roker) heel eerlijk is, weet hij ook niet goed hoe hij dit moet atmpakken of wat hij zou moeten beginnen. Dat makt dat hij op de korte termijn zeker miet werandert:

De docent in fase 3 . de fase van de voorbereiding, is wel bereid om op korte termijn aan le slag te gaan met vormen van ativerende didactiek. Hij is bereid om iets uit te proberen; maar ziet er wel tegenop. Hij heeft behoefte aan voorlichting over mogellylk te nemen stappen. met name conerete informatie over "wat' en 'hoe" en hij vraagt diar waar in zijn omgeving. Door deze informatie wordt hij optimistischer over zijn eigen vermogen tot verandering. Sonmige docenten in deze fase proberen op onderdelen wat uit. Deze fase wordt ook wel de beslissingsfase genoemd. Rokers in deze faste geven atn dat ze binnen nu en een mand echt gaan stoppen.

De docent in fase 4 , de fase van de witoering, past (met vallen en opstaan) op regelmatige basis activerende werkwormen toe in zijn lessen. Echter, de verleiding om terug te vallen in het oude patroon van de klassikale werkwijze is nog wel heell groot. De nieuwe werkwijze kost namelijk veel energie. Hierdoor is deze docent te vergelijken met de roker die gestopt is met rokent.

De docent in fase 5 , de fase van handhaving, is reeds een half jaar bezig met verschillende activerende werkvormen. Hoewel hij nog steeds ook klassikale instructiemethoden hanteert; kan hij zich niet meer voorstellen dat hij vroeger nauwelliks activerende werkvormen gebruikte. Ze zijn inmiddels cen vast onderdeel van zijn didactiek geworden. De roker in deze fase is een ex-roker geworden.

Geonchudeerd kan worden dat beide interventies, de individuele en de groepsinterventie, effectief waren om de learbereidheid van docenten te stimuleren. Bij zes van de weven docenten bleek na de interventieperiode de leerbereidheid te zijm toegenomen: zij bleken minimal eén fase opgeschoven te zijn bimnen het fasennodel (zie hierboven). Twes van deze docenten rapporteerden drie manden later echter wel een terugwal: nadat de begeleiding in het kader van het onderzoek stopte, stopten wij ook met hun inspanningen rondom samemwerkend leren. Tot slot is de relatie thissen leerbereidheid en de mate van self-efficacy gedeeltelijk aangetoond.

\section{Conclusies en discussie}

Het onderzoksthema van deze dissertatie was om na te gaan of en hoe docenten leren van huin eigen lespraktijk. Eerdere onderzoeken hiernaar gingen voornamelijk wit van en individueel constructivistische visie op leren. De leertheorieën en modellen die op deze visie zijn gebaseerd, zijn hoofdzakelijk prescriptief: leren is een zelfgestuurd proces, leren gebeurt veelal met en van anderen, reflecteren speelt cen belangrijke rol bij het leren, lerenden monitoren het leerproces, lerenden stellen 
leerdoelen op en voeren deze uit, etc. Vit ons onderzoek blikt dat dawe benadermg lang niet altijd van toepassing is op het leren van docenten op de werkplek.

De in de studies participerende docenten voldeden niet aan de verwachting dat zij op een systematische wije reflecteren op de ervarngen in hum werk, Dit wil niet zeggen dat prescriptieve modellen in theorie onjuist ajn, wel dat de docenten niet kunnen voldoen an het ideaalbeeld dat hen in deze modellen wordt voorgehouden. Ook bleek dat niet iedere docent het eigen lenen op en antiove manier zelf stuurt. De meeste van de gerapporterde leersituaties waren extern gestuurd (spontane leerervaringen) of gedeeltelik extern en zelfgestuma (niet-lineaire leerervaringen), in plaats van zelfgestwurd (geplande leetervaringen).

Hierwit zijn twee conchusies getrokken:

1. docenten verschillen in de mate warin ze hun eigen leren sturen en

2. docenten hoeven niet altijd hwm leren zelf te storen, ondat leren ook kan plats hebben via spontane en niet-lineaire leerervaringen.

Daarnaast bleek de leerbereidheid vam docenten onderling te versehillen. De leerbereidheid werd in drie verschillende vormen angetroffen. Door gerichte begeleiding blijkt de leerbereidheid van de groop dooenten die niet inzien warom ze iets zouden moeten leren, en de grotp docenten die zich afragen hoe ze ints moeten leren, wel toe te kumnen nemen.

Niet alleen de vier studies in deze dissertatie stellen de idealen van de prescriptieve leermodellen ter discussie, ook vanuit andere theoretische invalshoeken (zoals de neuropsychologie en de culturele antropologie) klimken kritisehe geluidien over deze idealen. Desondanks blijven in de praktijk deze preseriptieve modellen tot op heden richtinggevend in het aansturen van leerprocessen van doenten (en leerlingen). Waarom? Waarschijmlijk, omdat de ideaten van een lerende, die zelf vorm geeft aan zijn eigen leerprocessen, passen binnen het huidige liberaal matschappelijke ideaal van het autonome individu dat zelf en zelfstandig zijn keuzes makkt. Naar onze mening is en situationeel constructivistische visie echter toepasselijker om het leren van docenten te beschrijven. In dit perspectief, warvan Vygotsky én van de belangrijkste grondleggers is, bepaalt de dialectische relatie tussen situatie en individu of er cen will on te leren ontstaat en dus zelfsturing kan platsvinden.

De situationele visie is gebruikt on en meaw theoretiseh model op te stellen dat het leren van docenten van ervaringen in de praktijk beschriff. Het. model (zie pagina 124) laat xien dat het leren van docenten afhangt wan:

1. de relatie tussen individu en situatie,

2. de fase van leerbereidheid als gevolg van deze dialectische relatic,

3. de mogelijke vormen van sturing door de lerende, gerelateerd an de lase van leerbereidheid en

4. de mogelijke leervormen die als gevolg van deze sturing ontstanth.

\section{Aanbevelingen voor de pratijk en nethomstig onderzoek}

Op basis van dit model doen we de anbeveling dat docenten op mat. moeten worden begeleid in hun leerproces. Schoolbrede trainingen of bijenkonsten voldoen vaker niet dan well aan de individuele beboeften van docenten. Docenten verschillen per vakgebied en situatie in de mate warin ze willen leren en hun leren zelf kunnen sturen. Docenten en hun leidingigevenden gouden ur daarom goed an 
doen on samon te bekjken wat ner nodig is om het leren te laten plaatsvinden. De doeent die net insigt warom hij zou moeten leren, heeft bijwoorbeeld baat bij het voorturemd benadrakken wan de madelige gevolgen van zijn gedrag voor zichzelf en ziju omgewing (oloserveren wan wijn lessen en feedback geven). De docent die al wel wet wat hij will leren mas nog niel hoe, heeft baat bij het observeren van en collega met wie hij ach affeheert, concrete voorbeelden van hetgeen hij wenst te leren en hulp hit het voorbereiden van een gerste periment. De docent die graag wil leren en dat ook al doet, wil zo min mogelijk lastig worden gevallen met bureaucratische regels die zijn leren kunnen belemmeren. Eien leidinggevende, die perspectief biedt en die exwoor zong draagt dat belemmeringen om iets nieuws ait te proberen (rooster, lokad, ete.) zoved mogelijk verdwijnen, is woor de leerbereide doeent een bulangrijke steun in de rug. Met een docent die zich in fase 0 van de leerbereidheidsfasen bevindt, is het belangrijo om in gesprek te blijven, duidelijke afspraken te maken over wat wel of niet geleerd moet wordem en ophouden met het niet-lerend gedrag te gedogen.

Voor organisatieadviseurs on trainers is het aanbevelingswardig om zich te laten leiden door twee nieuwe adagia met betreking tot veranderingsprocessen in scholen. Het eerste oude adagium luidde: start met degenen die willen, en breidt dit langzan ait zodat ar een olievlekwerking op gang komt. Natranleiding van het succes van de omgekeende veranderaanpak die in de vierde studie is gehanteerd, luidt het nieuwe adagiums start met degenen die niet willen, degenen die wel willen, redden zich toch wel. Het tweede oude adagium luidder investeer niet to veel energie in die viff proeent van de mensen die toch niet willen. Naar aanleiding van het feit dat een leidinggevende bekende dit letterlijk op te vatten, luidt het neuwe adagium hiervoor als volgt: stop met gedogen van de vijf procent die toch niet wil, blijf in gesprek met hen of ga opnieuw het gesprek aan.

De aanbevelingen voor toekomstig onderzoek richten wich op twee aspecten. Enerzijds is het van belang om meer onderzoek te doen nat de wijze warop het informele leren, zoals het leren op de werkplek, "gemeten" kan worden. Wanneer

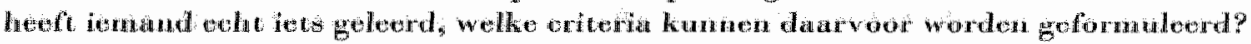
Anderzijds ig het van bellang om het bovenstaande model te onderwerpen aan. grootschaliger en gedetailleerder onderwoek. Dergelijk onderzoek zou meer imzicht kumen opleveren over de afbakening van de vijft fases die de leer- en veranderingsbereidheid vai docenten beschrijven on over de vragg hoe docenten zelf loren lenen. 


\section{Beknopt Curriculum Vitae}

Ilse van Eekelen studeerde na het behalen van liet wo-diploma an het Merlet College in Cuijk (1991) Onderwijskunde aan de Universiteit Utrecht. Tijdens har studie participeerde we als student assistent in diverse onderzoeksprojecten. Ook volgde ze gedurende een half jaar vakken Human Resource Development an de Graduate school of Education van The Ohio State University, Columbus, USA. Tegelijkertijd liep ze stage bij het Centre on Education and Training in Columbus. Na haar afstuderen werkte ze ranat 1996 als adviseur bij Twynstra Gudde Management Consultants in Amersfoort. Naast haar werkwaambeden als adviseur begon ze in 1999 aan een promotie onderzoek an de Universiteit van Maastricht, Capaciteitsgroep Onderwijsontwikkeling \& Onderwijsreseareh. Tijdens dit promotie traject maakte ze in 2000 de overstap naar Interstudie, een adviesbureau voor Onderwijsmanagement in Arnhem. Vanaf februari 2005 is ze werkzaam bij Onderbouw-VO, een projectgroep die in opdracht van het Ministerie van $O C \& W$, de ontwikkeling van de onderbouw van het voortgezet onderwijs onderstent. Op een part-time basis verzorgt ze trainingen en lezingen via haar eigen burean the Learning Paradox" over onderwijs en leren in schoolorganisaties. 


\section{Dankwoord}

Aan de basis voor dit proefschrift staan de docenten en thun leidinggevenden die tijd hebben vrijgemaakt om met mij in gesprek te gaan. Ordat ik julle anonimiteit heb beloofd, benoen ik jullie hier niet bij nam, matr wel in gedachten.. Bedankt!

Daanasist een groot woord wan dank voor Fls Boshuzen en Jan Vermunt. Dit proefsehrift is mede tot stand grekomen dankzij jullie inzet vertrowwen. Iullie vulden lkatr prima an; imhoudelijke feedback, kritische noten, aammoediging en humor wisselden zith in ten juste dosering af. Dan trad Jan weer even meer op de voorgrond, dan weer Els. Het ging lekker soepel, geen gedoe of gezeur. Als praktijkmens moest k regelmatig tot de orde van de wetenselhap worden geroepen, mar volgens mij moesten jullic daar inwendig ook wel om lachen. Echt jammer dat onze gesprekken nu voorbij zijn.

Len special woord van dank voor Cees van der Vleuten. Als directeur van de capateitsgroep 0 \& 0 durfle je het an om gedurende vijf jaar mij een anstelling woon éen dag in de week te bieden. Best een risico, aangezien ilk al die tijd bijna nooit in Mastricht was:

Vertrouwen kreeg ik bovendien van mijn opeenvolgende leidinggevenden: Rien Quist, Cees Anton de Vries (Twynstra Gudde) en Jan Oosting (Interstudie). Hoewel kenisontwikkeling woor adviesbureaus onontbeerlijk is, kan ik me ook voorstellen dat ik lastig te managen was, zo met mijn eigen project buiten de deur.

Tot slot een woord van dank voor alle mensen in en rondom het thuisfront. Nu het proefsehrift af is, besef ik hoeveel tijd ik erim heb gestoken. Soms $\mathrm{kwam}$ ik daardoor voor jullie tijd tekort. Bedankt dat jullie er zijn en altijd voor me klaar staan. 